University of Tennessee Health Science Center

UTHSC Digital Commons

\title{
Group IV Cytosolic Phospholipase A2 $\alpha$ Is Critical for the Development of Angiotensin II-Induced Hypertension and Associated Pathogenesis
}

Nayaab Shehbaz Khan

University of Tennessee Health Science Center

Follow this and additional works at: https://dc.uthsc.edu/dissertations

Part of the Cardiovascular Diseases Commons

\section{Recommended Citation}

Khan, Nayaab Shehbaz, "Group IV Cytosolic Phospholipase A2 $\alpha$ Is Critical for the Development of Angiotensin II-Induced Hypertension and Associated Pathogenesis" (2014). Theses and Dissertations (ETD). Paper 346. http://dx.doi.org/10.21007/etd.cghs.2014.0160. 


\title{
Group IV Cytosolic Phospholipase A2 $\alpha$ Is Critical for the Development of Angiotensin II-Induced Hypertension and Associated Pathogenesis
}

\author{
Abstract \\ Angiotensin II (Ang II) activates cytosolic phospholipase A2 $\alpha$ and releases arachidonic acid (AA) from \\ tissue phospholipids. AA metabolites mediate or modulate one or more renocardiovascular effects of this \\ peptide and have been implicated in hypertension. Since AA release is the rate limiting step in eicosanoid \\ production, it is possible that cPLA2 $\alpha$ might play a central role in the development of Ang II-induced \\ hypertension. To test this hypothesis, we investigated the effect of Ang II infusion for 13 days by micro- \\ osmotic pumps (700 $\mathrm{ng} / \mathrm{kg} / \mathrm{min})$, on systolic blood pressure and associated pathophysiological changes \\ in wild type (cPLA2 $\alpha+/+)$ and $\mathrm{CPLA} 2 \alpha-/-$ mice. Ang II infusion increased systolic blood pressure in \\ cPLA2 $\alpha+/+$ but not in cPLA2 $\alpha-/-$ mice. Ang II induced increase in systolic blood pressure was also \\ abolished by the AA metabolism inhibitor, 5,8,11,14-eicosatetraenoic acid in cPLA2 $\alpha+/+$ mice. Ang II \\ infusion in CPLA2 $\alpha+/+$ mice increased cardiac and renal CPLA2 activity, resulted in cardiovascular and \\ renal dysfunction, caused cardiovascular remodeling, endothelial dysfunction, increased vascular \\ reactivity and compromised renal hemodynamics in cPLA2 $\alpha+/+$ mice; these changes were diminished in \\ cPLA2 $\alpha-/-$ mice. Ang II also increased cardiac and renal infiltration of F4/80+ macrophages and CD3+ T \\ lymphocytes, caused cardiac fibrosis and produced cardiovascular and renal oxidative stress and end \\ organ damage, in CPLA2 $\alpha+/+$ but not CPLA2 $\alpha-/$ - mice. Infusion of Ang II increased cardiac ER stress and \\ activity of ERK $1 / 2$ and $\mathrm{CSrc}$ in CPLA2 $\alpha+/+$, but not CPLA2 $\alpha-/-$ mice. These data suggest that Ang II- \\ induced hypertension and associated renocardiovascular pathophysiological changes are mediated by \\ cPLA2 $\alpha$ activation, most likely through the release of AA and the generation of pro-hypertensive \\ eicosanoids.

\section{Document Type} \\ Dissertation \\ Degree Name \\ Doctor of Philosophy (PhD) \\ Program \\ Biomedical Sciences \\ Research Advisor \\ Kafait U. Malik, D.Sc., Ph.D. \\ Keywords \\ Cardiac dysfunction, Cytosolic phospholipase A2, End organ damage, Hypertension \\ Subject Categories \\ Cardiovascular Diseases | Diseases | Medicine and Health Sciences \\ Comments \\ One year embargo expired December 2015
}




\title{
Group IV Cytosolic Phospholipase $A_{2} \alpha$ Is Critical for the Development of
} Angiotensin II-Induced Hypertension and Associated Pathogenesis

\author{
A Dissertation \\ Presented for \\ The Graduate Studies Council \\ The University of Tennessee \\ Health Science Center \\ In Partial Fulfillment \\ Of the Requirements for the Degree \\ Doctor of Philosophy \\ From The University of Tennessee
}

By

Nayaab Shehbaz Khan

December 2014 
Copyright (C) 2014 by Nayaab Shehbaz Khan. All rights reserved. 


\section{DEDICATION}

I dedicate this thesis to my parents, Mr. Shehbaz Khan and Ms. Kherunisa Shaikh for inculcating in me the importance of education and providing me with the best they could. My loving sister Haneen Khan and my dear husband Noorullah Naqvi Mohammed, without whose support and patience, this journey would not have been possible. 


\section{ACKNOWLEDGEMENTS}

I would like to express my deepest appreciation to my mentor Dr. Kafait U. Malik, for his support, patience, motivation, enthusiasm, and immense knowledge. He is a teacher in the true sense of the word. He stood by me in times of thick and thin, empowered me with knowledge and skills. I could not have imagined having a better mentor for my Ph.D. study.

I would like to extend my gratitude to my committee members, Dr. Aviv Hassid, Dr. Suleiman Bahouth, Dr. Marshall Elam and Dr. Rennolds Ostrom for their insightful comments, support, appreciation and constant encouragement.

I thank my lab mates for being an extended family and for all the good times we shared. Special thanks to Dr. Chi Young Song and Ms. Fang for being my emotional and scientific support system in the lab.

I would like to thank the veterinary and husbandry staff of the Lab animal care unit for their support and assistance.

This would not have been possible without the support of my parents, Shehbaz Khan and Kheru Shaikh, my loving sister Haneen Khan, my dear husband Naqvi Mohammed. Thanks for tolerating my tantrums, complains and frustration during my troubled times. I am sure that wasn't easy.

I have been blessed with wonderful teachers throughout my academic life. Their faith in me, always compelled me to achieve greater heights. As I have earned the highest degree in education, I remember each one of them. It is for you that I am here today. Thanks for being by my side.

This year, 2014 also marks the passing away of Prof. Shivdasani, former dean, of Jai Hind College, Mumbai. Wish you were here Sir, I know you can still see me and you must be so very happy. Thank you Dr. Noronah, Dr. Avari, Niloufer mam, Candice mam and Siddiqui sir for all the hard work that you put in, not just me but all your students.

Thanks Dr. Renee Germack and Dr. Shiva Sivasubramaniam, from Nottingham Trent University. It is for you both, that I fell in love with Pharmacology.

This is not the end but a new beginning. Cheers to a good academic life! 


\begin{abstract}
Angiotensin II (Ang II) activates cytosolic phospholipase $\mathrm{A}_{2} \alpha$ and releases arachidonic acid (AA) from tissue phospholipids. AA metabolites mediate or modulate one or more reno-cardiovascular effects of this peptide and have been implicated in hypertension. Since AA release is the rate limiting step in eicosanoid production, it is possible that $\mathrm{CPLA}_{2} \alpha$ might play a central role in the development of Ang II-induced hypertension. To test this hypothesis, we investigated the effect of Ang II infusion for 13 days by micro-osmotic pumps (700 $\mathrm{ng} / \mathrm{kg} / \mathrm{min})$, on systolic blood pressure and associated pathophysiological changes in wild type $\left(\mathrm{cPLA}_{2} \alpha^{+/+}\right)$and $\mathrm{cPLA}_{2} \alpha^{-/-}$mice. Ang II infusion increased systolic blood pressure in $\mathrm{cPLA}_{2} \alpha^{+/+}$but not in $\mathrm{cPLA}_{2} \alpha^{-/-}$mice. Ang II induced increase in systolic blood pressure was also abolished by the AA metabolism inhibitor, $5,8,11,14$-eicosatetraynoic acid in $\mathrm{CPLA}_{2} \alpha^{+/+}$mice. Ang II infusion in $\mathrm{CPLA}_{2} \alpha^{+/+}$mice increased cardiac and renal cPLA 2 activity, resulted in cardiovascular and renal dysfunction, caused cardiovascular remodeling, endothelial dysfunction, increased vascular reactivity and compromised renal hemodynamics in $\mathrm{cPLA}_{2} \alpha^{+/+}$mice; these events were diminished in $\mathrm{cPLA}_{2} \alpha^{-/-}$mice. Ang II also increased cardiac and renal infiltration of $\mathrm{F} 4 / 80^{+}$macrophages and $\mathrm{CD}^{+} \mathrm{T}$ lymphocytes, caused cardiac fibrosis and produced cardiovascular and renal oxidative stress and end organ damage, in cPLA $\alpha_{2}{ }^{+/+}$ but not $\mathrm{CPLA}_{2} \alpha^{-/-}$mice. Infusion of Ang II increased cardiac ER stress and activity of ERK1/2 and cSrc in $\mathrm{cPLA}_{2} \alpha^{+/+}$, but not $\mathrm{cPLA}_{2} \alpha^{-/-}$mice. These data suggest that Ang IIinduced hypertension and associated reno-cardiovascular pathophysiological changes are mediated by $\mathrm{cPLA}_{2} \alpha$ activation, most likely through the release of AA and the generation of pro-hypertensive eicosanoids.
\end{abstract}




\section{TABLE OF CONTENTS}

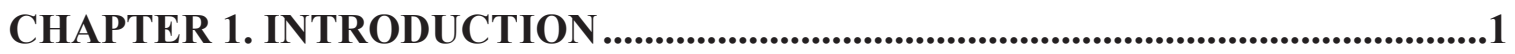

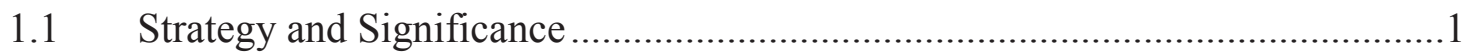

1.2 Specific Aims ....................................................................................2

1.2.1 Aim 1. To Determine the Contribution of $\mathrm{cPLA}_{2} \alpha$ to Ang II-Induced Hypertension and Associated Cardiovascular Pathophysiology ...................2

1.2.2 Aim 2. To Investigate if $\mathrm{cPLA}_{2} \alpha$ Is Essential for Renal Dysfunction and End Organ Damage Associated with Ang II-Induced Hypertension ............2

CHAPTER 2. LITERATURE REVIEW .............................................................3

2.1 Regulation of Arterial Blood Pressure ......................................................

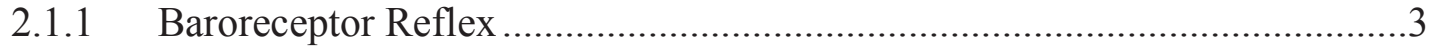

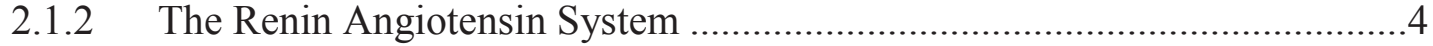

2.2 Pathogenesis of Hypertension ....................................................................

2.2.1 Renin Angiotensin Aldosterone System ..................................................

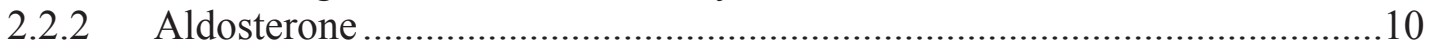

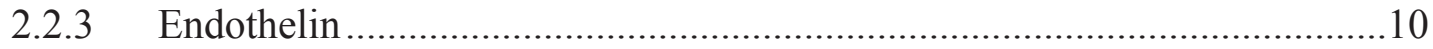

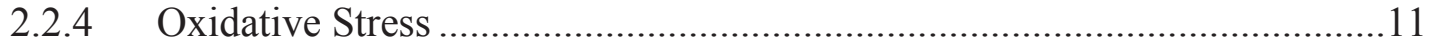

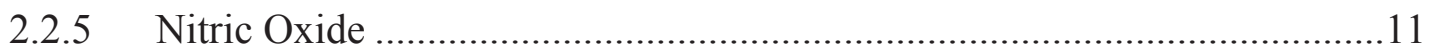

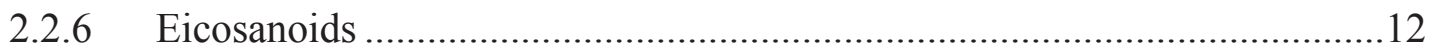

2.2.7 Emerging Concepts of the Immune System in Hypertension ...................... 15

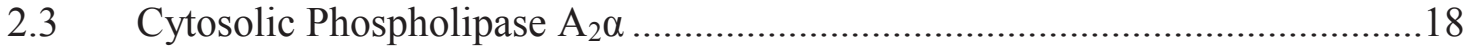

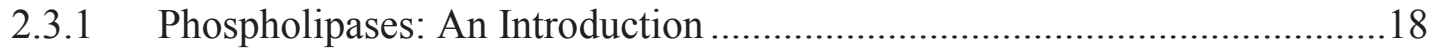

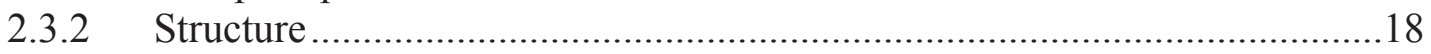

2.3.3 Regulation ........................................................................................... 18

2.3.4 $\mathrm{cPLA}_{2} \alpha$ in Disease Pathogenesis : Lessons from the Knockout Mouse .......20

CHAPTER 3. METHODOLOGY .......................................................................23

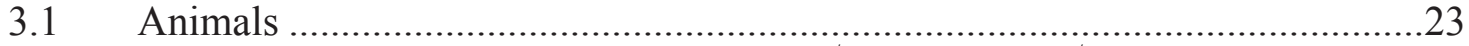

3.2 Ang II-Induced Hypertension in $\mathrm{CPLA}_{2} \alpha^{+/+}$and $\mathrm{cPLA}_{2} \alpha^{-/-}$Mice ......................23

3.3 Ultra Sound Imaging and Analysis ............................................................23

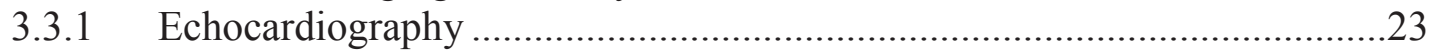

3.3.2 Pulsed Wave Doppler to Measure Renal Hemodynamics ...........................24

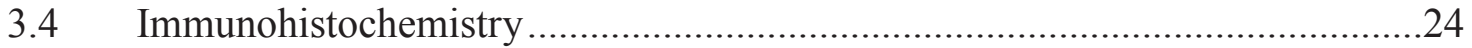

3.5 Collagen Accumulation ..............................................................................26

3.6 Measurement of Oxidative Stress.................................................................26

3.6.1 Measurement of NADPH Oxidase Activity .........................................26

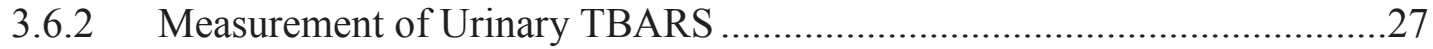

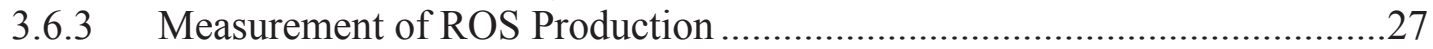

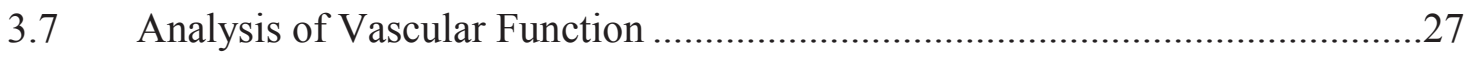

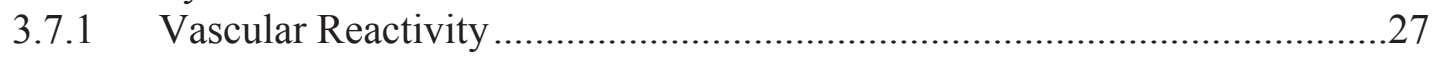

3.7.2 Endothelium-Dependent and Independent Vasodilation ............................27

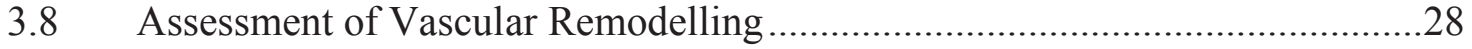

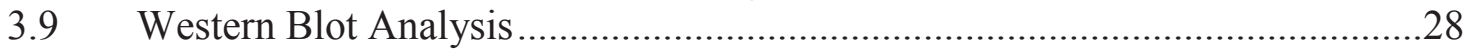




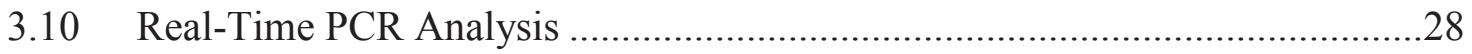

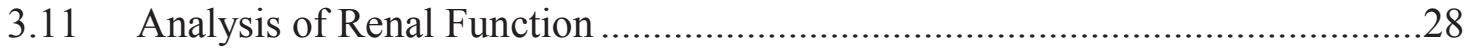

3.12 Urinary Levels of PGE2 Metabolite................................................................

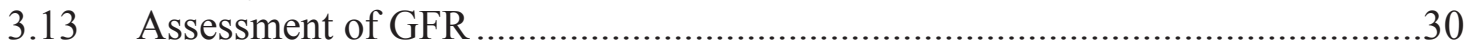

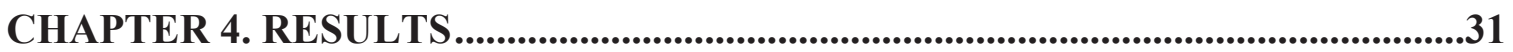

4.1 Aim 1. To Determine the Contribution of $\mathrm{CPLA}_{2} \alpha$ to Ang II-Induced Hypertension and Associated Cardiovascular Pathophysiology ..........................31

4.1.1 $\quad \mathrm{CPLA}_{2} \alpha$ Gene Disruption Does Not Alter Expression of Other Phospholipase Enzymes

4.1.2 $\mathrm{CPLA}_{2} \alpha$ Contributes to the Development of Ang II-Induced Hypertension, Activation of Cardiac $\mathrm{cPLA}_{2}$ and Increased Excretion of PGE2 Metabolites

4.1.3 Inhibition of Arachidonic Acid Metabolism, Abrogated Ang II-Induced Hypertension in $\mathrm{cPLA}_{2} \alpha^{+/+}$Mice.

4.1.4 $\mathrm{cPLA}_{2} \alpha$ Gene Disruption Attenuates Cardiac Dysfunction and Hypertrophy Associated with Ang II-Induced Hypertension..........................35

4.1.5 $\mathrm{CPLA}_{2} \alpha$ Gene Disruption Prevents Cardiac Interstitial Fibrosis....................35

4.1.6 $\mathrm{CPLA}_{2} \alpha$ Gene Disruption Prevents Cardiac Inflammation ............................35

4.1.7 cPLA $_{2} \alpha$ Gene Disruption Protects Against Ang II-Induced Vascular

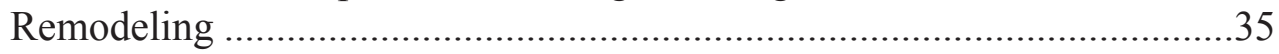

4.1.8 $\quad \mathrm{CPLA}_{2} \alpha$ Gene Disruption Prevents Increased Vascular Reactivity and Endothelial Dysfunction in Ang II-Induced Hypertension

4.1.9 $\mathrm{cPLA}_{2} \alpha$ Gene Disruption Does Not Alter Expression of AT1, AT2, MAS Receptors and ACE

4.1.10 cPLA $_{2} \alpha$ Gene Disruption Protects Against Ang II-Induced Cardiovascular Oxidative Stress

4.1.11 cPLA $_{2} \alpha$ Gene Disruption Prevents Endoplasmic Reticulum Stress in Ang II-Induced Hypertension.

4.1.12 cPLA $_{2} \alpha$ Gene Disruption Prevents Ang II-Induced Phosphorylation of ERK1/2 and c-Src.

4.2 Aim 2. To Demonstrate that $\mathrm{CPLA}_{2} \alpha$ Is Essential in Ang II-Induced Renal

Pathophysiology Associated with Hypertension..... .46

4.2.1 $\quad \mathrm{cPLA}_{2} \alpha$ Gene Disruption Prevents Against Ang II-Induced Altered Renal Hemodynamics...................................................................................46

4.2.2 $\mathrm{cPLA}_{2} \alpha$ Gene Disruption Prevents Ang II-Induced Renal Dysfunction .....46

4.2.3 cPLA $_{2} \alpha$ Gene Disruption Prevents Renal Fibrosis in the Kidney ................46

4.2.4 $\mathrm{CPLA}_{2} \alpha$ Gene Disruption Prevents Renal Inflammation ...............................51

4.2.5 $\mathrm{CPLA}_{2} \alpha$ Gene Disruption Protects Against Ang II-Induced Renal Oxidative Stress......................................................................................

4.2.6 Protection Against Ang II-Induced Hypertension in $\mathrm{cPLA}_{2} \alpha^{-/-}$Mice Is Independent of Endothelin ......................................................................51

CHAPTER 5. DISCUSSION

5.1 Aim 1. To Determine the Contribution of $\mathrm{CPLA}_{2} \alpha$ to Ang II-Induced Hypertension and Associated Cardiovascular Pathophysiology ..... 
5.2 Aim 2. To Investigate if $\mathrm{cPLA}_{2} \alpha$ Is Essential for Renal Dysfunction and End Organ Damage Associated with Ang II-Induced Hypertension .................58

CHAPTER 6. CONCLUSION ..........................................................................................62

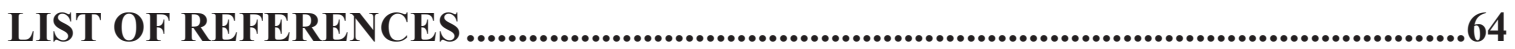

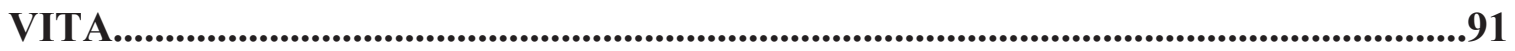




\section{LIST OF TABLES}

Table 3.1. List of antibodies and specific conditions ..............................................25

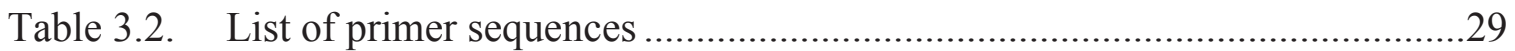

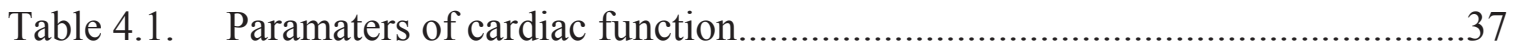




\section{LIST OF FIGURES}

Figure 2.1 Angiotensin metabolism pathway ............................................................

Figure 2.2 Interplay of the renin angiotensin aldosterone system in BP maintenance

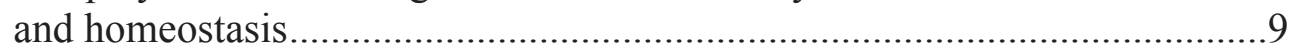

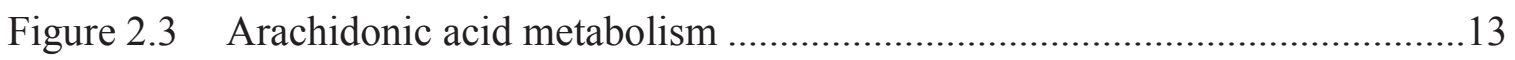

Figure 2.4 T cell mediated immunity in hypertension ................................................17

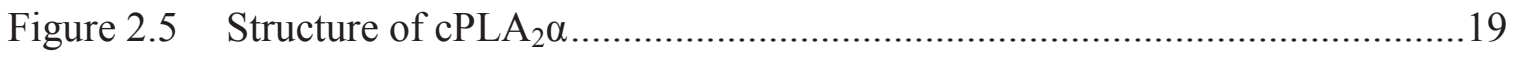

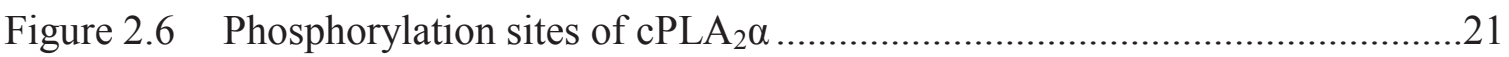

Figure $4.1 \quad$ CPLA $_{2} \alpha$ gene disruption prevents expression of $\mathrm{cPLA}_{2} \alpha$ but not other related phospholipase enzymes ……………………………………............32

Figure 4.2 $\mathrm{cPLA}_{2} \alpha$ contributes to the development of Ang II-induced hypertension, activation of cardiac $\mathrm{CPLA}_{2} \alpha$ and increased excretion of PGE2 metabolites

Figure 4.3 Inhibition of arachidonic acid metabolism, abrogated Ang II-induced hypertension in $\mathrm{cPLA}_{2} \alpha^{+/+}$mice.

Figure 4.4 cPLA $_{2} \alpha$ gene disruption attenuates cardiac dysfunction and hypertrophy associated with Ang II-induced hypertension .................................................36

Figure 4.5 cPLA $_{2} \alpha$ gene disruption prevents cardiac interstitial fibrosis........................38

Figure 4.6 cPLA $_{2} \alpha$ gene disruption prevents cardiac inflammation ................................39

Figure 4.7 cPLA $_{2} \alpha$ gene disruption protects against Ang II-induced vascular remodeling.

Figure 4.8 $\mathrm{cPLA}_{2} \alpha$ gene disruption prevents increased vascular reactivity and endothelial dysfunction in Ang II-induced hypertension

Figure $4.9 \quad$ cPLA $_{2} \alpha$ gene disruption does not alter expression of AT1, AT2, MAS receptors and $\mathrm{ACE}$

Figure $4.10 \mathrm{cPLA}_{2} \alpha$ gene disruption protects against Ang II-induced cardiovascular oxidative stress

Figure 4.11 cPLA $_{2} \alpha$ gene disruption prevents ER stress in Ang II-induced hypertension 
Figure 4.12 cPLA $_{2} \alpha$ gene disruption prevents Ang II-induced phosphorylation of $\mathrm{ERK} 1 / 2$ and $\mathrm{cSrc}$

Figure $4.13 \mathrm{cPLA}_{2} \alpha$ gene disruption prevents against Ang II-induced altered renal

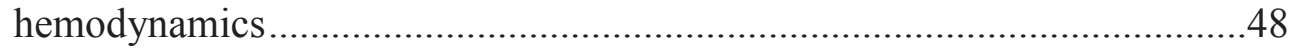

Figure 4.14 cPLA $_{2} \alpha$ gene disruption prevents Ang II-induced renal dysfunction ..........49

Figure $4.15 \mathrm{cPLA}_{2} \alpha$ gene disruption prevents renal fibrosis in the kidney......................50

Figure $4.16 \mathrm{cPLA}_{2} \alpha$ gene disruption prevents renal inflammation.................................52

Figure $4.17 \mathrm{cPLA}_{2} \alpha$ gene disruption protects against Ang II-induced renal oxidative

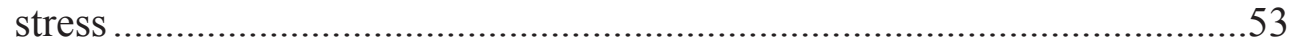

Figure 4.18 Protection against Ang II-induced hypertension in $\mathrm{CPLA}_{2} \alpha^{-/-}$mice is independent of endothelin ..........................................................................54

Figure 6.1 Proposed mechanism of $\mathrm{cPLA}_{2} \alpha$ dependent Ang II-induced hypertension and associated pathophysiology .................................................................63 


\section{LIST OF ABBREVIATIONS}

$\begin{array}{ll}\text { AA } & \text { Arachidonic Acid } \\ \text { ACE } & \text { Angiotensin Converting Enzyme } \\ \text { Ach } & \text { Acetylcholine } \\ \text { Ang } & \text { Angiotensin } \\ \text { AT1R } & \text { Angiotensin Type 1 Receptor } \\ \text { BH }_{4} & \text { Tetrahydrobiopterin } \\ \text { BP } & \text { Blood Pressure } \\ \text { CAMKII } & \text { Calcium Calmodulin Kinase II } \\ \text { CO } & \text { Cardiac Output } \\ \text { COX } & \text { Cyclooxygenase } \\ \text { cPLA } & \text { Cytosolic Phospholipase A2 } \\ \text { Cyp 450 } & \text { Cytochrome P450 } \\ \text { DAG } & \text { Diacylglycerol } \\ \text { Ddw } & \text { Deionized Distilled Water } \\ \text { DHE } & \text { Dihydroethidium } \\ \text { DOCA } & \text { Deoxycorticosterone Acetate } \\ \text { EDV } & \text { End Diastolic Volume } \\ \text { EET } & \text { Epoxyeicosatetraenoic Acid } \\ \text { EF } & \text { Ejection Fraction } \\ \text { EGFR } & \text { Epithelial Growth Factor Receptor } \\ \text { ENaC } & \text { Epithelial Sodium Channel } \\ \text { eNOS } & \text { endothelial Nitric Oxide Syntase } \\ \text { ER } & \text { Endoplasmic Reticulum } \\ \text { ERK } & \text { Extracellular Signal Regulated Kinase } \\ \text { ESV } & \text { End Systolic Volume } \\ \text { ET } & \text { Endothelin } \\ \text { ET } & \text { Endothelin Receptor Type A } \\ \text { ET } & \text { Endothelin Receptor Type B } \\ \text { ETYA } & \text { 5,8,11,14-Eicosatetraynoic Acid } \\ \text { FS } & \text { Fractional Shortening } \\ \text { GFR } & \text { Glomerular Filtration Rate } \\ \text { HETE } & \text { Hydroxyeicosatetraenoic Acid } \\ \text { HPETE } & \text { Hydroperoxyeicosatetraenoic Acid } \\ \text { IL } & \text { Interleukin } \\ \text { INF } & \text { Interferon } \\ \text { iPLA } & \text { Independent Phospholipase A } \\ \text { IP3 } & \text { Inositol Triphosphate } \\ \text { IVS } & \text { Intra Ventricular Septum } \\ \text { JG } & \text { Juxtaglomerular } \\ \text { JNK } & \text { c-Jun N-terminal kinase } \\ \text { LDV } & \text { Lowest Diastolic Velocity } \\ \text { L-NAME } \\ \text { LOX } & \end{array}$




$\begin{array}{ll}\text { LT } & \text { Leukotrienes } \\ \text { LV } & \text { Left Ventricle } \\ \text { LVAW } & \text { Left Ventricle Anterior Wall } \\ \text { LVID } & \text { Left Ventricle Internal Dimension } \\ \text { LVPW } & \text { Left Ventricle Posterior Wall } \\ \text { MAP } & \text { Mean Arterial Pressure } \\ \text { MAPK } & \text { Mitogen Activated Protein Kinase } \\ \text { MR } & \text { Mineralocorticoid Receptor } \\ \text { NADPH } & \text { Nicotinamide Dinucleotide Phosphate } \\ \text { NE } & \text { Norepinephrine } \\ \text { NO } & \text { Nitric Oxide } \\ \text { NTS } & \text { Nucleus Tractus Solitarius } \\ \text { OCT } & \text { Optimal Cutting Temperature } \\ \text { Pa } & \text { Arterial Pressure } \\ \text { PBS } & \text { Phosphate Buffered Saline } \\ \text { PDGF } & \text { Platelet Derived Growth Factor } \\ \text { PE } & \text { Phenylephrine } \\ \text { PG } & \text { Prostaglandin } \\ \text { PGEM } & \text { Prostaglandin E Metabolites } \\ \text { PKC } & \text { Protein Kinase C } \\ \text { PSV } & \text { Peak Systolic Velocity } \\ \text { RAAS } & \text { Renin Angiotensin Aldosterone System } \\ \text { RAS } & \text { Renin Angiotensin System } \\ \text { ROS } & \text { Reactive Oxygen Species } \\ \text { RRA } & \text { Right Renal Artery } \\ \text { RVLM } & \text { Rostral Ventrolateral Medulla } \\ \text { SBP } & \text { Systolic Blood Pressure } \\ \text { SFO } & \text { Subfornical Organ } \\ \text { SHR } & \text { Spontaneous Hypertensive Rat } \\ \text { siRNA } & \text { Short interfering RNA } \\ \text { SMA } & \text { Smooth Muscle Actin } \\ \text { SNP } & \text { Sodium Nitro Prusside } \\ \text { sPLA } & \text { Secretory Phospholipase } \\ \text { SV } & \text { Stroke Volume } \\ \text { TBARS } & \text { Thiobarbituric Acid Reactive Substances } \\ \text { TFG } \beta & \text { Tumor Growth Factor } \beta \\ \text { TNF } & \text { Tumor Necrosis Factor } \\ \text { TPR } & \text { Total Peripheral Resistance } \\ \text { Tregs } & \text { T-regulatory Cells } \\ \text { Tx } & \text { Thromboxane } \\ \text { VSMC } & \text { Vascular Smooth Muscle Cell } \\ \text { VTI } & \text { Velocity Time Integral } \\ \text { WT } & \\ & \end{array}$




\section{CHAPTER 1. INTRODUCTION}

\subsection{Strategy and Significance}

Cardiovascular disease is prevalent in modern societies, and hypertension is the leading cause of cardiovascular morbidity/mortality. According to the latest AHA statistics, in the United States, 76.4 million (33.5\%) individuals $\geq 20$ years of age are hypertensive, and more than $70 \%$ of patients who suffer a heart attack, stroke, or congestive heart failure are hypertensive. ${ }^{1}$ Moreover, hypertension is a major risk factor for ischemic heart disease and renal failure. Clearly, physicians need better approaches to prevent hypertension-related morbidity and mortality; thus, the focus of this study is to explore the potential of a promising therapeutic target, i.e., cytosolic phospholipase $\mathrm{A}_{2} \alpha$ $\left(\mathrm{cPLA}_{2} \alpha\right)$.

$\mathrm{CPLA}_{2} \alpha$ is a subset of a large family of phospholipase enzymes that release fatty acids from the second carbon of phospholipids. Mammals have at least 15 groups of $\mathrm{PLA}_{2}$ enzymes, which have been classified into four groups based on structure, catalytic mechanism, localization, and evolutionary relationship: $\mathrm{Ca}^{2+}$-dependent $\mathrm{CPLA}_{2} \alpha, \mathrm{Ca}^{2+}$ independent $\mathrm{PLA}_{2}\left(\mathrm{iPLA}_{2}\right)$, secretory $\mathrm{PLA}_{2}\left(\mathrm{SPLA}_{2}\right)$, and platelet-activating acetylhydrolases. ${ }^{2} \mathrm{cPLA}_{2} \alpha$ is widely expressed and constitutively active; however, nanomolar levels of $\mathrm{Ca}^{2+}$ and various mitogen-activated protein kinases and calcium/calmodulin-dependent kinase II (CAMKII) via phosphorylation regulate cPLA ${ }_{2} \alpha$ activity. ${ }^{3-6}$ CPLA $_{2} \alpha$ has been implicated in a number of physiological and pathophysiological conditions including allergy, asthma, brain ischemia injury, and arthritis. $^{7}$

With regard to hypertension and cardiovascular disease, $\mathrm{PLA}_{2}$ activity is increased in the renal medulla and cortex of stroke-prone, spontaneously hypertensive rats (SHR), ${ }^{8}$ and a recent study demonstrated that $\mathrm{CPLA}_{2} \alpha$ gene disruption prevented LNG-nitroarginine methyl ester (L-NAME), an inhibitor of nitric oxide synthesis-induced hypertension. ${ }^{9}$ But the most compelling reason for focusing on $\mathrm{CPLA}_{2} \alpha$ is that this enzyme is activated by numerous blood pressure (BP) regulating-hormones and is highly selective for arachidonic acid (AA)-containing phospholipids. Thus, $\mathrm{cPLA}_{2} \alpha$ is a major center of convergence for the transduction of hormone signaling via generation of eicosanoids, which represent a complex family of AA metabolites that are critically engaged in BP regulation and end organ damage. In view of the release of AA from tissue lipids by neuro-humoral agents and AA's metabolism via multiple pathways into pro- and anti-hypertensive eicosanoids, it appears that the effect/levels of prohypertensive eicosanoids predominate during hypertension. Importantly, the production of pro-hypertensive eicosanoids depends upon the release of AA by cPLA ${ }_{2} \alpha$ from tissue lipids, a rate-limiting step in the synthesis of eicosanoids. Thus, activation of cPLA $\alpha$ by angiotensin (Ang) II and other vasoactive agents could be a key step in the development of hypertension and associated cardiovascular and renal pathophysiology. 
Thus the hypothesis of my study is that Group IV $\mathrm{cPLA}_{2} \alpha$ is critical for the development of Ang II-induced hypertension and its pathogenesis and associated target organ damage. To test this hypothesis, the following are the aims of this study.

\subsection{Specific Aims}

\subsubsection{Aim 1. To Determine the Contribution of $\mathrm{CPLA}_{2} \alpha$ to Ang II-Induced Hypertension and Associated Cardiovascular Pathophysiology}

Rationale: Ang II activates one or more phospholipases. However, AA released in cardiovascular and renal tissues and infiltration of macrophages is primarily due to activation of $\mathrm{cPLA}_{2} \alpha{ }^{3,10,11} \mathrm{AA}$ and/or its metabolites activate nicotinamide dinucleotide phosphate (NADPH) oxidase and generate reactive oxygen species (ROS) in the cardiovascular system, both of which have been implicated in the development of hypertension and cardiovascular and renal dysfunction. ${ }^{12-16}$ These observations, and our preliminary data that the inhibitor of AA metabolism, 5,8,11,14-eicosa-tetraynoic acid (ETYA), prevents Ang II-induced increase in systolic blood pressure (SBP) and that $\mathrm{cPLA}_{2} \alpha$ gene disruption in mice minimizes Ang II-induced hypertension, cardiac dysfunction as determined by echocardiography, and cardiac fibrosis and cardiovascular oxidative stress as indicated by increased dihydroethidium (DHE) staining have led us to the following hypothesis:

$\mathrm{cPLA}_{2} \alpha$ is critical for the development of Ang II-induced hypertension, hypertrophy, and activation of NADPH oxidase, generation of ROS, cardiovascular dysfunction and fibrosis.

\subsubsection{Aim 2. To Investigate if $\mathrm{cPLA}_{2} \alpha$ Is Essential for Renal Dysfunction and End Organ Damage Associated with Ang II-Induced Hypertension}

Rationale: To determine the role of $\mathrm{cPLA}_{2} \alpha$ in renal pathophysiology associated with hypertension, I have compared the effects of Ang II on kidney structure and function in $\mathrm{cPLA}_{2} \alpha^{+/+}$versus $\mathrm{cPLA}_{2} \alpha^{-/-}$mice. The renin-angiotensin system (RAS) plays an important role in regulating renal function, and alterations in renal function promote development of hypertension, which in turn leads to renal damage. Although cPLA ${ }_{2} \alpha$ gene disruption in mice does not alter basal renal function, except in older mice $(>40$ weeks) that exhibit a urinary concentrating defect, it is not known if cPLA ${ }_{2} \alpha$ contributes to renal dysfunction, inflammation, and end organ damage associated with Ang IIinduced hypertension. My data shows that $\mathrm{cPLA}_{2} \alpha$ gene disruption results in the loss of cPLA $_{2}$ expression and, consequently, Ang II-induced phosphorylation and prevents proteinuria, renal fibrosis, and oxidative stress. Thus, my second hypothesis is:

$\mathrm{cPLA}_{2} \alpha$ is crucial for renal dysfunction, activation of NADPH oxidase, generation of ROS, and end organ damage associated with Ang II-induced hypertension. 


\section{CHAPTER 2. LITERATURE REVIEW}

\subsection{Regulation of Arterial Blood Pressure}

The main function of the cardiovascular system is to meet the demands of tissue perfusion by providing oxygen and nutrients and eliminating waste products. These are achieved by difference in pressures across the arterial and venous network. The driving force of this blood flow is called mean arterial pressure (MAP), denoted as Pa (arterial pressure)

$$
\mathrm{Pa}=\text { cardiac output }(\mathrm{CO}) \mathrm{x} \text { total peripheral resistance }(\mathrm{TPR})
$$

In order to perform the vital function of tissue perfusion, MAP must at all times be maintained at a high set point of approximately $100 \mathrm{mmHg}$. This is achieved by two major regulatory systems: (i) baroreceptor reflex and (ii) renin angiotensin-aldosterone system.

\subsubsection{Baroreceptor Reflex}

Baroreceptors play an essential role in stabilizing perfusion pressure during altered or disturbed circulatory homeostasis by specific neuronal ${ }^{17,18}$ or hormonal adjustments ${ }^{19,20}$ via changes in sympathetic and parasympathetic output signals to the heart and sympathetic output to the vasculature. These responses are processed by specialized mechanoreceptors often referred to as stretch receptors located in the aortic arch and carotid sinus. At resting BP levels, the baroreceptor afferents deliver tonic excitatory input to the neurons in the nucleus tractus solitarius (NTS) ${ }^{21}$ where the glossopharyngeal and vagus nerve fibers synapse. The NTS is the site of afferent baroreceptor inputs whereas the rostral ventrolateral medulla (RVLM) is the site for output of the efferent sympathetic nerve activity. ${ }^{22}$ The RVLM also receives input signals from other areas that are linked to baroreceptors: the medullary lateral tegmental field ${ }^{23}$ and the ventrolateral periaqueductal gray. ${ }^{24}$ The outflow of the neurons of RVLM is harmonious with cardiac rhythm. Thus, baroreceptor activation decreases the activity of these neurons. It has been demonstrated that sensitivity of the baroreceptor reflex appears to be directly related to the neuronal activity within the pressure region of the RVLM. ${ }^{25}$

An increase in $\mathrm{Pa}$ is sensed as an increase in stretch in the blood vessel that results in an increased firing rate. In order to restore BP to normal, parasympathetic activity increases and sympathetic activity decreases resulting in a decrease in heart rate and contractility, and a decrease in venous and arteriolar constriction, together resulting in decreased CO and TPR and increased unstressed volume. The operating point of reflex and its sensitivity are the key determinants of baroreceptor function. ${ }^{22}$ These are often altered during various physiological and pathophysiological conditions such as hypertension, ${ }^{26}$ sleep, ${ }^{27}$ aging, ${ }^{28}$ altered thermoregulation, ${ }^{29}$ and pregnancy. ${ }^{30}$ In spite of such a vigilant system, sustained increased or decreased $\mathrm{Pa}$ may result in alteration of the 
afferent signal as seen in patients suffering from essential hypertension, wherein the set point is reset to a higher level of $\mathrm{Pa}^{31}$

\subsubsection{The Renin Angiotensin System}

\subsubsection{The Historic Timeline of the Renin Angiotensin System (RAS)}

It wasn't until Tigerstedt and Bergmann, in 1898 published their study detailing the existence of renin, a heat labile substance extracted from rabbit renal cortex. ${ }^{32}$ Their idea that renin is the humoral pressor agent, was widely criticized by many until in 1934, when Goldblatt et al. demonstrated that renal ischemia could result in hypertension. ${ }^{32}$ They further showed that renin, through its proteolytic action, cleaved angiotensinogen, a short-lived heat labile peptide, to generate angiotensin, which was then called angiotonin or hypertensin. ${ }^{32}$ Almost two decades later, Ang I and Ang II were discovered by Skeggs and colleagues. ${ }^{33}$ They successfully demonstrated that angiotensin converting enzyme (ACE) cleaved Ang I to generate Ang II. ${ }^{34}$ Shortly after, the work of many other investigators led to the discovery that Ang II also stimulates the release of aldosterone, the master regulator of $\mathrm{Na}^{+}-\mathrm{K}^{+}$balance, ${ }^{35}$ and thus evolved the concept of the RAS.

\subsubsection{The Major Players of the RAS}

The discovery of renin as the rate limiting pressor substance gave impetus to further research that led to the emergence of new frontiers. RAS system has become the most well studied subject in the field of cardiovascular research and has since been recognized as the master regulator of BP and fluid homeostasis. The afferent arteriole of the glomerulus is lined by specialized smooth muscle cells called the juxtaglomerular (JG) cells that synthesize renin in its preprohormone form. Clevage of 43 amino acids from its $\mathrm{N}$ terminal results in the formation of active renin, an aspartyl protease that is stored in the granules of the JG cells. ${ }^{36}$ Renin release is governed by four inter related factors: 1) changes in perfusion pressure sensed by the renal baroreceptors in the afferent arteriole, 2) alterations in the $\mathrm{NaCl}$ load sensed by the macula densa cells, 3) changes in sympathetic nerve activity, and 4) negative feedback mechanism by Ang II directly on the JG cells. ${ }^{37}$ Renin is not only synthesized by the kidneys but also by adipose tissue, adrenal gland, ovaries, brain, and possibly heart and the vasculature; the synthesis and regulation of renin in other tissues is not well understood. ${ }^{36}$ The action of renin (Figure 2.1) on angiotensinogen, which is produced primarily by the liver to generate the biologically inert decapeptide Ang I, is the rate limiting step in the RAS cascade. ACE which is localized mostly in various cell types such as vascular endothelial cells and microvillar brush border of epithelial cells then hydrolyses Ang I by cleaving the Cterminal dipeptide to form the biologically active and potent vasoconstrictor, Ang II, an octapeptide. ACE also metabolizes many other peptides including bradykinin and kallidin to its inactive state. ${ }^{38}$ It is well-established that Ang II is the most important player of the RAS; however, there are other metabolites of Ang that serve important biological 


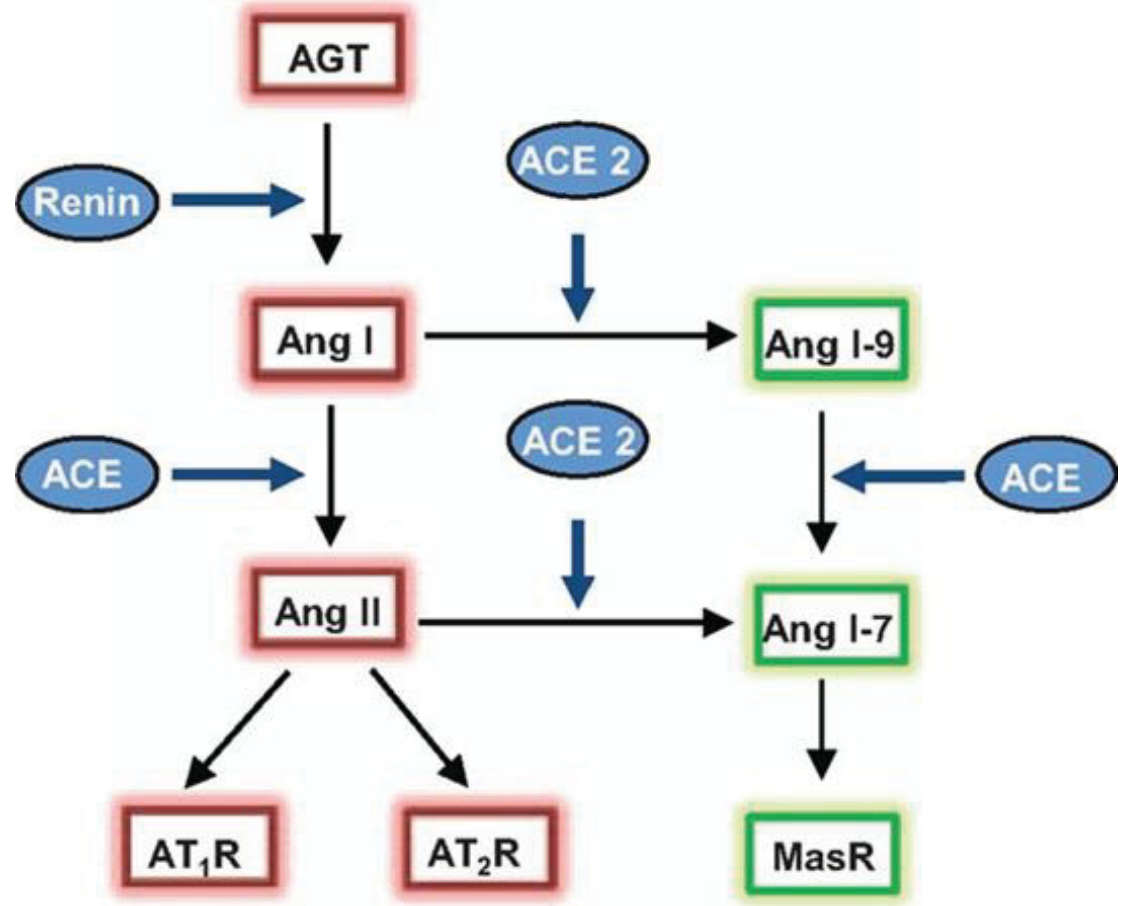

Figure 2.1 Angiotensin metabolism pathway

Reprinted with permission. Conti S, Cassis P, Benigni A. Aging and the reninangiotensin system. Hypertension. 2012;60:878-883. ${ }^{39}$ 
functions too. Ang III, a heptapeptide, formed by the removal of amino acids from the Nterminal of Ang II, present in the central nervous system, may play a role in tonic BP maintenance and hypertension. ${ }^{40}$ Further enzymatic degradation of Ang III results in the generation of Ang IV, a hexapeptide. Not only do the metabolites of Ang II serve specific function, the peptides generated at the C-terminal in this process by stepwise enzymatic cleavage also tend to have specific biological activity. One such important fragment formed is Ang 1-7, generated by the cleavage of Ang II by the carboxypeptidase, ACE 2. Ang 1-7, by binding to the Mas receptor, acts as a vasodilator and has been implicated in promoting natriuresis, anti-proliferation and cardio protection. ${ }^{40,41}$ Thus, the balance between ACE and ACE 2 is of critical importance in maintaining Ang II levels. ${ }^{42}$

Of all the components of the RAS, Ang II is the most important effector responsible for a multitude of physiological and pathophysiological actions. Four Ang receptors have been discovered so far. ${ }^{41}$ Most of the effects of Ang II are mediated via angiotensin type 1(AT1) receptor (R), whereas the AT2R might mediate a counterregulatory mechanism by inhibiting the actions of Ang II. ${ }^{43}$ The function of AT3R is not well known, while AT4R is thought to mediate the release of plasminogen activator inhibitor- $1 .{ }^{41}$

\subsubsection{Ang II Signal Transduction}

Ang II not only plays an important role in regulating cardiovascular and renal homeostasis, it is also involved in various cardiovascular diseases including hypertension, atherosclerosis, restenosis and heart failure. In spite of extensive ongoing research, the contribution of Ang II to these pathologies remains obscure. The functions of Ang II are mediated by at least two of the four, 7 transmembrane G-protein coupled receptors; AT1 and AT2. Most of the actions of Ang II that are predominantly located in vascular smooth muscle cells (VSMC) are mediated via AT1R and on activation, promote hypertrophy, hyperplasia, proliferation and migration of $\mathrm{VSMC},{ }^{44}$ vasoconstriction, and aldosterone release. ${ }^{45}$ Increased Ang II levels results in increased expression of AT1R, however, sustained or chronic Ang II exposure causes downregulation of the receptors. In spite of this tight negative feedback regulation, under certain pathological conditions including hyperlipidemia, ${ }^{46}$ and hyperinsulinemia ${ }^{47}$ AT1Rs are upregulated.

On activation by Ang II, AT1R generates second messengers including inositol triphosphate (IP3), diacylglycerol (DAG), and ROS via its interaction with several heterotrimeric $\mathrm{G}$ proteins. It also activates intracellular protein kinases such as Ser/Thr kinases, tyrosine kinases, mitogen activated protein kinase (MAPK) family, and protein kinase $\mathrm{C}$ (PKC) isoforms. ${ }^{48-51}$ Binding of IP3 to its receptors on sarcoplasmic reticulum results in calcium efflux into the cytoplasm. $\mathrm{Ca}^{2+}$ released, binds to calmodulin and results in phosphorylation of myosin light chain via activation of myosin light chain kinase. This promotes interaction between actin and myosin resulting in smooth muscle cell contraction. ${ }^{52}$ DAG also activates PKC, which contributes to the Ras/Raf/MEK/ERK pathway by which Ang II promotes hypertrophy. ${ }^{53}$ Ang II also phosphorylates PLA 2 and releases AA, which is metabolized to various vasoactive eicosanoids. (discussed later) 
Another important signaling molecule is ROS, generated via NADPH oxidase. In VSMC, Ang II activates membrane NADPH oxidase to produce ROS via upstream mediators Src/EGFR/PI3K/Rac-1. ${ }^{54,55}$ Several biological actions of Ang II-mediated effects are ROS dependent. One of the most well studied outcomes of Ang II-induced ROS production is the inactivation of nitric oxide (NO), resulting in endothelial dysfunction. ${ }^{56,57}$ It has been reported that ROS can cause inflammation of the vasculature by recruiting monocytes, macrophages, and $\mathrm{T}$ cells at sites of endothelial damage by promoting release of cytokines and leukocyte adhesion molecules. ${ }^{58}$

MAPKs have long been identified as players in the Ang II signal transduction cascade. They have been involved in an array of functions including gene expression, protein synthesis and metabolism, transport, volume regulation, and growth. ${ }^{59}$ Studies have demonstrated that Ang II activates MAPKs such as extracellular signal regulated kinases (ERK1/2), c-Jun N-terminal kinases (JNK), and p38 that are involved in VSMC proliferation, differentiation, migration, and fibrosis. ${ }^{60,61}$ Touyz et al showed that Ang IIinduced VSMC contraction, mediated via ERK signaling may result in increased intracellular $\mathrm{Ca}^{2+} \cdot{ }^{62}$ Evidence suggests that activation of ERK1/2 and Akt/PKB inhibits apoptosis ${ }^{63-65}$ and, through regulation of PHAS-1, is involved in cell growth and protein synthesis. ${ }^{66}$ Ang II-induced ERK1/2 activation results in increased gene expression of anti-apoptotic transcription factors, c-fos and c-jun, that form the AP-1 complex and promote cell differentiation, migration, and adhesion. ${ }^{67}$ Enhanced ERK1/2 activation has been implicated in hypertension and end organ damage. ${ }^{68}$ In addition to ERK1/2, Ang II also activates p38 MAPK, implicated in ROS production via stimulation of NADPH oxidase. $^{69}$

Non-receptor tyrosine kinases also participate in Ang II-induced cellular effects. cSrc has emerged as a key second messenger in Ang II-mediated effects. Downstream, cSrc activates Ras, FAK, JAK/STAT, and PLC- $\gamma$ and results in sustained $\mathrm{Ca}^{2+}$ release. ${ }^{70}$ cSrc also plays a role in Ang II-induced focal adhesion complex formation and actin bundling in $\mathrm{VSMC}^{71}$ and, thus, is responsible for reorganization of the cytoskeleton matrix leading to remodeling. Stimulation of AT1R also results in activation of the JAK/STAT pathway, which results in gene transcription of early response genes including c-fos and myc. ${ }^{71}$

Receptor tyrosine kinases including platelet derived growth factor (PDGF), epidermal growth factor (EGF) are also involved in Ang II-induced hypertrophy. PDGFs have been well documented in the pathogenesis of vascular disease by promoting VSMC proliferation and migration. ${ }^{72-74}$ Linseman et al. demonstrated cross talk between AT1R and PDGF receptor in VSMC. They showed that stimulation of VSMC with Ang II resulted in phosphorylation of Shc and formation of the Shc-Grb2 complex, which further activates $\mathrm{cSrc}^{75}$ that has been previously implicated in Ang II-induced contractile responses. ${ }^{76}$ Another major mechanism by which Ang II triggers growth related signaling pathway is transactivation of the EGF receptor in a Src dependent manner that occurs in the cholesterol rich domains in the caveolae. ${ }^{77,78}$ This further leads to activation of the PI3K/PDK1/Akt1 and the Ras/Raf/ERK pathways via HB-EGF-induced dimerization and 
autophosphorylation of EGFR, resulting in growth, hypertrophy, survival, and inflammation. ${ }^{79}$

\subsection{Pathogenesis of Hypertension}

Uncontrolled hypertension results in approximately 7.6 million premature deaths per year and is now the number one risk factor for cardiovascular deaths ${ }^{1}$ The prevalence of hypertension has increased with the increase in life expectancy, more so in developed nations where the problem seems to be worse compared to developing countries where only a small fraction of the population develops hypertension. In the United States alone, $50 \%$ of the population between $60-70$ years old and $75 \%$ over the age of 70 , suffer from hypertension. ${ }^{1}$ Despite an extensive body of evidence and advances in medicine, hypertension remains a poorly controlled condition. Primary or essential hypertension, accounts for $95 \%$ of all cases of hypertension for which there is no secondary cause.

\subsubsection{Renin Angiotensin Aldosterone System}

The renin angiotensin aldosterone system (RAAS) (Figure 2.2) is probably the most powerful hormone system regulating BP. As explained earlier, Ang II is the most potent vasoconstrictor and plays a role in both the long and short term regulation of BP. It helps in maintaining acute blood volume and sodium depletion in times of physiological crisis. ${ }^{80}$ The long term effects of Ang II on BP are interrelated with volume homeostasis through direct and indirect effects on the kidney; however, high salt intake can be a major game changer and can reduce the effectiveness of various RAAS blockers. ${ }^{80}$ High levels of Ang II, attenuate the ability of the kidneys to excrete salt and impair pressure natriuresis, thereby resulting in increased BP to maintain sodium balance.

The mechanisms that mediate the potent anti-natriuretic effects of ANG II include direct and indirect effects to increase tubular reabsorption as well as renal hemodynamic effects. ${ }^{81}$ Volume depletion and/or under perfusion of kidneys such as sodium depletion, hemorrhage, or heart failure, result in activation of RAAS, which leads to aldosterone secretion, resulting in salt and water retention by direct effects on hemodynamics and epithelial transport. Ang II brings about a reduction in renal blood flow and peritubular capillary hydrostatic pressure and increases peritubular colloid osmotic pressure by constricting efferent arterioles; these actions result in increased filtration fraction, thus facilitating an increase in the driving force for fluid reabsorption across tubular epithelial cells. ${ }^{81}$ At very low concentrations, Ang II, by acting on the luminal membrane of the proximal tubules, stimulates $\mathrm{Na}^{+}-\mathrm{H}^{+}$exchanger, and, on the basolateral membrane, increases the activity of $\mathrm{Na}^{+}-\mathrm{K}^{+}$-ATPase, as well as $\mathrm{Na}^{+}-\mathrm{HCO}_{3}$ cotransport. ${ }^{81,82}$ Ang II also mediates its effects on loop of Henle, macula densa, and distal nephron segments. It stimulates bicarbonate reabsorption on loop of Henle and promotes $\mathrm{Na}^{+}-\mathrm{K}^{+}-2 \mathrm{Cl}^{-}$transport in the medullary thick ascending loop of Henle. ${ }^{82,83}$ In the distal nephron segments, Ang II facilitates $\mathrm{Na}^{+}$-ATPase activity as well as epithelial $\mathrm{Na}$ channel activity in the cortical collecting ducts. ${ }^{82,83}$ 


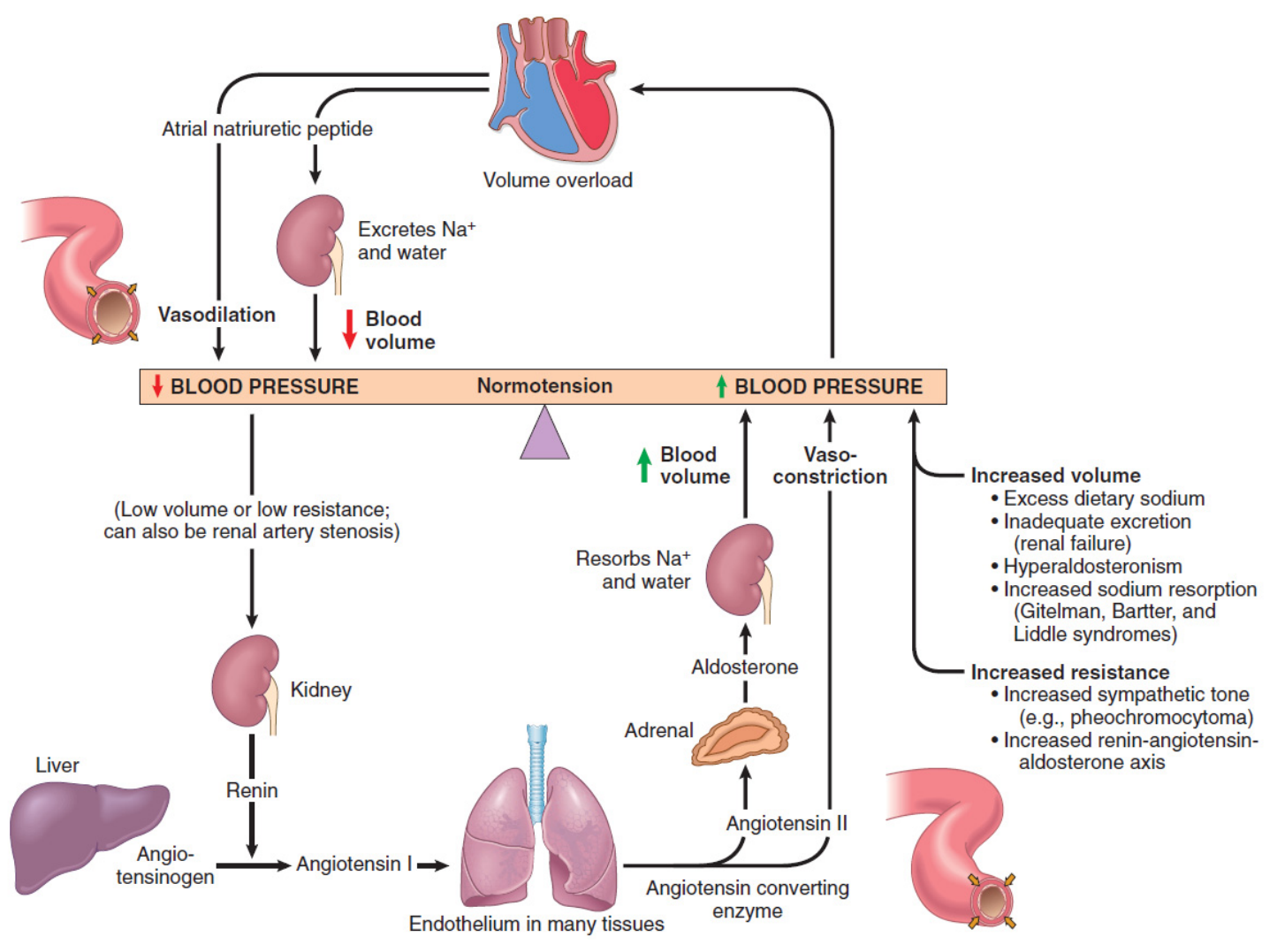

Figure 2.2 Interplay of the renin angiotensin aldosterone system in BP maintenance and homeostasis

Reprinted with permission. Vinay Kumar AKA, Jon C. Aster, Nelson Fausto. Robbins \& Cotran Pathologic Basis of Disease, 8th edn. Saunders, 2009, page $496 .^{84}$ 
Not only does Ang II regulates BP via renal sodium reabsorption, it does so through its potent ability to cause vasoconstriction that is mostly confined, but not limited to post glomerular efferent arterioles. Low levels of Ang II produce an increase in glomerular filtration rate (GFR) by constricting efferent arteriole but high Ang II levels constrict both efferent and afferent arterioles resulting in a decrease in GFR. During hemorrhage, when kidney perfusion in threatened, RAAS is activated, to prevent excessive reduction in BP, and high levels of Ang II constrict both efferent and afferent arterioles to decrease GFR and renal blood flow.

\subsubsection{Aldosterone}

Aldosterone, another powerful hormone, is involved in BP regulation via sodium retention and potassium excretion and thus plays an important role in renal pressure natriuresis and has functions similar to those of Ang II. The role of aldosterone in human hypertension has recently gained a lot of attention, because $20 \%$ of hypertensive patients suffer from primary aldosteronism. ${ }^{85}$ Aldosterone is synthesized within the zona glomerulosa of adrenal cortex and acts primarily on the principal cells of the distal tubules, cortical collecting tubules and collecting ducts. Aldosterone binds to mineralocorticoid receptors (MR) and exerts both genomic and non-genomic effects. It promotes transcription of certain target genes and stimulates synthesis of $\mathrm{Na}^{+}-\mathrm{K}^{+}$-ATPase pump on the basolateral epithelial membrane and activates amiloride-sensitive sodium channels on the luminal side of the epithelial membrane, ${ }^{86}$ which results in increased sodium current in the principal cells of the cortical collecting tubule and also stimulates

$\mathrm{Na}^{+}-\mathrm{K}^{+}$exchanger. ${ }^{86,87}$ Low sodium intake triggers increased aldosterone release to curb sodium loss to prevent reduction in BP and high sodium intake inhibits aldosterone secretion in an attempt to prevent sodium retention and lower BP. MR antagonism is emerging as a therapeutic tool for treating hypertension and associated end organ damage. $^{85}$

\subsubsection{Endothelin}

Endothelial dysfunction resulting from an altered balance between endothelial derived relaxing and contracting factors has been observed in many forms of experimental and human hypertension. One such potent constricting factor is endothelin (ET)-1. ET-1 can activate ET type A ( $\left.\mathrm{ET}_{\mathrm{A}}\right)$ receptor and elicit a hypertensive response or it can activate $\mathrm{ET}$ type $\mathrm{B}\left(\mathrm{ET}_{\mathrm{B}}\right)$ receptor and elicit an antihypertensive response, thus, the nature of response produced by ET depends on the type of receptor it acts on.

Endothelin, via $\mathrm{ET}_{\mathrm{A}}$ receptor mostly localized on VSMC, produces systemic and renal vasoconstriction, impairs pressure natriuresis and increases BP and could contribute to progressive renal injury. ET-1 stimulates contraction of VSMC and mesangial cell resulting in decreased GFR and renal blood flow and chronic actions of ET-1 may also lead to renal mesangial cell proliferation, VSMC hypertrophy and remodeling. ${ }^{88,89}$ 
Several studies have shown that $\mathrm{ET}_{\mathrm{B}}$ activation by ET-1 on the other hand, causes vasodilation, enhances pressure natriuresis and decreases BP. $\mathrm{ET}_{\mathrm{B}}$ deficient rats exhibit severe salt sensitive hypertension ${ }^{90}$ and mice develop endothelial dysfunction independent of salt loading. ${ }^{91}$

\subsubsection{Oxidative Stress}

It is well established that ROS contributes to the onset and progression of hypertension and associated cardiovascular pathology. ${ }^{92}$ The ROS family consists of many molecules that have varied effects on growth, differentiation, modulation and breakdown of extracellular matrix, inactivation of antioxidant defense system, and initiation and maintenance of pro-inflammatory cascades. ${ }^{93-95}$ Xanthine oxidase, uncoupling of $\mathrm{NO}$ and tetrahydrobiopterin $\left(\mathrm{BH}_{4}\right)$, and NADPH oxidase are the important sources of ROS in vascular disease, of which NADPH oxidase derived ROS

plays a major role in Ang II-induced hypertension. ${ }^{16,96-98}$ The prototypic NADPH oxidase has three cytosolic subunits (p47 phox, p67 phox, p40phox) and two membrane subunits (p22 phox and the catalytic subunit gp91 phox) that occur as a heterodimeric flavoprotein: cytochrome b558. ${ }^{99,100}$ On stimulation, $\mathrm{p} 47$ phox undergoes phosphorylation, and the cytosolic subunits assemble to form a complex and translocate to the membrane where it associates with cytochrome b558 to form the active oxidase. The NADPH oxidase comprises seven members: NOX 1, 2, 3, 4, and 5 and Duox 1, and 2 .

Many models of hypertension have demonstrated the link between oxidative stress and increased BP. It has been shown that in SHRs, increased ROS formation precedes development of hypertension thus implying that ROS is important for the development and maintenance of hypertension. ${ }^{101,102}$ Also in experimental hypertension, several markers of oxidative stress, such as thiobarbituric acid reactive substances (TBARS) and F2-isoprostanes are increased. ${ }^{103-105}$ Many studies have also successfully demonstrated the involvement of specific subunits of NADPH oxidase in Ang II-induced hypertension. Ang II infusion failed to induce hypertension, vascular hypertrophy, and endothelial dysfunction in p47 phox and gp91 phox knockout mice compared to their WT counterparts. ${ }^{98,106,107}$ Another study showed that mice treated with (short interfering RNA) siRNA against renal p22 phox demonstrated blunted hypertension and reduced ROS formation, implying that p22 phox is essential for Ang II-induced hypertension, ${ }^{108}$ however, its overexpression did not significantly increase BP but did result in increased oxidative stress and endothelial dysfunction. ${ }^{109}$ Pharmacological inhibition of NADPH oxidase with apocynin, reduced vascular $\mathrm{O}_{2}$ production, prevented cardiovascular remodeling and attenuated Ang II-induced hypertension. ${ }^{97}$

\subsubsection{Nitric Oxide}

Many studies have established that NO-induced arterial vasodilation is impaired in various models of hypertension ${ }^{110,111}$ and NO bioavailability plays a major role in 
endothelial dysfunction. ${ }^{112} \mathrm{NO}$ is produced in the vascular endothelin from L-arginine by endothelial nitric oxide synthase (eNOS). eNOS null mice and inhibition of eNOS by LNAME exhibit severe hypertension, ${ }^{113,114}$ and administration of $\mathrm{L}$-arginine and $\mathrm{BH}_{4}, \mathrm{a}$ cofactor of eNOS, have demonstrated a reduction in BP and improvement in endothelial function in both animal models and patients. ${ }^{115-118}$ Nebivolol, a NO releasing $\beta$ blocker improves endothelial function by increasing NO bioavailability not through its $\beta$ blocking ability. ${ }^{119}$ The most important cause for decreased bioavailability of NO is ROS. ${ }^{120}$ Hypertension, smoking, obesity, and dyslipidemia, disrupt antioxidant defense mechanisms, such as NO bioactivity, thus resulting in oxidation of biomolecules that leads to vascular inflammation, and development of atherosclerosis and cardiovascular diseases. ${ }^{120}$ A balance between NO bioavailability and ROS production must at least be maintained if not favored towards NO. A tilt towards ROS may lead to decreased endothelium-dependent vasodilation, thus resulting in, or further exacerbating, hypertension. ${ }^{121,122}$ Many studies have shown that Ang II decreases NO bioavailability by promoting production of $\operatorname{ROS}^{123}$ and superoxide dismutase, and antioxidants such as vitamin $\mathrm{C}$ restore endothelial function in both humans and animal models. ${ }^{124,125}$

\subsubsection{Eicosanoids}

Eicosanoids (Figure 2.3) generated from AA, released from tissue phospholipids by the action of one or more phospholipases, mainly PLA 2 . AA is metabolized by cyclooxygenase, lipoxygenase and cytochrome P450 monooxygenase into various vasoactive eicosanoids. These eicosanoids exert pro-hypertensive as well as antihypertensive effects. ${ }^{126-130}$

\subsubsection{Cyclooxygenase Derived Eicosanoids}

There are at least two forms of COX enzymes: COX-1, the constitutively active form and COX-2 the inducible form. COX catalyzes the metabolism of AA into prostaglandin (PG) H2, which by the action of prostacyclin synthase is further converted to PGI2 (prostacyclin), E2, D2, and F2 $\alpha$. PGH2 is also metabolized by thromboxane (Tx) A2 synthase to TxA2.

PGE2 and $\mathrm{I} 2$ are known to exert anti-hypertensive effects by dilating resistance vessels, reducing release of norepinephrine (NE), attenuating response to vasoconstrictors, and promoting salt and water excretion. ${ }^{131}$ Treatment with COX inhibitors results in decreased production of PGE2 and I2, leading to increased vascular resistance, responsiveness to vasoconstrictors including Ang II, and suppression of pressure natriuresis response, ${ }^{132,133}$ thereby resulting in increased BP and renal dysfunction to a greater extent in hypertensive than normotensive states. ${ }^{134}$ Also, it has been shown that rats infused with Ang II show an increase in plasma concentration of derivative of PGI2; 6-keto-PGF1 $\alpha .{ }^{135}$ The general consensus is that PGE2 and I2 


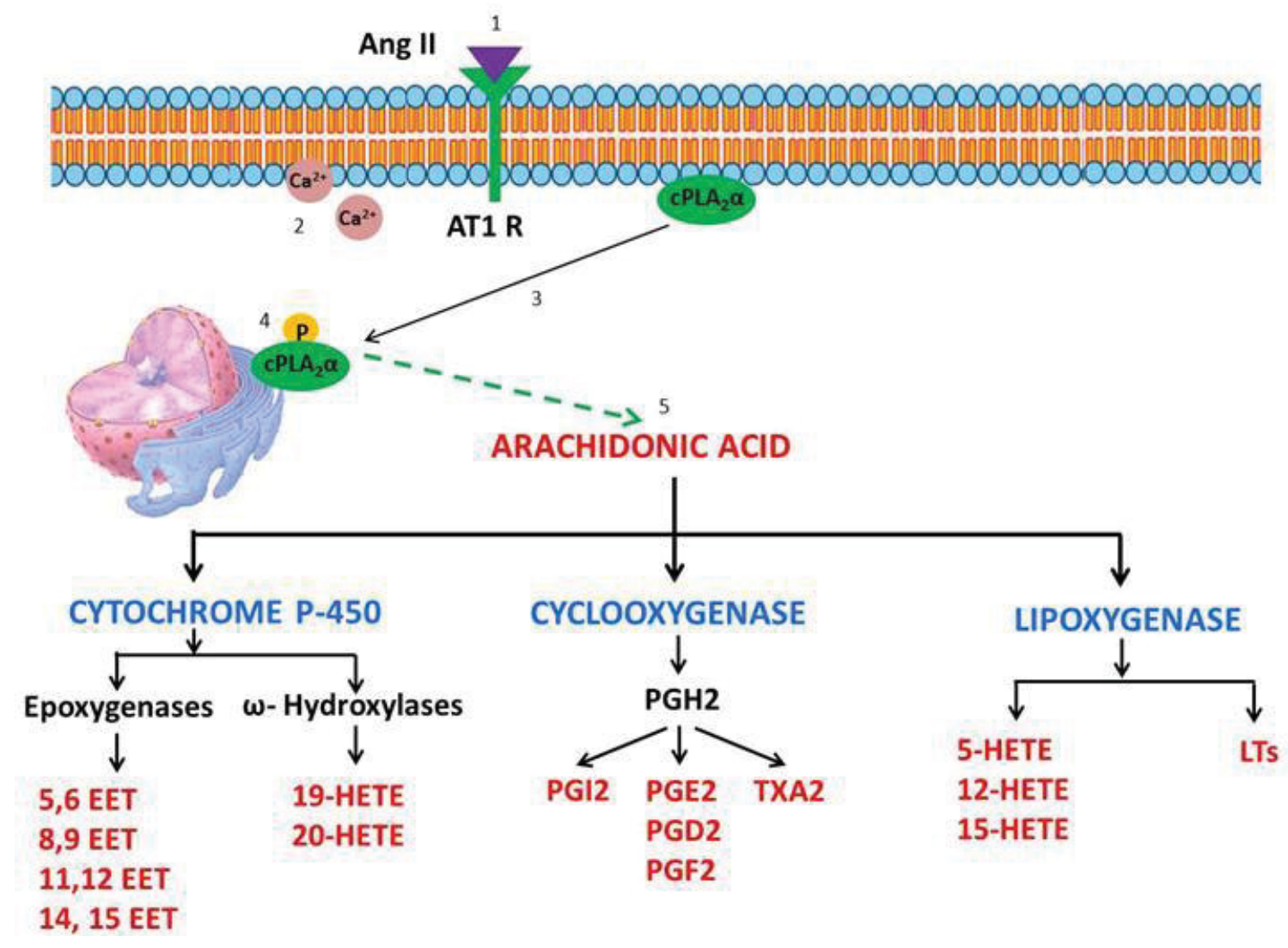

\section{Figure 2.3 Arachidonic acid metabolism}

Agonist (Ang II) induced (1) influx of $\mathrm{Ca}^{2+}(2)$ results in translocation of $\mathrm{CPLA}_{2} \alpha$ from cytosol to nuclear envelope (golgi, ER) (3) and undergoes phosphorylation (4) which increases its hydrolytic activity that results in AA release (5) from tissue phospholipids. AA is metabolized by cytochrome P450, cyclooxygenase and lipoxygenase to various pro and anti-hypertensive eicosanoids. 
contribute to anti-hypertensive mechanisms however, this view is somewhat controversial. These eicosanoids are also known to stimulate renin secretion, ${ }^{136}$ and, in some studies, treatment with Cox inhibitors has been shown to lower BP and reduce plasma renin activity. ${ }^{137}$ Also it has been demonstrated that $\mathrm{PGH} 2$, is a mediator of endothelium dependent vasoconstriction in arteries of hypertensive animals. ${ }^{138}$ TXA2, a powerful vasoconstrictor, is known to serve pro-hypertensive effects, and both TXA2 and $\mathrm{PGH} 2$ receptors may function in concert to stimulate contraction of VSMC, produce renal vasoconstriction and reduce renal blood flow. ${ }^{127}$ It has been demonstrated that infusion of TXA2/ $\mathrm{PGH}_{2}$ receptor agonist results in BP elevation, ${ }^{139}$ while inhibition of thromboxane synthase lowers BP in certain models of experimental hypertension. ${ }^{140,141}$

\subsubsection{Lipoxygenase Derived Eicosanoids}

Lipoxygenases (LOX) are a group of non-heme iron containing dioxygenases ${ }^{142}$ that metabolize AA into 5,- 12,- 15- hydroxyeicosatetraenoic acids (HETE) and different forms of leukotrienes (LT). ${ }^{143}$ Many studies have demonstrated the role of 12-HETE in BP regulation. Some studies suggest its role as an anti-hypertensive eicosanoid, while others refer it to as pro-hypertensive. 12-HETE has been shown to inhibit renin secretion in rat renal slices, and inhibition of LOX increases plasma renin activity in rats suggesting that 12-HETE could serve as a negative regulator of renin. ${ }^{144}$ However, many studies have also shown that 12- hydroperoxyeicosatetraenoic acid (HPETE) and 15HPETE (precursors of 12-and 15- HETEs) inhibit prostacyclin synthase, ${ }^{145,146}$ indicating its pro-hypertensive function. 12-HETE also mediates Ang II-induced afferent artery constriction in the kidney. Inhibition of LOX has also been shown to attenuate Ang IIinduced vasoconstriction ${ }^{147}$ and to reduce BP in SHR. ${ }^{148}$ Moreover, Ang II has been shown to increase the protein, as well as mRNA expression, of 12-LOX in VSMC. ${ }^{149}$ In various models of hypertension including two-kidney one clip ${ }^{150}$ and aortic coarctationinduced hypertension, ${ }^{145}$ an increase in the levels of HETEs has been observed. Thus, it appears that LOX derived eicosanoids serve a pro-hypertensive function.

\subsubsection{Cytochrome P450 Monooxygenase Derived Eicosanoids}

Until 1981, cytochrome P450s (Cyp 450) were recognized only as enzymes required for metabolism and detoxification of xenobiotics. The discovery of their role in the AA cascade opened new vistas, and the diverse nature and functions of the enzyme was identified. One of the earliest studies, by McGiff and his collaborators, demonstrated the contribution of renal CYP4A in the pathophysiology of hypertension. ${ }^{151,152}$ Cyp 450 via its epoxygenases metabolizes AA into biologically active cis-epoxyeicosatrienoic (EET) acids; 5,6-, 8,9-, 11,12-, 14,15-EETs and via its $\omega$-hydroxylase activity into 19and 20-HETEs. ${ }^{153,154}$ Subsequent studies recognized EETs in the activation of calcium sensitive potassium channels, resulting in hyperpolarizing of membrane potential. ${ }^{155}$

They play a major role in regulating vascular tone, ion transport, proliferation inflammation, and hemostasis. ${ }^{154,156-158}$ More recent studies have sketched an anti- 
hypertensive image of EETs. Overexpression of P450 epoxygenases or treatment with synthetic EETs resulted in upregulation of eNOS via activation of MAPK and PKC signaling pathways. ${ }^{159}$ In another long term study, overexpression of CYP2J2 using a type 8 recombinant adeno-associated virus vector in SHR increased urinary expression of 14,15 EETs, enhanced mRNA expression of atrial natriuretic peptide, decreased BP, and improved cardiac output. Furthermore, when the specific inhibitor of CYP2J2 was administered, it blocked this hypotensive effect and attenuated the increase in the levels of EETs. ${ }^{160}$ Furthermore, Capdevila et al, demonstrated that Cyp $2 c 44^{-/-}$mice on a high salt diet develop hypertension and exhibit increased epithelial sodium channel (ENaC) activity, ${ }^{161}$ thus implying the importance of Cyp2c44 in regulating BP by controlling ENaC activity.

CYP4A metabolites of AA have been much appreciated as the anti-hypertensive, anti-inflammatory arm of the AA metabolism cascade; however, studies in our lab have demonstrated that the effect of Ang II on VSMC migration, proliferation, and hypertrophy is via AA release and its metabolism to ROS by CYP1B1. ${ }^{162}$ Moreover, male Cyp $1 b 1^{-/-}$mice infused with Ang $\mathrm{II}^{13,14}$ or treated with deoxycorticosterone acetate $(\mathrm{DOCA}) / \mathrm{salt}^{163}$ are protected against hypertension, endothelial dysfunction, cardiac hypertrophy, fibrosis, and inflammation. Also, treatment with the inhibitor of CYP1B1, 2, 3', 4, 5'-tetramethoxystilbene minimizes hypertension caused by Ang II in Cyplb1 ${ }^{+/+}$ mice. ${ }^{14,164}$ Moreover, ROS generated via the metabolism of AA by CYP 1B1, via second messenger systems, ERK1/2, p38 MAPK, and cSrc stimulate VSMC growth, and contribute to the development of hypertension and associated pathophysiology. ${ }^{162}$

AA metabolism is also associated with generation of $\operatorname{ROS}^{165}$ that have been implicated in hypertension. ${ }^{166}$ Therefore, the balance between pro- and anti-hypertensive eicosanoids and generation of ROS, would determine the level of BP. Whether AA metabolites generated via different pathways, following their release by activation of $\mathrm{cPLA}_{2}$ by Ang II, contribute primarily to pro- or antihypertensive mechanisms, is not known.

\subsubsection{Emerging Concepts of the Immune System in Hypertension}

One of the earliest reports demonstrated that lymph node cells from hypertensive rats, when introduced in normotensive rats, raised their BP. ${ }^{167}$ Later, it was shown that nude mice lacking a thymus or thymectomized mice did not exhibit hypertension following renal infarction. ${ }^{168}$ Another study demonstrated that SHR that received donor thymus from Wistar Kyoto rats showed a reduction in BP. ${ }^{169}$

More recent studies have shown that mice lacking B and T cells $\left(\mathrm{RAG}^{-/-}\right)$are protected against Ang II-induced hypertension, endothelial dysfunction, and superoxide production compared to wild type (WT) mice, and adoptive transfer of T but not B cells restored hypertension. ${ }^{170}$ Ang II infusion in WT mice, resulted in an increase in circulating levels of $\mathrm{CD} 9^{+}, \mathrm{CCR} 5^{+}$, and $\mathrm{CD} 44^{\text {high }}$, suggesting the involvement of $\mathrm{T}$ cells 
in hypertension. ${ }^{170}$ Furthermore, Dahl salt sensitive rats deficient in RAG-1 demonstrated decreased BP, kidney damage, and albuminuria. ${ }^{171}$

$\mathrm{T}$ cells have many subgroups, one of them being $\mathrm{CD}^{+} \mathrm{T}$ cells that include Th1, Th2, Th17, and T regulatory cells ( $\left.\mathrm{T}_{\text {regs }}\right) .{ }^{172}$ Interleukin (IL)-17A, a cytokine released by Th17 cells, has been implicated in the pathogenesis of many autoimmune and inflammatory diseases, such as rheumatoid arthritis, psoriasis, multiple sclerosis, asthma, inflammatory bowel disease, and periodontal disease. ${ }^{173,174}$ Recent studies have demonstrated the role of Th17 cells in Ang II-induced hypertension. IL-17 ${ }^{-/}$mice infused with Ang II demonstrated an initial increase in BP, which dropped after 7 days, and T cell infiltration that was observed in WT mice was abolished in IL-17/- mice. Ang II increased IL-17 protein deposition in the aortic wall of WT mice. ${ }^{175}$ The involvement of other cytokines has also been reported. Marko et al, demonstrated that interferon (IFN)- $\gamma$ receptor knockout mice are protected against Ang II-induced cardiac hypertrophy, macrophage and T-cell infiltration, fibrosis, and arrhythmogenic electric remodeling compared to WT mice. Also the researchers observed reduced renal inflammation, tubulointerstitial damage, and improved GFR. ${ }^{176}$ In another study, tumor necrosis factor (TNF)- $\alpha$ inhibitor etanercept reduced infiltration of inflammatory and immune cells in a model of Ang II-induced renal damage. ${ }^{177}$ Zhang et al. presented evidence in both human and mice demonstrating the role of cytokine IL-6 in Ang II induced hypertension. They reported a significant increase in IL-6 expression in kidney samples collected from chronic kidney disease patients with hypertension. They also showed that Ang II is responsible for IL-6 induction in murine studies and its genetic deletion significantly reduced hypertension, ET production, renal injury, and fibrosis. ${ }^{178}$

Patients suffering from AIDS who have a low $\mathrm{CD}^{+} \mathrm{T}$ cell count, show a low incidence of hypertension, but when treated with aggressive antiretroviral therapy, develop increased SBP. ${ }^{179}$ Mycophenolate mofetil, a T-lymphocyte specific immunosuppressant used to treat psoriasis and rheumatoid arthritis, ameliorates hypertension in patients, thus suggesting the involvement of the immune system, more so the role of T cells in hypertension. ${ }^{180}$

Based on these and other findings, Harrison et al, proposed a model of T cell mediated immunity in hypertension ${ }^{15}$ (Figure 2.4), which suggests that hypertensive triggers such as Ang II, catecholamines, stress, ROS, and a high salt diet via its actions on the circumventricular organs in the brain, may result in microglial activation, cytokine production, and increased sympathetic activity resulting in a small elevation in BP (pre hypertension) which may result in formation of neo antigens. These neo antigens may further promote $\mathrm{T}$ cell activation resulting in $\mathrm{T}$ cell infiltration in the vasculature and kidney, further causing severe hypertension. Thus the evidence presented above strongly implicates the involvement of the immune system in hypertension. 


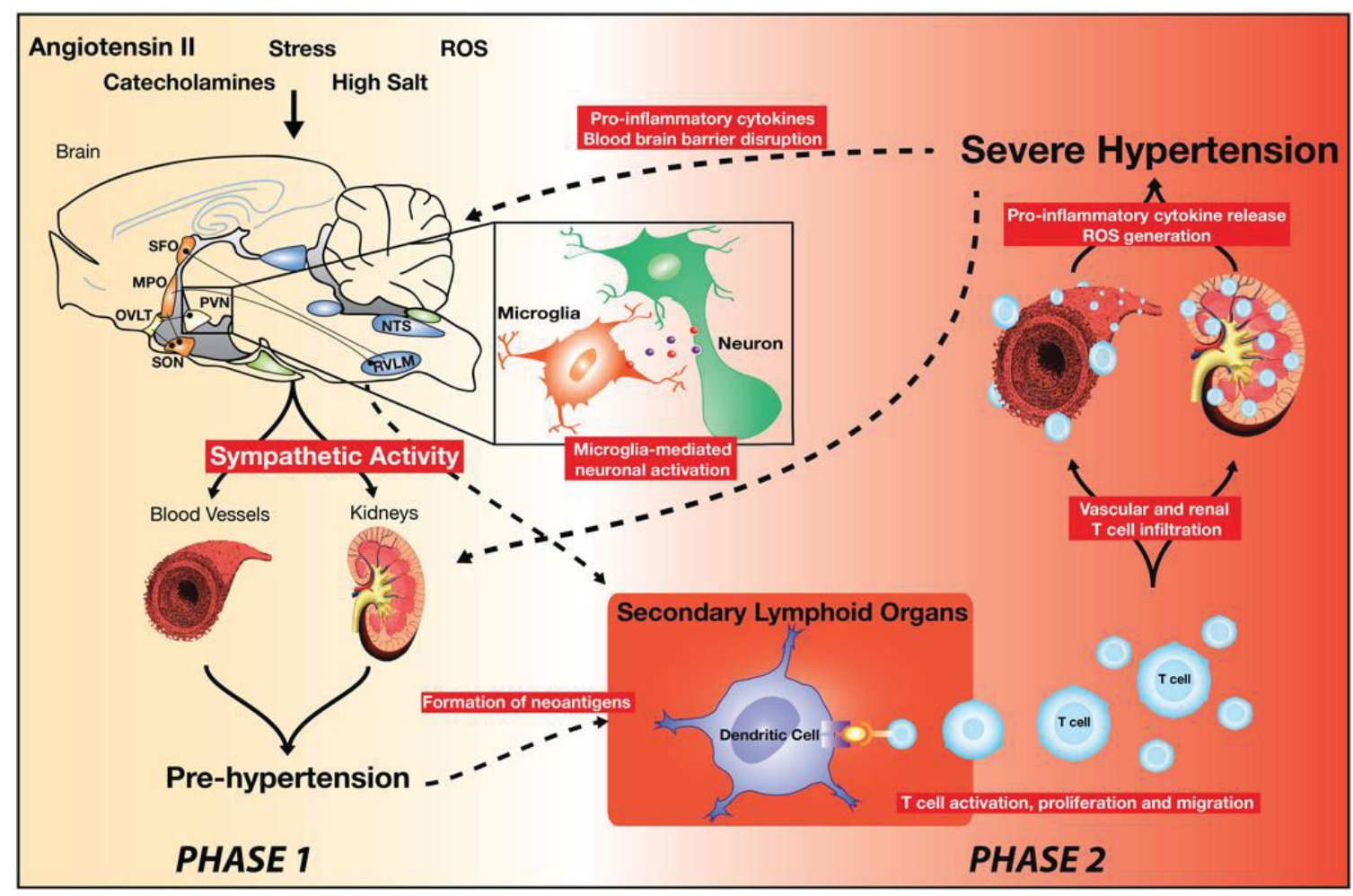

\section{Figure 2.4 T cell mediated immunity in hypertension}

Reprinted with permission. Harrison DG, Guzik TJ, Lob HE, Madhur MS, Marvar PJ, Thabet SR, Vinh A, Weyand CM. Inflammation, immunity, and hypertension. Hypertension. 2011;57:132-140. ${ }^{15}$ 


\subsection{Cytosolic Phospholipase $\mathrm{A}_{2} \alpha$}

\subsubsection{Phospholipases: An Introduction}

More than 30 phospholipases that catalyze the hydrolysis of membrane glycerophospholipids at the sn-2 position, liberating AA, and lysophospholipids have been discovered so far. ${ }^{181}$ Based on the evolutionary relationship, structure, function, and catalytic activity, $\mathrm{PLA}_{2}$ has been classified into $\mathrm{SPA}_{2}, \mathrm{cPLA}_{2}, \mathrm{PLA}_{2}$ also called patatin like phospholipase domain-containing lipases, and platelet activating factor acetylhydrolase. ${ }^{2}$ Hereafter, I shall focus on the role, significance, and function of cPLA $_{2} \alpha$ in hypertension. Of all the phospholipases, $\mathrm{cPLA}_{2} \alpha$ specifically catalyzes the hydrolysis of phospholipids containing AA. ${ }^{182}$

\subsubsection{Structure}

Group IV cytosolic phospholipase $\mathrm{A}_{2}$, an $85 \mathrm{KDa}$ molecule, was first identified in human platelets in 1986. ${ }^{183}$ The structure (Figure 2.5) of the enzyme consists of a C2 domain at the N-terminal, composed of eight antiparallel $\beta$ strands interconnected by six loops. It contains the $\mathrm{Ca}^{2+}$ binding motif followed by the catalytic domain composed of $14 \beta$ strands and $13 \alpha$ helices and houses the $\alpha / \beta$ hydrolase segment, which is conserved across many lipases. ${ }^{184}$ Unique to $\mathrm{CPLA}_{2} \alpha$, within the hydrolase segment, lies, the novel cap region, which also has a lid region. The $\mathrm{C} 2$ domain has two $\mathrm{Ca}^{2+}$ binding sites and is required for its membrane translocation from cytosol to membrane in response to $\mathrm{Ca}^{2+}$ signaling, whereas the catalytic domain contains crucial sites of phosphorylation ${ }^{185}$ and is required for the stable binding of the enzyme to the membrane after $\left[\mathrm{Ca}^{2+}\right]_{\mathrm{i}}$ decreases. ${ }^{186}$

\subsubsection{Regulation}

AA release via the hydrolytic activity of $\mathrm{cPLA}_{2} \alpha$ is mediated by two very important post translation mechanisms: being: increase in $\left[\mathrm{Ca}^{2+}\right]_{i}$ and phosphorylation. ${ }^{187,188}$ During agonist-induced $\left[\mathrm{Ca}^{2+}\right]_{\mathrm{i}}$ increase, two $\mathrm{Ca}^{2+}$ ions bind to calcium binding loops in the C2 domain. ${ }^{189-192}$ The electrostatic potential of the surface exposed calcium binding loops is reduced, this facilitates the penetration of the hydrophobic residues into the Golgi membrane. ${ }^{193,194}$ The basic residues in the C2 domain bind to ceramide 1 phosphate, and the catalytic domain positions itself on the phospholipid membrane, and $\operatorname{Ser}^{505}$ on the catalytic domain is phosphorylated by MAPK, resulting in increased hydrolytic activity of the enzyme. The basic residues in the catalytic domain bind to phosphatidylinositol 4,5-bisphosphate and stimulate the ability of the enzyme to release AA.

Both the amplitude and duration of $\left[\mathrm{Ca}^{2+}\right]_{\mathrm{i}}$ are important determinants for translocation and regulation of $\mathrm{CPLA}_{2} \alpha$ activity. ${ }^{195}$ The initial transient release of $\mathrm{Ca}^{2+}$ 

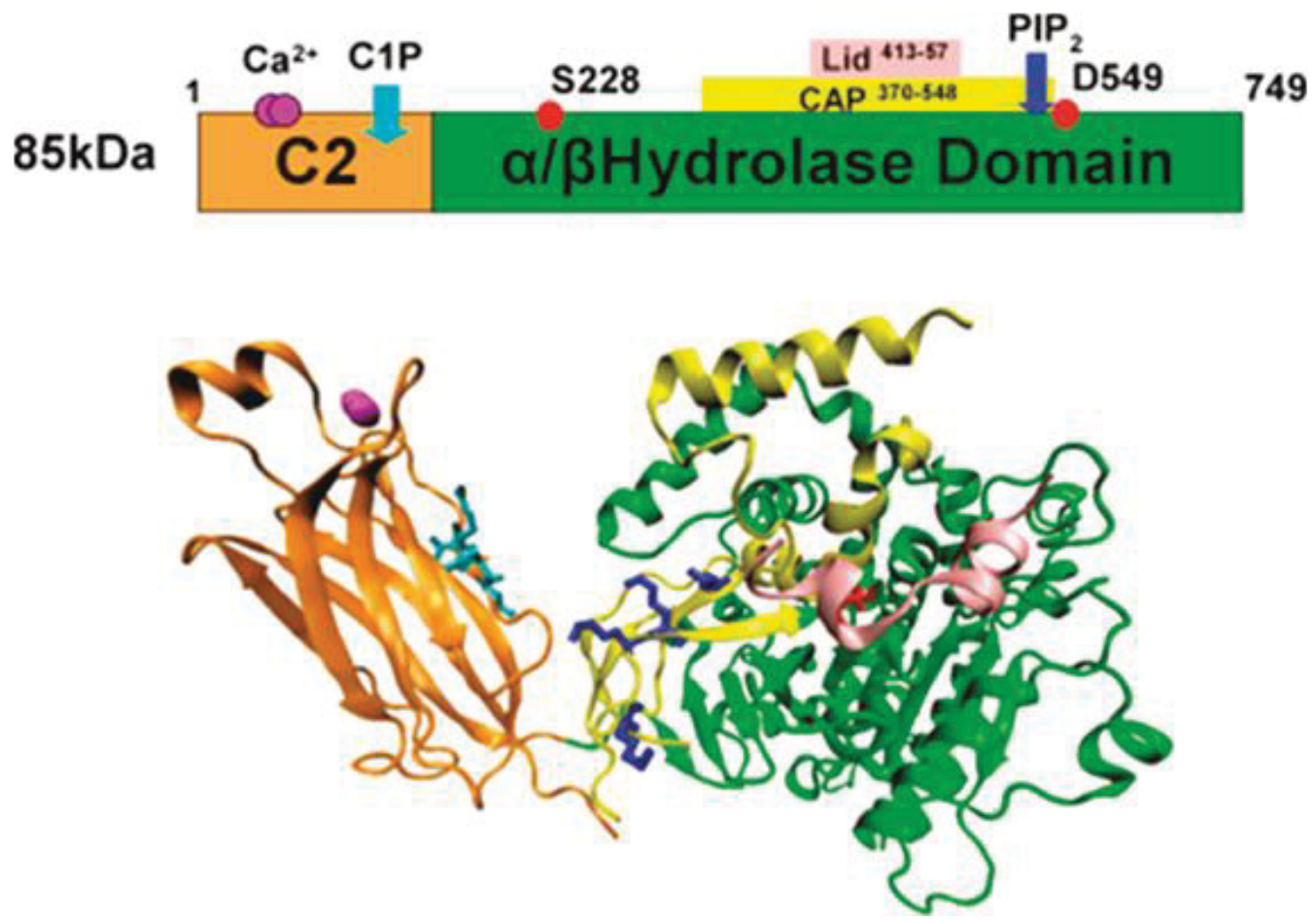

\section{Figure 2.5 Structure of $\mathrm{cPLA}_{2} \alpha$}

Reprinted with permission. Dennis EA, Cao J, Hsu YH, Magrioti V, Kokotos G.

Phospholipase A2 enzymes: physical structure, biological function, disease implication, chemical inhibition, and therapeutic intervention. Chemical reviews. Oct 12

2011;111(10):6130-6185. ${ }^{196}$ 
from intracellular stores is important for immediate translocation of $\mathrm{cPLA}_{2} \alpha$ to Golgi; ${ }^{197}$ however, the subsequent influx of $\mathrm{Ca}^{2+}$ is required for maintaining the stable binding of the enzyme to Golgi to release AA. ${ }^{197}$ The hydrolytic activity of the enzyme is tightly regulated by phosphorylation (Figure 2.6). Of the three phosphorylation sites, $\mathrm{Ser}^{505}$ is the best studied. Phosphorylation of $\mathrm{Ser}^{505}$ is not sufficient for the release of AA, but is important as it enhances membrane binding affinity even at low $\mathrm{Ca}^{2+}$ levels ${ }^{198}$ and facilitates AA release. The main function of $\mathrm{Ser}^{505}$ phosphorylation is to induce a conformation change in the enzyme and to facilitate penetration of the hydrophobic residues in the active site, even at submicromolar levels of $\mathrm{Ca}^{2+} \cdot{ }^{198}$ Studies have shown that phosphorylation of $\mathrm{Ser}^{505}$ depends on phosphorylation of $\mathrm{Ser}^{515}$ by CamKII. ${ }^{199}$ Activation of $\mathrm{cPLA}_{2} \alpha$ by CaMKII results in generation of AA metabolites, particularly HETEs, which in turn by activating ERK1/2, phosphorylates cPLA $2 \alpha$ at $\operatorname{Ser}^{505}$ thereby releasing further AA. ${ }^{200}$ Another important site of $\mathrm{CPLA}_{2} \alpha$ phosphorylation is $\mathrm{Ser}^{727}$ by MAPK-activated protein kinase. ${ }^{5}$ It is also a site for binding of the p11anexin, an inhibitory complex that prevents binding of the enzyme to the Golgi. Phosphorylation of $\operatorname{Ser}^{727}$ disrupts this interaction and allows enzyme activation. ${ }^{201}$

\subsection{4 $\mathrm{cPLA}_{2} \alpha$ in Disease Pathogenesis : Lessons from the Knockout Mouse}

cPLA $_{2 \alpha}$ has been implicated in the pathogenesis of various inflammatory diseases. Studies on $\mathrm{cPLA}_{2} \alpha^{-/-}$mice have revealed that stimulus induced production of prostaglandins and leukotrienes are greatly reduced in inflammatory and noninflammatory cells obtained from these mice. ${ }^{202-205}$ In an acute respiratory distress syndrome model, it has been shown that pulmonary edema, neutrophil sequestration and pulmonary fibrosis are markedly attenuated in $\mathrm{cPLA}_{2} \alpha^{-/-}$mice, and inhibition of cPLA ${ }_{2} \alpha$ may be the key in treating various pulmonary disorders. ${ }^{206,207}$ CPLA $_{2} \alpha$ has also been implicated in multiple sclerosis, an autoimmune, inflammatory demyelinating disease resulting in motor and sensory defects. Multiple Sclerosis is thought to be mediated by the Th1/Th17 axis, in which several lipid mediators: PGE2, LTB4 and PAF are involved. $^{208-212}$ cPLA $_{2} \alpha^{-/-}$mice have been shown to be less susceptible than WT mice to experimental autoimmune encephalomyelitis disease model (animal model for multiple sclerosis), and pharmacological inhibition of $\mathrm{cPLA}_{2} \alpha$ blocked its onset and progression. ${ }^{213}$ Myelin oligodendrocyte glycoprotein specific $\mathrm{T}$ cells from the knockout mice revealed that loss of $\mathrm{CPLA}_{2} \alpha$ results in deficient production of Th1 cytokines, and administration of IL-12 (Th1 cytokine) once again makes the mice more susceptible to the disease, thus suggesting that $\mathrm{cPLA}_{2} \alpha$ facilitates the differentiation of T cells towards Th1 and Th17 phenotypes in autoimmune diseases. PGE2, PGI2 and LTB4 are involved in collagen-induced arthritis, which is also Th17 dependent; the incidence and severity of the disease are greatly reduced in $\mathrm{cPLA}_{2} \alpha^{-/-}$mice. ${ }^{214}$. Also, in a study of post ischemic brain injury, it was observed that $\mathrm{cPLA}_{2} \alpha^{-/-}$mice had smaller infarcts, less brain edema and fewer neurological deficits after transient middle cerebral artery occlusion. ${ }^{204}$. In a more recent study, Saito et al, demonstrated that disruption of $\mathrm{cPLA}_{2} \alpha$ attenuates myocardial ischemia/reperfusion injury compared to its WT counterparts, partly through inhibition of TNF- $\alpha$-mediated pathways. ${ }^{215}$ Tanaka et al, showed the involvement of 


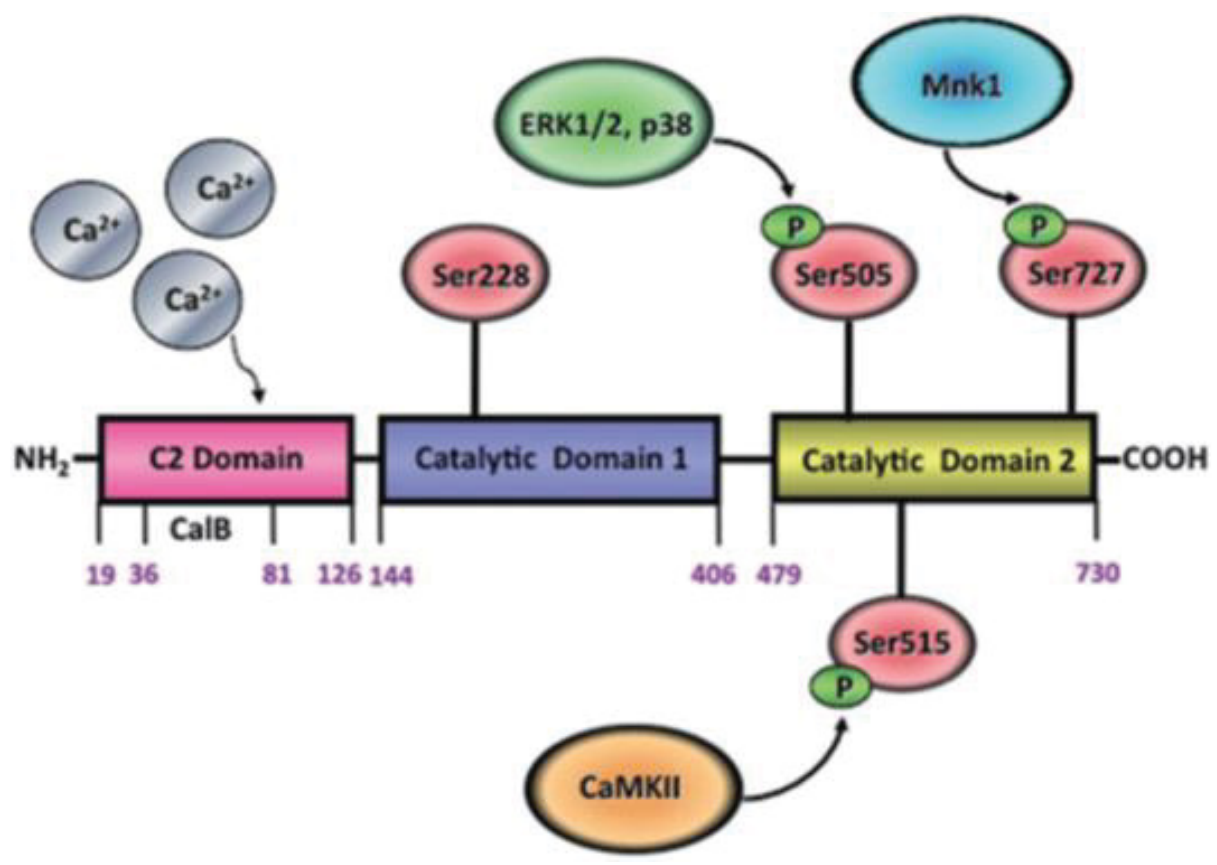

Figure 2.6 Phosphorylation sites of $\mathrm{cPLA}_{2} \alpha$

Reprinted with permission. Linkous A, Yazlovitskaya E. Cytosolic phospholipase A2 as a mediator of disease pathogenesis. Cell Microbiol. 2010;12(10):1369-1377. ${ }^{7}$ 
endothelial $\mathrm{cPLA}_{2} \alpha$ in L-NAME-induced hypertension. ${ }^{9}$ All the above findings suggest the interplay of $\mathrm{cPLA}_{2}$ with the immune system in various disease pathologies. $\mathrm{CPLA}_{2}$ seems to act as a catalyst in disease pathogenesis and progression; thus, cPLA $\mathrm{A}_{2}$ inhibition may be the key in treating hypertension, which is now being recognized as an immune system driven disease as discussed above.

Therefore, based on the above review of the literature, it is possible that $\mathrm{CPLA}_{2} \alpha$, which is highly selective in releasing AA, might function as the major center of convergence for the transduction of Ang II signaling to produce pro-hypertensive eicosanoids and ROS. These would, in turn, result in development of hypertension and associated cardiovascular and renal dysfunction and pathophysiological changes including activation of immune system, inflammation, and end organ damage. Thus, this central hypothesis is the major objective of my thesis, to test this hypothesis; I have investigated the effect of $\mathrm{cPLA}_{2} \alpha$ gene disruption in mice on Ang II-induced hypertension and associated cardiovascular and renal function and pathogenesis. 


\section{CHAPTER 3. METHODOLOGY}

\subsection{Animals}

Experiments were performed according to protocols approved by our Institutional Animal Care and Use Committee in accordance with the National Institutes of Health Guide for the Care and Use of Laboratory Animals. cPLA $2 \alpha^{-/-}$mice on a BALB/c background were generated as described ${ }^{204}$ and provided by Dr. Joseph V. Bonventre at Brigham and Women's Hospital, Boston, MA. Homozygotes (cPLA $\alpha^{-/-}$) were interbred in our facility, and their genotypes were regularly confirmed by polymerase chain reaction analysis. WT male BALB/c mice $\left(\mathrm{cPLA}_{2} \alpha^{+/+}\right)$used in this study were purchased from Charles River Laboratories, Inc., Wilmington, MA. All animals were 20-30 g and approximately 10 weeks of age at the beginning of the experiment.

\subsection{Ang II-Induced Hypertension in $\mathrm{CPLA}_{2} \alpha^{+/+}$and $\mathrm{CPLA}_{2} \alpha^{-/-}$Mice}

Mice were anesthetized with $1.5 \%$ isofluorane to implant micro-osmotic pumps (Alzet®, Cupertino, CA; model 1002) subcutaneously to infuse Ang II (700 ng/kg/min) or vehicle $(0.9 \%$ saline $)$ for 2 weeks, and BP was measured once a week by the noninvasive tail cuff method (Kent Scientific, Torrington, CT; model XBP 1000). Prior to implanting the pumps, mice were acclimated twice to the BP measuring device, with 5 days between measurements. These measurements were also confirmed by instrumenting the mice with a radio telemetry device (TPA-C10, Data Sciences International, St. Paul, Minnesota) as described previously. ${ }^{216} \mathrm{BP}$ was recorded every third day. In another series, $\mathrm{cPLA}_{2} \alpha^{+/+}$mice were infused with Ang II and injected i.p. with inhibitor of AA metabolism, 5,8,11,14-eicosatetraynoic acid (ETYA) (50 mg/kg/3day) (BML-ET0040020, Enzo Lifesciences, NY). At the end of the experiment, the mice were euthanized with a cocktail of ketamine $(100 \mathrm{mg} / \mathrm{kg})$, xylazine $(10 \mathrm{mg} / \mathrm{kg})$, and acepromazine $(3 \mathrm{mg} / \mathrm{kg})$ i.p., and their tissues were harvested.

\subsection{Ultra Sound Imaging and Analysis}

\subsubsection{Echocardiography}

On the $12^{\text {th }}$ day of the study, mice were anesthetized with $1.5 \%$ isoflurane, core body temperature was maintained at $37^{\circ} \mathrm{C}$, and heart rate and respiration were continuously monitored with a pulse oximeter. Echocardiography was performed as described $^{217}$ by using the Vevo 2100 (VisualSonics, Inc., Toronto, Canada). Briefly, Mmode and B-mode images in the parasternal long-axis and the left ventricular (LV) shortaxis views at the mid papillary level were taken. Measurements were averaged from three consecutive beats. M-mode images were used to calculate various parameters of cardiac 
function including ejection fraction (EF), fractional shortening (FS), stroke volume (SV), cardiac output $(\mathrm{CO})$, and LV mass.

\subsubsection{Pulsed Wave Doppler to Measure Renal Hemodynamics}

On the $12^{\text {th }}$ day of the study, mice were anesthetized with $1.5 \%$ isoflurane, core body temperature was maintained at $37^{\circ} \mathrm{C}$, heart rate and respiration was continuously monitored with pulse oximeter. Imaging was performed using the Vevo 2100 (VisualSonics Inc Toronto, Canada). Briefly, mice were placed on the platform in supine position. Long axis of the micro scan transducer was placed on the lateral side, aligned perpendicular to the long axis of the animal. M-mode and B-mode images were taken. The Right Renal Artery Peak Systolic Velocity (RRA PSV), Right Renal Artery Lowest Diastolic Velocity (RRA LDV), Right Renal Artery Velocity Time Integral (RRA VTI) were measured to calculate :-

Renal Artery Pulsatility Index: (RRA PSV-RRA LDV)/RRA VTI, mean velocity Renal Artery Resistive Index: (RRA PSV-RRA LDV)/RRA PSV.

Measurements were averaged from 3 consecutive waveforms.

\subsection{Immunohistochemistry}

Immunohistochemical analysis for $\alpha$-smooth muscle actin (SMA) and transforming growth factor $\beta$ (TGF- $\beta$ ) was performed to determine the extent of interstitial fibrosis as previously described. ${ }^{218}$ Also, tissue sections were processed for infiltration of $\mathrm{CD}^{+} \mathrm{T}$ cell and $\mathrm{F} 4 / 80^{+}$monocyte/macrophage. The hearts, thoracic aortas and kidneys were dissected free and placed in Optimal Cutting Temperature (OCT) compound (Sakura Finetek USA, Inc., Torrance, CA). Serial transverse cryosections (8$\mu \mathrm{m}$ thick) were cut at $-20^{\circ} \mathrm{C}$ with a Leica Cryostat CM1850 (Leica Microsystems, Inc., IL). For $\alpha$-SMA and TGF- $\beta$ staining, sections were fixed in formalin for $10 \mathrm{~min}$ followed by three washes in PBS to remove the mounting medium, after which they were allowed to incubate in $0.3 \%$ hydrogen peroxide for 10 min to block endogenous peroxidase activity. The sections were then rinsed once in PBS and blocked in 5\% BSA for 30 min. Sections were incubated with their respective primary antibodies overnight at $4^{\circ} \mathrm{C}$. All antibodies were diluted in background reducing diluent (Cat \#S3022, Dako, CA). Next day, sections were washed three times in PBS and incubated with anti-mouse IgG peroxidase-conjugated secondary antibody for $1 \mathrm{~h}$, washed three times in PBS, and incubated in diaminobenzidine (Cat \#D4293, Sigma Aldrich) that was prepared according to manufacturer's instructions, and the tissue sections were then washed with deionized distilled water (ddw). For staining $\mathrm{CD}^{+}$and $\mathrm{F} 4 / 80^{+}$cells, tissue sections were fixed in cold acetone after which they were allowed to air dry 5-10 min to facilitate complete removal of acetone (sections should appear opaque white). Sections were then washed, followed by the steps described above (Table 3.1 contains detailed conditions). All 
Table 3.1. List of antibodies and specific conditions

\begin{tabular}{|c|c|c|c|c|c|c|c|}
\hline \multirow[t]{2}{*}{ Antibody } & \multirow[t]{2}{*}{ Application } & \multicolumn{3}{|c|}{ Primary Antibody } & \multirow[t]{2}{*}{ Blocking Buffer } & \multicolumn{2}{|c|}{ Secondary Antibody } \\
\hline & & Cat \# & Dilution & Host & & Cat \# & Dilution \\
\hline$\alpha$-SMA & $\mathrm{IHC}$ & Sigma A2547 & $1: 400$ & Mouse & $5 \%$ BSA & A3682 & $1: 150$ \\
\hline TGF- $\beta$ & $\mathrm{IHC}$ & Santa Cruz sc-146 & $1: 400$ & Rabbit & Goat normal serum & Vectastain ABC kit PK6101 & - \\
\hline CD3 & $\mathrm{IHC}$ & Abcam ab5690 & $1: 100$ & Rabbit & $5 \%$ BSA & Abcam ab97051 & $1: 100$ \\
\hline $\mathrm{F} 4 / 80$ & $\mathrm{IHC}$ & AbDSerotec MCA497R & $1: 50$ & Rat & Rabbit normal serum & AbD Serotec STAR72 & $1: 50$ \\
\hline PLC $\beta$ & WB & Santa Cruz sc-205 & $1: 500$ & Rabbit & $5 \% \mathrm{BSA}$ & ECL Rabbit IgG NA934V & $1: 2000$ \\
\hline PLD1 & WB & Gift $* *$ & $1: 500$ & Rabbit & $5 \%$ BSA & ECL Rabbit IgG NA934V & $1: 1000$ \\
\hline PLD2 & WB & Gift** & $1: 500$ & Rabbit & $5 \% \mathrm{BSA}$ & ECL Rabbit IgG NA934V & $1: 1000$ \\
\hline AT1 & WB & Santa Cruz sc-1173 & $1: 500$ & Rabbit & $5 \% \mathrm{BSA}$ & ECL Rabbit IgG NA934V & $1: 1000$ \\
\hline AT2 & WB & Santa Cruz sc-9040 & $1: 1000$ & Rabbit & $5 \%$ BSA & ECL Rabbit IgG NA934V & $1: 1000$ \\
\hline MAS & WB & Santa Cruz sc-135063 & $1: 500$ & Rabbit & $5 \%$ BSA & ECL Rabbit IgG NA934V & $1: 1000$ \\
\hline $\mathrm{ACE}$ & WB & Santa Cruz sc-23908 & $1: 500$ & Mouse & $5 \% \mathrm{BSA}$ & ECL Mouse IgG NA931 & $1: 1000$ \\
\hline P-cPLA 2 & WB & Cell Signaling cs-2831 & $1: 1000$ & Rabbit & $5 \% \mathrm{BSA}$ & ECL Rabbit IgG NA934V & $1: 2000$ \\
\hline $\mathrm{cPLA}_{2}$ & WB & Santa Cruz sc-454 & $1: 1000$ & Mouse & $5 \% \mathrm{BSA}$ & ECL Mouse IgG NA931 & $1: 2000$ \\
\hline P-ERK1/2 & WB & Cell Signaling cs-9106 & $1: 1000$ & Mouse & $5 \% \mathrm{BSA}$ & ECL Mouse IgG NA931 & $1: 2000$ \\
\hline ERK1/2 & WB & Cell Signaling cs-9102 & $1: 1000$ & Rabbit & $5 \% \mathrm{BSA}$ & ECL Rabbit IgG NA934V & $1: 2000$ \\
\hline P-Src & WB & Cell Signaling cs-2101 & $1: 1000$ & Rabbit & $5 \%$ BSA & ECL Rabbit IgG NA934V & $1: 2000$ \\
\hline c-Src & WB & Santa Cruz sc-8056 & $1: 1000$ & Mouse & $5 \%$ BSA & ECL Mouse IgG NA931 & $1: 2000$ \\
\hline$\beta$-actin & WB & Santa Cruz sc-47778 & $1: 10000$ & Mouse & $5 \% \mathrm{BSA}$ & ECL Mouse IgG NA931 & $1: 2000$ \\
\hline
\end{tabular}

** Dr. Sylvain G. Bourgoin, Centre Hospitalier de l'Université Laval, Québec, Canada 
sections were counterstained with hematoxylin, dehydrated, mounted, and viewed with an Olympus ${ }^{\circledR}$ inverted system microscope (Olympus America, Inc., model BX41) and photographed with a SPOT ${ }^{\mathrm{TM}}$ Insight $^{\mathrm{TM}}$ digital camera (Diagnostic Instruments, Inc., model Insight 2MP Firewire).

\subsection{Collagen Accumulation}

Masson's trichrome staining (Cat \#HT15-1KT, Sigma Aldrich) for collagen accumulation was performed on the heart, aorta and kidney sections according to manufacturer's instructions with some modifications. Briefly, slides were prefixed in $10 \%$ formalin for 20 min followed by fixation in Bouin's reagent overnight at room temperature. Next day, slides were washed in running tap water to drain the yellow stain from Bouin's reagent completely followed by washing in ddw. Weigert's iron hematoxylin solution (Cat\# HT1079, Sigma Aldrich) was prepared according to vendor's instructions and applied on the sections for $5 \mathrm{~min}$, and excess stain was removed by rinsing under tap water followed by rinsing with ddw. Slides were then incubated with scarlet-fuschin for $5 \mathrm{~min}$, then washed again with tap water followed by washing in ddw. 1:1:2 volume of phosphotungstic acid, phosphomolybdic acid, and ddw was applied on the slide for $10 \mathrm{~min}$. The solution from the slides was drained on a paper towel and then incubated with analine blue for $7 \mathrm{~min}$, then washed with ddw. Tissue sections were then differentiated in 1\% glacial acetic acid for $30 \mathrm{sec}$ and then washed twice in ddw followed by dehydration in increasing strengths of alcohol and clearing in xylene after which slides were mounted using permount.

\subsection{Measurement of Oxidative Stress}

\subsubsection{Measurement of NADPH Oxidase Activity}

NADPH oxidase activity was determined in heart homogenates by measuring lucigenin ( $N, N^{\prime}$-dimethyl-9,9'-biacridinium dinitrate)-enhanced chemiluminescence, as

described previously, ${ }^{219}$ with some modifications. Following anesthesia, a transcardial PBS perfusion was performed; hearts and kidneys were harvested and snap-frozen in liquid $\mathrm{N}_{2}$ and stored at $-80^{\circ} \mathrm{C}$ until use. Tissues were homogenized and sonicated in lysis buffer containing protease inhibitors $(20 \mathrm{mmol} / \mathrm{L}$ phosphate buffer, $1 \mathrm{mmol} / \mathrm{L}$ EGTA, 10 $\mu \mathrm{g} / \mathrm{ml}$ aprotinin, $0.5 \mu \mathrm{g} / \mathrm{ml}$ leupeptin, $0.7 \mu \mathrm{g} / \mathrm{ml}$ pepstatin, $0.5 \mathrm{mmol} / \mathrm{L}$ phenylmethylsulphonylfluoride, and $150 \mathrm{mmol} / \mathrm{L}$ sucrose). Samples were then centrifuged at $3,000 \mathrm{~g}$ for $10 \mathrm{~min}$ at $4^{\circ} \mathrm{C}$, and supernatants were kept on ice until use. Protein content in the samples was determined by the Bradford method, and equal amounts of protein were combined 1:1 with a reaction mixture containing $5 \mu \mathrm{mol} / \mathrm{L}$ lucigenin (final concentration) and $100 \mu \mathrm{mol} / \mathrm{L} \mathrm{NADPH}$ (final concentration). Luminescence was measured every minute for $10 \mathrm{~min}$ with a luminometer (Turner Designs, Sunny Vale, CA; model TD-20/20). Lysis buffer was used as a blank and subtracted from each reading and activity expressed as arbitrary units. 


\subsubsection{Measurement of Urinary TBARS}

Levels of TBARS, byproduct of lipid peroxidation in the urine were measured using TBARS assay kit (Cayman cat \# 10009055) as per manufacturer's instructions.

\subsubsection{Measurement of ROS Production}

To measure ROS productions, sections of thoracic aortae, hearts and kidneys were exposed to DHE (Cat \#D-2310, Life Technologies, NY) following the previously described and validated method. ${ }^{220}$ Aortic sections were incubated in PBS for $30 \mathrm{~min}$ at $37^{\circ} \mathrm{C}$ and then encircled with a hydrophobic pen. DHE $(2 \mu \mathrm{M}$ for aorta, $5 \mu \mathrm{M}$ for heart and kidney) was topically applied. Sections were further incubated at $37^{\circ} \mathrm{C}$ in a lightprotected humidified chamber for $30 \mathrm{~min}$. Sections were then rinsed in PBS, and fluorescence was detected with a 585-nm filter and an Olympus ${ }^{\circledR}$ inverted system microscope (Olympus America, Inc.; model DP71). Superoxide production, was measured as fluorescence intensity of 2-Hydoxyethiduim (OHE). Images were photographed with an Olympus ${ }^{\circledR}$ digital camera (Olympus America, Inc., model DP71) and analyzed using ImageJ 1.42 (http://rsb.info.nih.gov/nih-image; National Institutes of Health).

\subsection{Analysis of Vascular Function}

\subsubsection{Vascular Reactivity}

Following anesthesia, the thoracic aortas were quickly dissected free and cleaned of surrounding tissue, and approximately 2-mm rings were mounted in a wire myograph system (Danish Myo Technology, Aarhus, Denmark; model 610M) as previously described. ${ }^{14}$ Vessels were continuously bathed in Krebs buffer (composition in mmol/L: $118 \mathrm{NaCl}, 4.7 \mathrm{KCl}, 25 \mathrm{NaHCO}_{3}, 1.2 \mathrm{MgSO}_{4}, 1.2 \mathrm{KH}_{2} \mathrm{PO}_{4}, 11.1$ glucose, 2.5

$\mathrm{CaCl}_{2} \cdot 2 \mathrm{H}_{2} \mathrm{O}$ ) at $37^{\circ} \mathrm{C}$, which was gassed with $95 \% \mathrm{O}_{2}$ and $5 \% \mathrm{CO}_{2}$ to maintain $\mathrm{pH}$ 7.4. An initial tension of $9 \mathrm{mN}$ was placed on the vessels and allowed to equilibrate for approximately $30 \mathrm{~min}$. To confirm the viability of the vessels, they were initially tested for constriction to $60 \mathrm{mM} \mathrm{KCl}$ and then washed three times with fresh Krebs buffer. Cumulative concentration response curves to phenylephrine (PE) and ET-1 were obtained and responses measured as force of contraction $(\mathrm{mN})$.

\subsubsection{Endothelium-Dependent and Independent Vasodilation}

Endothelial function was examined ${ }^{14}$ by constricting the vessels with the concentration of PE that evoked a maximal response followed by adding increasing concentrations of acetylcholine (ACh). Changes in the response of vessels to ACh were measured and presented as a percentage of the PE-induced constriction. Endothelium- 
independent vasodilation was studied by constricting the vessels with the concentration of PE that evoked a maximal response followed by adding increasing concentrations of sodium nitroprusside (SNP). Changes in the response of vessels to SNP were measured and presented as a percentage of the PE-induced constriction.

\subsection{Assessment of Vascular Remodelling}

Aortic sections were stained with hematoxylin and eosin and viewed using an Olympus ${ }^{\circledR}$ inverted system microscope (Olympus America, Inc., Melville, NY; model IX50) and photographed with an Olympus ${ }^{\circledR}$ digital camera (Olympus America,Inc.; model DP71). Images were analyzed using ImageJ 1.42 (http://rsb.info.nih.gov/nihimage; National Institutes of Health).

\subsection{Western Blot Analysis}

Heart and kidney samples were homogenized in lysis buffer, and protein content was determined by the Bradford method. $50 \mu \mathrm{g}$ of proteins were loaded and resolved on $8 \%$ or $12 \%$ SDS-polyacrylamide gels and processed for western blot analysis as described. ${ }^{221}$ Blots were probed with different primary and corresponding secondary antibodies (Table 3.1) Intensity of the bands was measured with ImageJ 1.42 software.

\subsection{Real-Time PCR Analysis}

Total RNA was extracted from the hearts with TRIzol reagent (Invitrogen, Grand Islands, NY) according to the manufacturer's protocol. $1 \mu \mathrm{g}$ of purified RNA was reverse transcribed using SuperScript ${ }^{\mathrm{TM}}$ III First Strand synthesis system (Invitrogen). Transcription level was normalized to cyclophilin D. Primers were designed (Table 3.2). The values were calculated by $2^{-\Delta \Delta \mathrm{Ct}}$ method. ${ }^{222}$

\subsection{Analysis of Renal Function}

Mice were individually housed in tecniplast metabolic cages. They were allowed to acclimate to the cages for $24 \mathrm{hrs}$ on day 11 of the experiment. On day 13, urine was collected and its volume was measured along with food and water intake. Renal function including urine output, osmolality using a Vapro ${ }^{\circledR}$ vapor pressure osmometer (Wescor, South Logan, UT; model 5520), protein content by the standard Bradford method was determined as described previously. Serum ET was measured at our endocrinology core unit using an ELISA assay. 
Table 3.2. List of primer sequences

\begin{tabular}{lll}
\hline Genes & \multicolumn{1}{c}{ Forward Sequence } & \multicolumn{1}{c}{ Reverse Sequence } \\
\hline cPLA $_{2} \alpha$ & GGG CCA TGG TGG GAT TC & TAC CAT GTG GAT CCA GAA AGA C \\
CPLA $_{2} \beta$ & CCT GAG TAC CTT TGA CTT TGG G & CTT TGT CAG GAG GTC AGT GAA G \\
CPLA $_{2} \gamma$ & GGA TCC TTT GCA CTA CTT GGA G & GTT GTG CTC TAG CTT TAG GGT C \\
sPLA $_{2} \alpha$ & CAA AGG GAA GAA GCC CAA ATG & AGG AAG TTG GAT GCC AAG AG \\
PLC- $\beta 1$ & GGA GGT GGT TCA GTA CAT CAA G & CCT GGG TTC TCT CTT TCT ATC TCC \\
PLC- $\beta 2$ & ATA GCC TCT CCT GTT ATC CTC C & CTT GTA CAC GGA TTC TGG GAA G \\
PLC- $\beta 3$ & GAG AGG ATG AGG AGG AAG ATG AAG & GAA GAG CTG AGG CAT GTA GTT G \\
PLC- $\beta 4$ & GGA CAA GTG CTA GAA TGT TCC C & GTT CTA GTG ATA CTC CTC ACT GGG \\
PLD1 & GGA AAG GAA TAT CAG GCT GGT C & GAA ATA GAG AGG GAA CTG CAC C \\
PLD2 & CCT CCA GAG ACA CAA AGT CTT G & CAC CTC TTG GAC CAT CGA TAA C \\
p58 ${ }^{I P K}$ & TGG AGT AAA TGC GGA TGT GG & ACG GTC GCT CTC CTA TAG TAT G \\
Xbp1 & AAG AAA GCC CGG ATG AGC & AGC GTG TTC TTA ACT CCT GG \\
CHOP & TGT TGA AGA TGA GCG GGT G & AGG TTC TGC TTT CAG GTG TG \\
GRP78 & AGT TGA TAT TGG AGG TGG GC & CAT TGA AGT AAG CTG GTA CAG TAA C \\
\hline
\end{tabular}




\subsection{Urinary Levels of PGE2 Metabolite}

PGE2 is rapidly converted in vivo to its 13,14 -dihydro-15-keto metabolite that further under goes degradation to PGA products, thus we measured the concentration of PGE2 metabolites (PGEM) using an Prostaglandin E Metabolite EIA ELISA kit (Cayman Cat\# 514531) as per manufacturer's instructions.

\subsection{Assessment of GFR}

Plasma and urine creatinine levels were determined at the national mouse metabolic phenotyping center at Yale University. Creatinine clearance as a measure of GFR was calculated using the below formula and expressed as $\mathrm{ul} / \mathrm{min}$.

$$
\text { Creatinine clearance }=\frac{\text { Urine Creatinine } \mathrm{x} \text { Urine Volume }}{\text { Plasma Creatinine x } 24 \times 60}
$$




\section{CHAPTER 4. RESULTS}

\subsection{Aim 1. To Determine the Contribution of $\mathrm{CPLA}_{2} \alpha$ to Ang II-Induced Hypertension and Associated Cardiovascular Pathophysiology}

\subsection{1 cPLA $_{2} \alpha$ Gene Disruption Does Not Alter Expression of Other Phospholipase Enzymes}

To asses if $\mathrm{cPLA}_{2} \alpha$ gene disruption alters the expression of other related genes in the phospholipase family; mRNA expression of various phospholipase enzymes was determined by quantitative Real-time PCR. Total RNA was extracted from the hearts of both $\mathrm{cPLA}_{2} \alpha^{+/+}$and $\mathrm{cPLA}_{2} \alpha^{-/-}$mice as described in the methods. mRNA expression of cPLA $_{2} \alpha$ was absent but not of PLA 2 , PLC, PLD in the cardiac tissue of cPLA $\alpha_{2}^{-/-}$mice. (Figure 4.1A)

PL-C $\beta 2$, D1, D2 have been implicated in cardiovascular diseases. To asses if Ang II infusion and/or $\mathrm{cPLA}_{2} \alpha$ gene disruption altered their protein expression, western blot analysis was performed. $\mathrm{cPLA}_{2} \alpha$ gene disruption did not alter protein expression of these enzymes in the hearts of $\mathrm{cPLA}_{2} \alpha^{--}$mice. (Figure 4.1B)

\subsection{2 $\mathrm{cPLA}_{2} \alpha$ Contributes to the Development of Ang II-Induced Hypertension, Activation of Cardiac cPLA $A_{2}$ and Increased Excretion of PGE2 Metabolites}

Ang II infusion over a period of 13 days significantly increased SBP, measured by the tail cuff method (Figure 4.2A) and radio telemetry (Figure 4.2B) in cPLA $\alpha^{+/+}$but not $\mathrm{cPLA}_{2} \alpha^{-/-}$mice. $\mathrm{cPLA}_{2}$ activity measured by its phosphorylation, but not its protein expression, was significantly increased in the cardiac tissue of Ang II-infused cPLA $\alpha^{+/+}$ mice; the expression of $\mathrm{cPLA}_{2}$ protein was absent in $\mathrm{cPLA}_{2} \alpha^{-/-}$mice. (Figure 4.2C, D) This increase in SBP and activity of CPLA $_{2}$ correlated with increased urinary excretion of PGE2 metabolites in $\mathrm{CPLA}_{2} \alpha^{+/+}$but not $\mathrm{cPLA}_{2} \alpha^{-/-}$mice. (Figure 4.2E)

\subsubsection{Inhibition of Arachidonic Acid Metabolism, Abrogated Ang II-Induced Hypertension in $\operatorname{cPLA}_{2} \alpha^{+/+}$Mice}

In order to confirm our hypothesis that AA metabolism via $\mathrm{CPLA}_{2} \alpha$ is crucial in development of hypertension, ETYA, a competitive inhibitor of AA metabolism was used. In a separate series of experiments, BP was recorded in 4 groups of $\mathrm{cPLA}_{2} \mathrm{\alpha}^{+/+}$mice. Mice were infused with vehicle-saline, Ang II, vehicle-ETYA (i.p) and Ang II+ETYA for a period of 13 days. BP was recorded once every week. Ang II increased SBP and treatment with ETYA every third day abrogated Ang II-induced hypertension (Figure 4.3). 


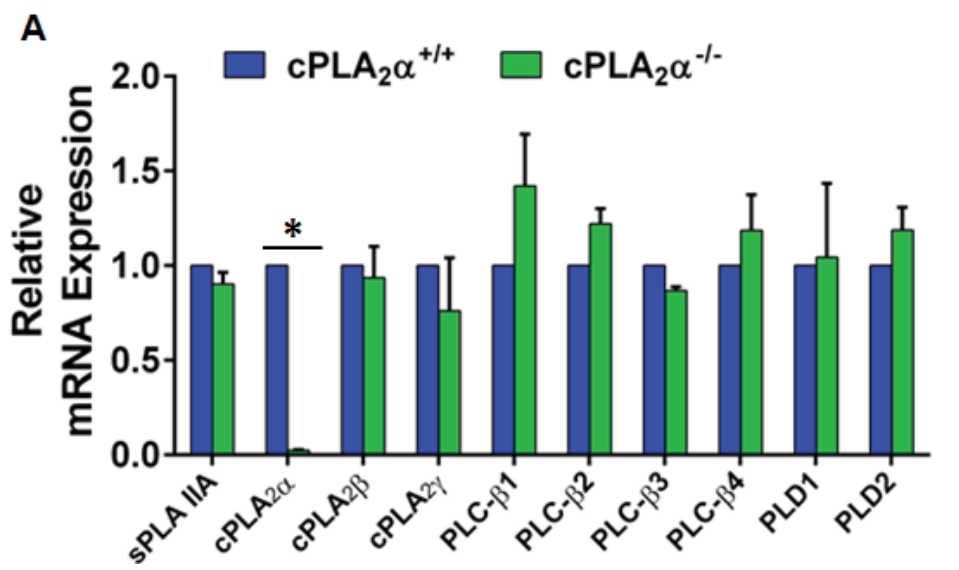

B
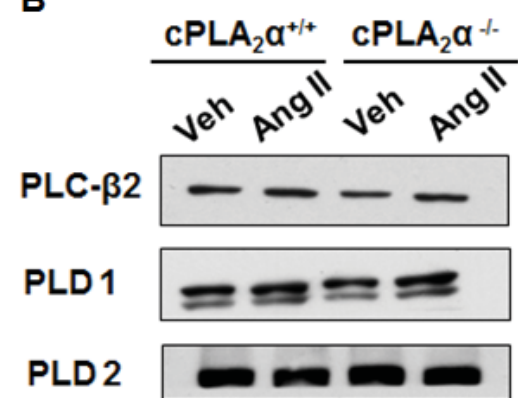

a-Actin

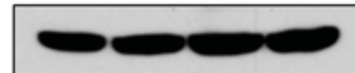

Figure 4.1 $\quad \mathrm{CPLA}_{2} \alpha$ gene disruption prevents expression of $\mathrm{CPLA}_{2} \alpha$ but not other related phospholipase enzymes

Comparison of myocardial mRNA expression levels of various phospholipases between $\mathrm{cPLA}_{2} \alpha^{+/+}$and $\mathrm{cPLA}_{2} \alpha^{-/-}$mice at baseline (A). Comparison of protein expression in the heart from both vehicle and Ang II-treated cPLA $\alpha^{+/+}$and $\mathrm{cPLA}_{2} \alpha^{-/-}$mice (B).

$* P<0.05 \mathrm{cPLA}_{2} \alpha^{+/+}$vs. $\mathrm{cPLA}_{2} \alpha^{-/-}(\mathrm{n}=4$ for all experiments, and data are expressed as mean \pm SEM) 

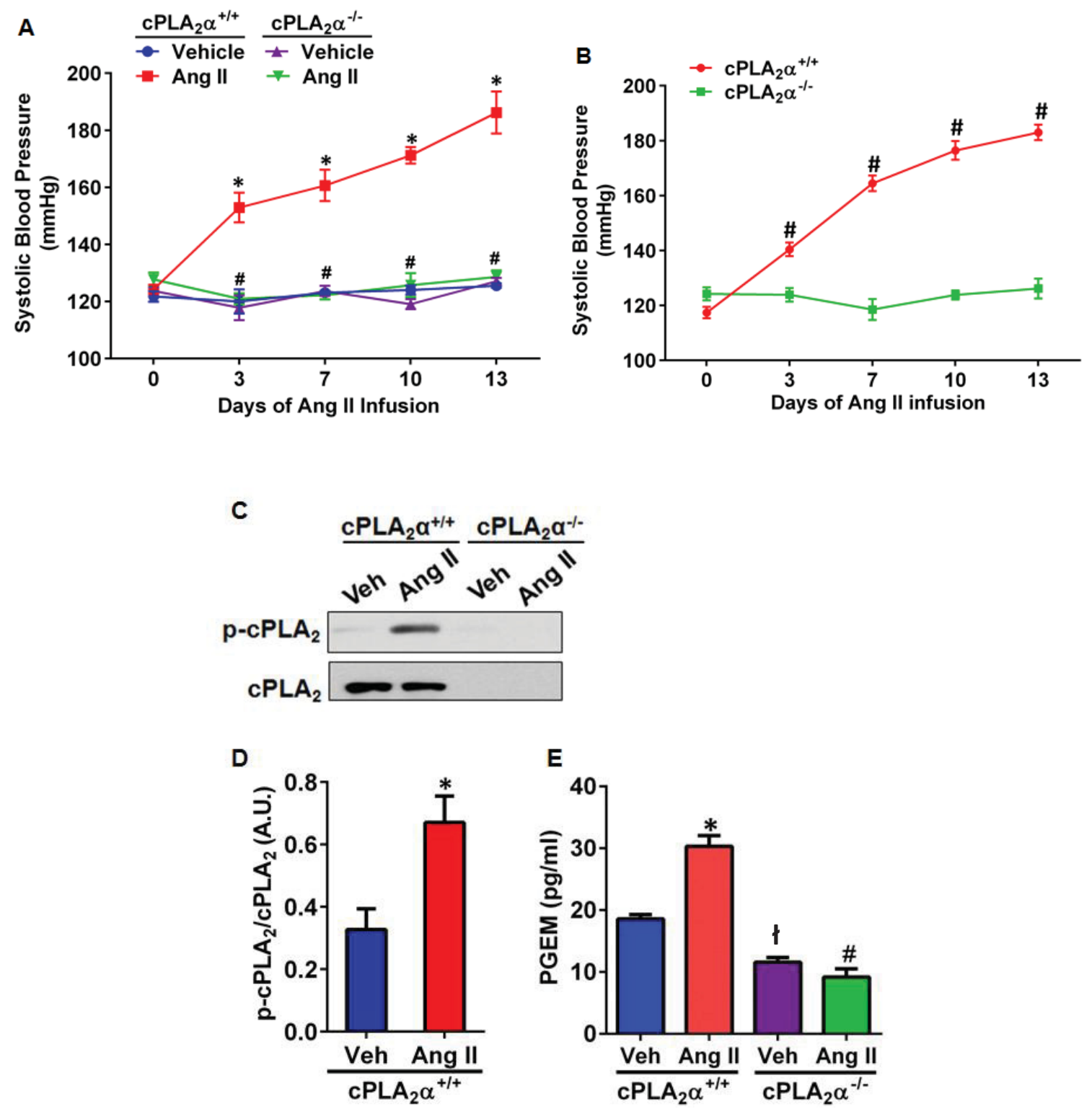

Figure 4.2 $\mathrm{CPLA}_{2} \alpha$ contributes to the development of Ang II-induced hypertension, activation of cardiac cPLA $A_{2} \alpha$ and increased excretion of PGE2 metabolites

SBP measured by tail cuff (A) and radiotelemetry (B). cPLA 2 activity measured by its phosphorylation by western blot analysis (C) in the cardiac tissue. Quantified data (D) PGE2 metabolite excretion in urine (D) $* P<0.05 \mathrm{cPLA}_{2} \alpha^{+/+}$Veh vs. $\mathrm{cPLA}_{2} \alpha^{+/+}$Ang II, $\nmid P<0.05 \mathrm{cPLA}_{2} \alpha^{+/+}$Veh vs. cPLA $2 \alpha^{-/-}$Veh $\# P<0.05 \mathrm{cPLA}_{2} \alpha^{+/+}$Ang II vs. cPLA $\alpha_{2} \alpha^{-/}$Ang II $(n=3-6)$ for all experiments, and data are expressed as mean $\pm \mathrm{SEM})$ 


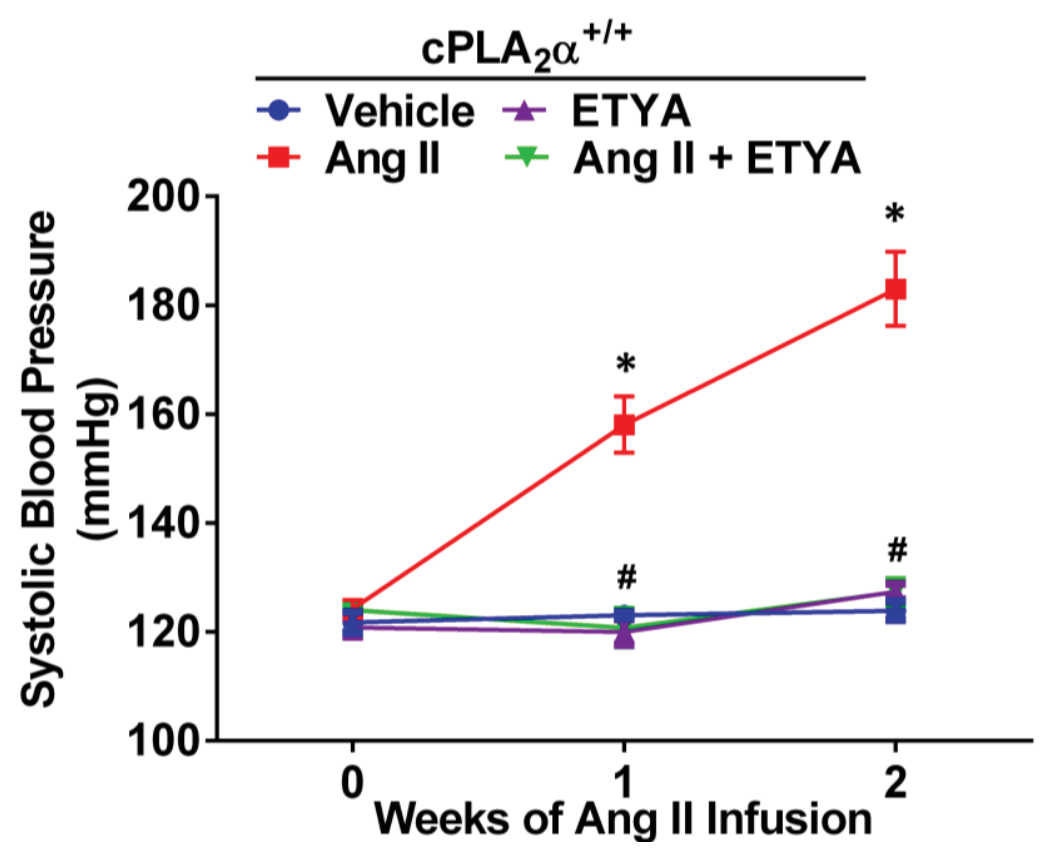

Figure 4.3 Inhibition of arachidonic acid metabolism, abrogated Ang II-induced hypertension in $\mathrm{CPLA}_{2} \alpha^{+/+}$mice

${ }^{*} P<0.05$ vehicle vs. Ang II, ${ }^{\#} P<0.05$ Ang II vs. Ang II+ETYA. $(\mathrm{n}=6$ for all experiments; data are expressed as mean \pm SEM). 


\subsubsection{CPLA $_{2} \alpha$ Gene Disruption Attenuates Cardiac Dysfunction and Hypertrophy Associated with Ang II-Induced Hypertension}

Cardiac functional and structural changes were measured by echocardiography on the $12^{\text {th }}$ day of infusion of Ang II or its vehicle. M-mode images of the left ventricle (LV) in the parasternal long-axis view demonstrated dilated cardiomyopathy as indicated by LV chamber enlargement and impaired contractility in Ang II-infused cPLA ${ }_{2} \alpha^{+/+}$but not $\mathrm{CPLA}_{2} \alpha^{-/ 2}$ mice (Figure 4.4). Various parameters, measured, (Table 4.1), revealed cardiac dysfunction including an increase in LV mass in Ang II-infused $\mathrm{CPLA}_{2} \alpha^{+/+}$but not $\mathrm{cPLA}_{2} \alpha^{-/-}$mice.

\subsection{5 $\mathrm{cPLA}_{2} \alpha$ Gene Disruption Prevents Cardiac Interstitial Fibrosis}

It is well established that hypertension, in both humans and animal models results in fibrosis in the cardiac, vascular and renal tissues. To determine the contribution of $\mathrm{CPLA}_{2} \alpha$ in Ang II-induced cardiac interstitial fibrosis, immunohistochemical analysis was performed on cardiac sections for $\alpha$-smooth muscle actin and TGF- $\beta$. Masson's trichrome staining was also performed on the heart sections to assess collagen accumulation. The heart sections of Ang II-infused $\mathrm{CPLA}_{2} \alpha^{+/+}$but not $\mathrm{CPLA}_{2} \alpha^{-/-}$mice showed fibrosis as indicated by increased staining with intracardiac $\alpha$-smooth muscle actin (Figure 4.5A), transforming growth factor (TGF)- $\beta$ (Figure 4.5B), and collagen (Figure 4.5C).

\subsection{6 $\operatorname{cPLA}_{2} \alpha$ Gene Disruption Prevents Cardiac Inflammation}

Recent studies have demonstrated the role of immune system activation in various models of hypertension. To determine the contribution of $\mathrm{cPLA}_{2} \alpha$ to inflammation associated with Ang II-induced hypertension, immunohistochemistry was performed for $\mathrm{F} 4 / 80^{+}$macrophages, and $\mathrm{CD}^{+}$T-lymphocytes in the cardiac tissue of $\mathrm{cPLA}_{2} \mathrm{\alpha}^{+/+}$and $\mathrm{cPLA}_{2} \alpha^{-/-}$mice. Ang II caused infiltration of $\mathrm{F} 4 / 80^{+}$macrophages (Figure 4.6A) and $\mathrm{CD}^{+} \mathrm{T}$ cells (Figure 4.6B) in the hearts of $\mathrm{cPLA}_{2} \alpha^{+/+}$but not $\mathrm{CPLA}_{2} \alpha^{-/-}$mice.

\subsection{7 $\operatorname{cPLA}_{2} \alpha$ Gene Disruption Protects Against Ang II-Induced Vascular Remodeling}

To assess vascular remodeling, aortas were stained with Hematoxylin and Eosin (Figure 4.7A) and media:lumen ratio was calculated (Figure 4.7B). The aortae were also stained for $\alpha$-smooth muscle actin and collagen. Ang II increased media:lumen ratio (Figure 4.7B), $\alpha$-smooth muscle actin muscle actin (Figure 4.7C, D) positive stained cells and collagen accumulation (Figure 4.7E, F) in aortas of $\mathrm{cPLA}_{2} \alpha^{+/+}$mice compared to $\mathrm{CPLA}_{2} \alpha^{-/-}$mice. 

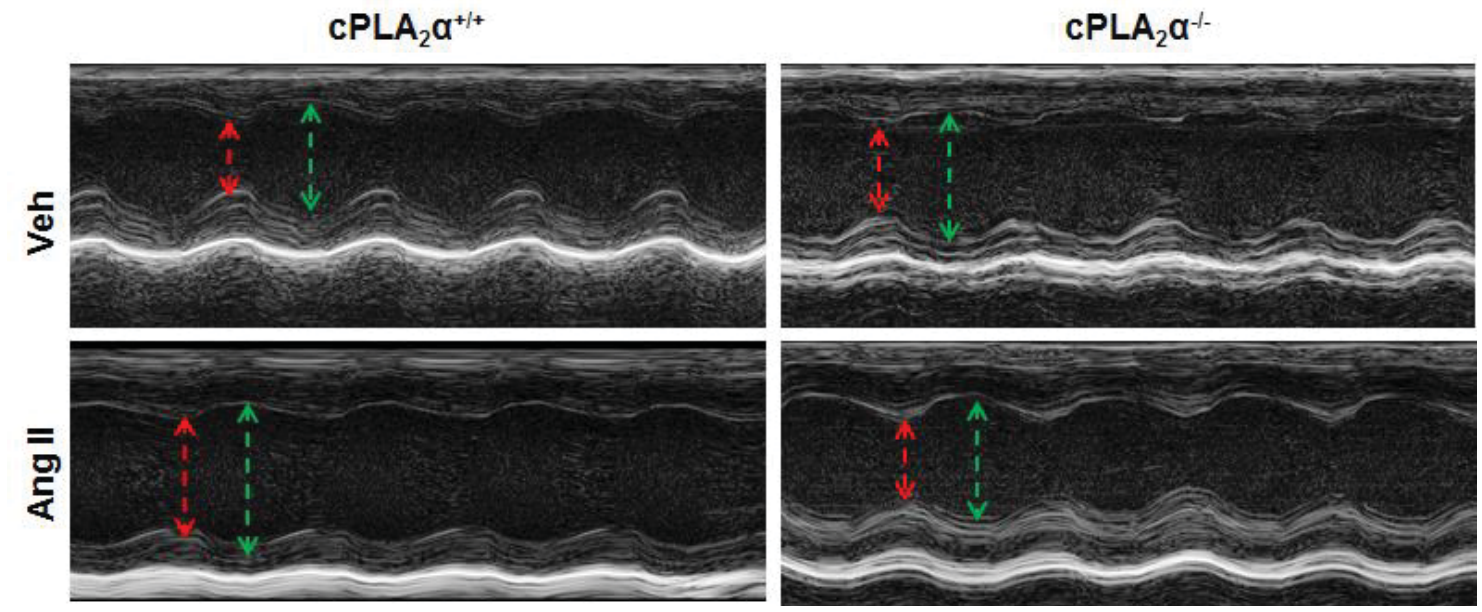

Figure 4.4 $\quad \mathrm{CPLA}_{2} \alpha$ gene disruption attenuates cardiac dysfunction and hypertrophy associated with Ang II-induced hypertension

Echocardiograms of the left Ventricle obtained in M mode parasternal long axis view. Red dotted line indicates LVIDs and green dotted line indicates LVIDd. 
Table 4.1. Paramaters of cardiac function

\begin{tabular}{lccccc}
\hline & \multicolumn{2}{c}{$\mathbf{c P L A}_{2} \boldsymbol{\alpha}^{+/+}$} & & \multicolumn{2}{c}{$\mathbf{c P L A}_{2} \boldsymbol{\alpha}^{-/-}$} \\
\cline { 2 - 3 } \cline { 5 - 6 } Parameters & Vehicle & Ang II & & Vehicle & Ang II \\
\hline EF\% & $63.94 \pm 1.0$ & $40.66 \pm 3.2^{*}$ & & $63.47 \pm 2.4$ & $63.97 \pm 1.3^{\#}$ \\
FS\% & $34.19 \pm 0.8$ & $19.39 \pm 1.9^{*}$ & & $33.77 \pm 1.7$ & $34.17 \pm 0.9^{\#}$ \\
SV & $39.78 \pm 1.2$ & $23.48 \pm 1.6^{*}$ & & $37.33 \pm 2.8$ & $36.60 \pm 2.5^{\#}$ \\
CO & $16.35 \pm 0.6$ & $11.80 \pm 1.1^{*}$ & & $15.11 \pm 0.7$ & $16.84 \pm 2.5^{\#}$ \\
LV mass & $83.07 \pm 7.3$ & $146.66 \pm 6.2^{*}$ & & $92.90 \pm 2.9$ & $107.56 \pm 7.8^{\#}$ \\
LVID-d & $3.61 \pm 0.2$ & $4.31 \pm 0.05^{*}$ & & $3.60 \pm 0.2$ & $3.66 \pm 0.1^{\#}$ \\
LVID-s & $2.33 \pm 0.1$ & $3.63 \pm 0.1^{*}$ & & $2.33 \pm 0.2$ & $2.37 \pm 0.1^{\#}$ \\
LVAW-s & $1.24 \pm 0.1$ & $1.44 \pm 0.2$ & & $1.31 \pm 0.1$ & $1.55 \pm 0.1$ \\
LVAW-d & $1.10 \pm 0.1$ & $1.36 \pm 0.1$ & & $0.97 \pm 0.1$ & $1.07 \pm 0.1$ \\
LVPW-s & $0.95 \pm 0.1$ & $1.15 \pm 0.01$ & & $1.22 \pm 0.2$ & $1.56 \pm 0.1$ \\
LVPW-d & $0.68 \pm 0.03$ & $1.05 \pm 0.04$ & & $0.85 \pm 0.1$ & $0.91 \pm 0.04$ \\
EDV & $62.36 \pm 1.8$ & $75.78 \pm 1.9^{*}$ & & $57.63 \pm 4.7$ & $58.59 \pm 4.3^{\#}$ \\
ESV & $21.39 \pm 0.7$ & $53.50 \pm 3.5^{*}$ & & $22.38 \pm 2.9$ & $21.97 \pm 2.5^{\#}$ \\
IVS-s & $1.48 \pm 0.02$ & $1.44 \pm 0.01$ & & $1.21 \pm 0.1$ & $1.65 \pm 0.1$ \\
IVS-d & $0.98 \pm 0.04$ & $1.06 \pm 0.02$ & & $0.86 \pm 0.1$ & $1.05 \pm 0.1$ \\
\hline
\end{tabular}

EF, ejection fraction; FS, fractional shortening; SV, stroke volume (ul); CO, cardiac output (ml/min); LV mass, left ventricular mass (mgs); LVID, LV internal dimension (mm); LVAW, LV anterior wall (mm); LVPW, LV posterior wall (mm); EDV, end diastolic volume (ul); ESV, End systolic volume; IVS, Intraventricular septum (mm). s, d indicate systole or diastole.

The parameters listed in the table were measured using M-mode and B-mode images in the short and parasternal long-axis views as described in the methods. ${ }^{*} P<0.05 \mathrm{cPLA}_{2} \alpha^{+/+}$vehicle vs. $\mathrm{cPLA}_{2} \alpha^{+/+}$Ang II, \#P<0.05 cPLA ${ }_{2} \alpha^{+/+}$Ang II vs. $\mathrm{cPLA}_{2} \alpha^{-/-}$Ang II ( $n=4-6$ for each group; data are expressed as mean $\left.\pm \mathrm{SEM}\right)$. 


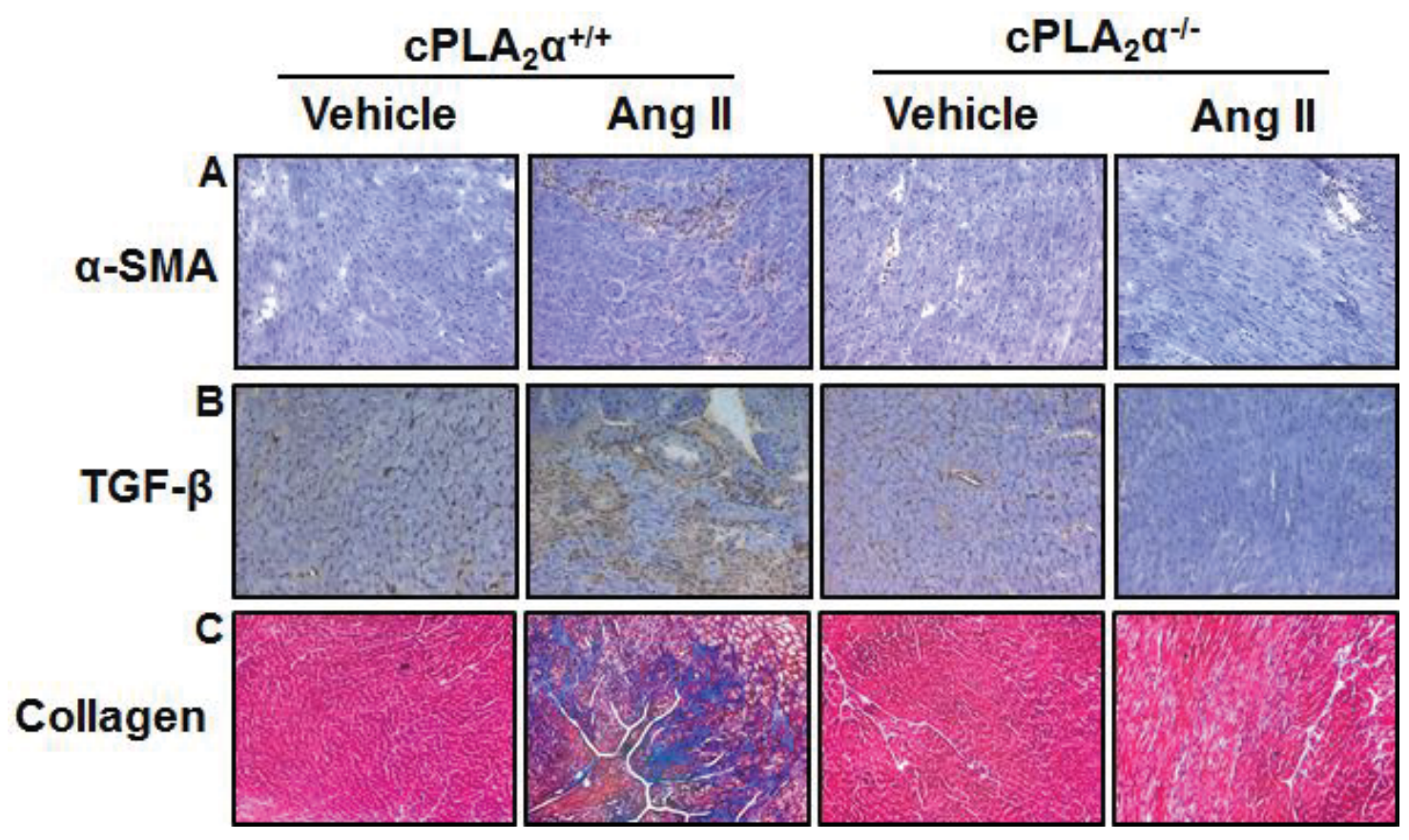

Figure 4.5 $\quad \mathrm{CPLA}_{2} \alpha$ gene disruption prevents cardiac interstitial fibrosis

Immunohistochemical staining of $\alpha$-smooth muscle actin (A) and TGF- $\beta$ (B), (indicators of interstitial fibrosis). Masson's trichrome staining for collagen accumulation (intense blue staining) (C) ( $\mathrm{n}=4$ for each group) 

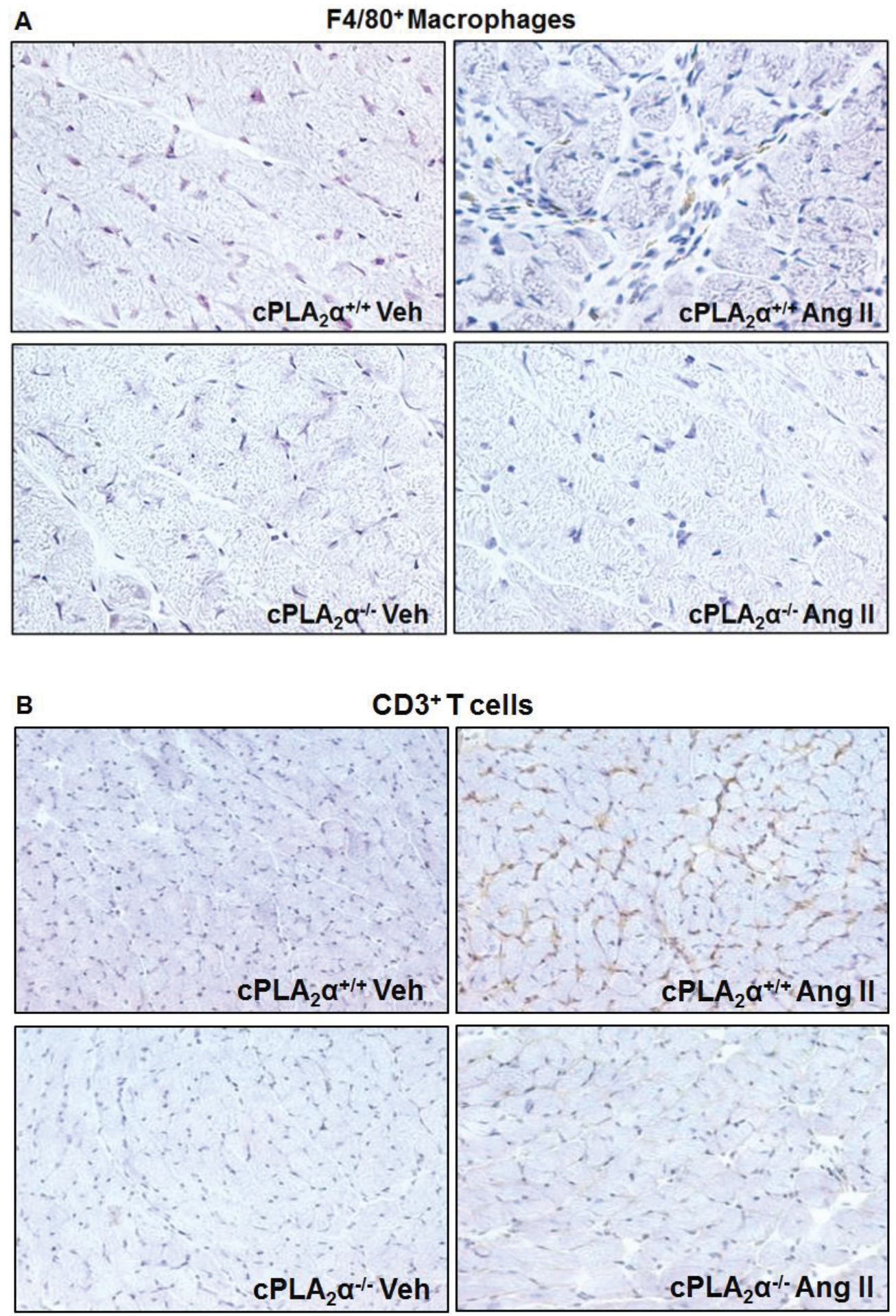

Figure 4.6 $\quad \mathrm{cLA}_{2} \alpha$ gene disruption prevents cardiac inflammation

Immunohistochemical analysis for $\mathrm{F} 4 / 80^{+}$macrophages $(\mathbf{A})$ and $\mathrm{CD}^{+} \mathrm{T}$ cells $(\mathbf{B})$ in cardiac sections ( $\mathrm{n}=4$ for each group) 


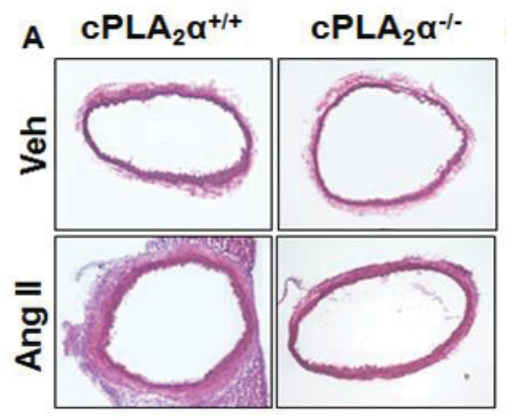

B

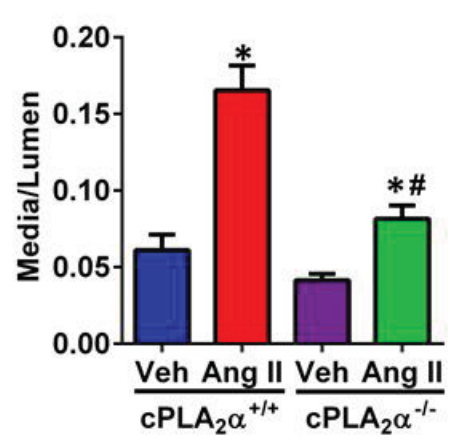

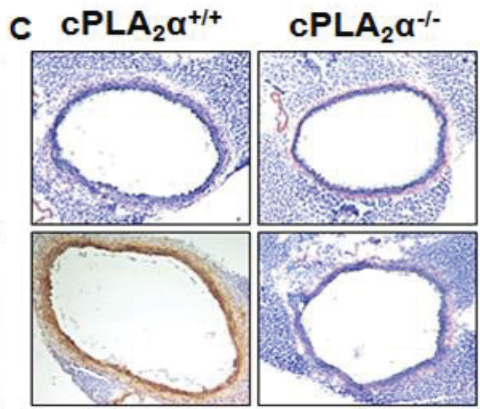

D

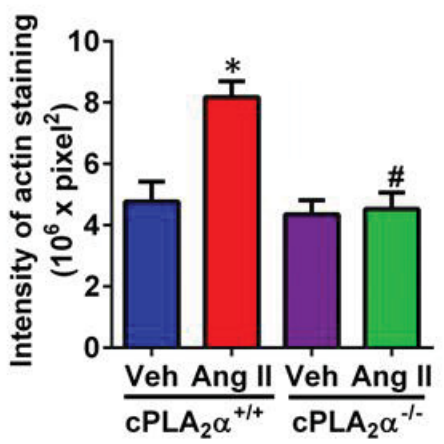

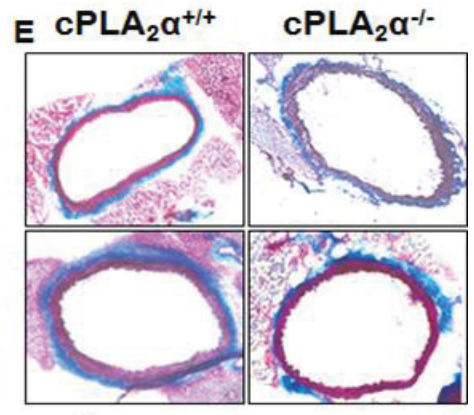

$\mathbf{F}$

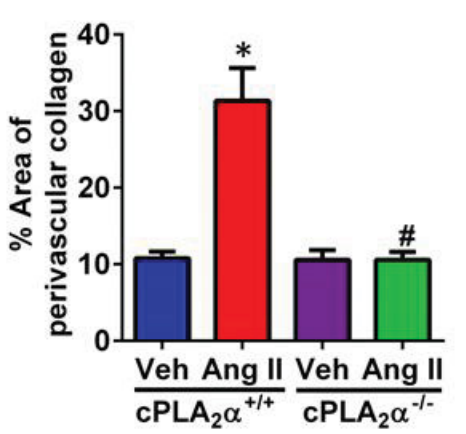

Figure 4.7 CPLA $_{2} \alpha$ gene disruption protects against Ang II-induced vascular remodeling

Sections of aortae were stained with hematoxylin and eosin (A), $\alpha$-smooth muscle actin (C), and Masson's trichrome for collagen (E). (B,D,F represent corresponding quantification of data)

$* P<0.05 \mathrm{cPLA}_{2} \alpha^{+/+}$vehicle vs. $\mathrm{cPLA}_{2} \alpha^{+/+}$Ang II, \#P<0.05 $\mathrm{cPLA}_{2} \alpha^{+/+}$Ang II vs. $\mathrm{cPLA}_{2} \alpha^{-/-}$Ang II ( $\mathrm{n}=3-5$ for each group; data are expressed as mean $\pm \mathrm{SEM}$ ). 


\subsubsection{CPLA $_{2} \alpha$ Gene Disruption Prevents Increased Vascular Reactivity and Endothelial Dysfunction in Ang II-Induced Hypertension}

Ang II-induced hypertension was associated with increased response of aorta to vasoconstrictors phenylephrine (Figure 4.8A) and endothelin-1 (Figure 4.8B) in $\mathrm{CPLA}_{2} \mathrm{\alpha}^{+/+}$mice; these increases were abrogated in $\mathrm{CPLA}_{2} \alpha^{-/-}$mice. Ang II-infusion caused endothelial dysfunction, as indicated by diminished dilation to ACh in aorta preconstricted with phenylephrine in $\mathrm{CPLA}_{2} \alpha^{+/+}$but not $\mathrm{cPLA}_{2} \alpha^{-/}$mice (Figure 4.8C). The endothelial-independent relaxation of aorta to SNP, that acts directly on vascular smooth muscle was not altered (Figure 4.8D).

\subsection{9 $\operatorname{cPLA}_{2} \alpha$ Gene Disruption Does Not Alter Expression of AT1, AT2, MAS Receptors and $\mathrm{ACE}$}

To determine if decreased BP during Ang II-infusion in $\mathrm{CPLA}_{2} \alpha^{-/-}$mice is a result of alterations in expression of AT1, AT2, Ang (1-7) Mas receptor, or ACE, western blot analysis was performed to determine their protein expression in the cardiac tissue. Expression of AT1, AT2, Mas receptor, and ACE were not altered in any treatment groups (Figure 4.9).

\subsubsection{0 $\mathrm{cPLA}_{2} \alpha$ Gene Disruption Protects Against Ang II-Induced Cardiovascular Oxidative Stress}

Oxidative stress has been implicated in various models of hypertension including Ang II ${ }^{16,166}$, and Ang II-induced activation of cardiac NADPH oxidase depends on PLA activity in vascular smooth muscle cells in vitro. ${ }^{223,224}$ Therefore, we investigated whether $\mathrm{cPLA}_{2}$ gene disruption prevents Ang II-induced oxidative stress in heart and aorta. NADPH oxidase activity measured by lucigenin-based luminescence assay was increased in the hearts of Ang II-infused cPLA $2 \alpha^{+/+}$but not $\mathrm{CPLA}_{2} \alpha^{-/-}$mice (Figure 4.10A). Infusion of Ang II increased cardiac (Figure 4.10B, C) and aortic (Figure 4.10D, E) ROS production in $\mathrm{CPLA}_{2} \alpha^{+/+}$but not in $\mathrm{CPLA}_{2} \alpha^{-/-}$mice measured by fluorescence of 2hydroxyethidium generated after exposure to DHE.

\subsubsection{CPLA $_{2} \alpha$ Gene Disruption Prevents Endoplasmic Reticulum Stress in Ang II- Induced Hypertension}

Endoplasmic reticulum (ER) stress has been implicated in Ang II-induced hypertension. ${ }^{225}$ To determine if Ang II-infusion promotes ER stress in the heart and if it is dependent on $\mathrm{cPLA}_{2} \alpha$, we measured mRNA expression of ER stress biomarkers p58 $8^{I P K}$, GRP78, XBP and CHOP. Ang II infusion increased cardiac mRNA expression of $\mathrm{p} 58^{I P K}$ that is induced in the early adaptive phase of the unfolded protein response, and CHOP (GADD153), a chronic ER stress marker ${ }^{226}$ in $\mathrm{CPLA}_{2} \alpha^{+/+}$but not in $\mathrm{CPLA}_{2} \alpha^{-/ /}$mice (Figure 4.11). 

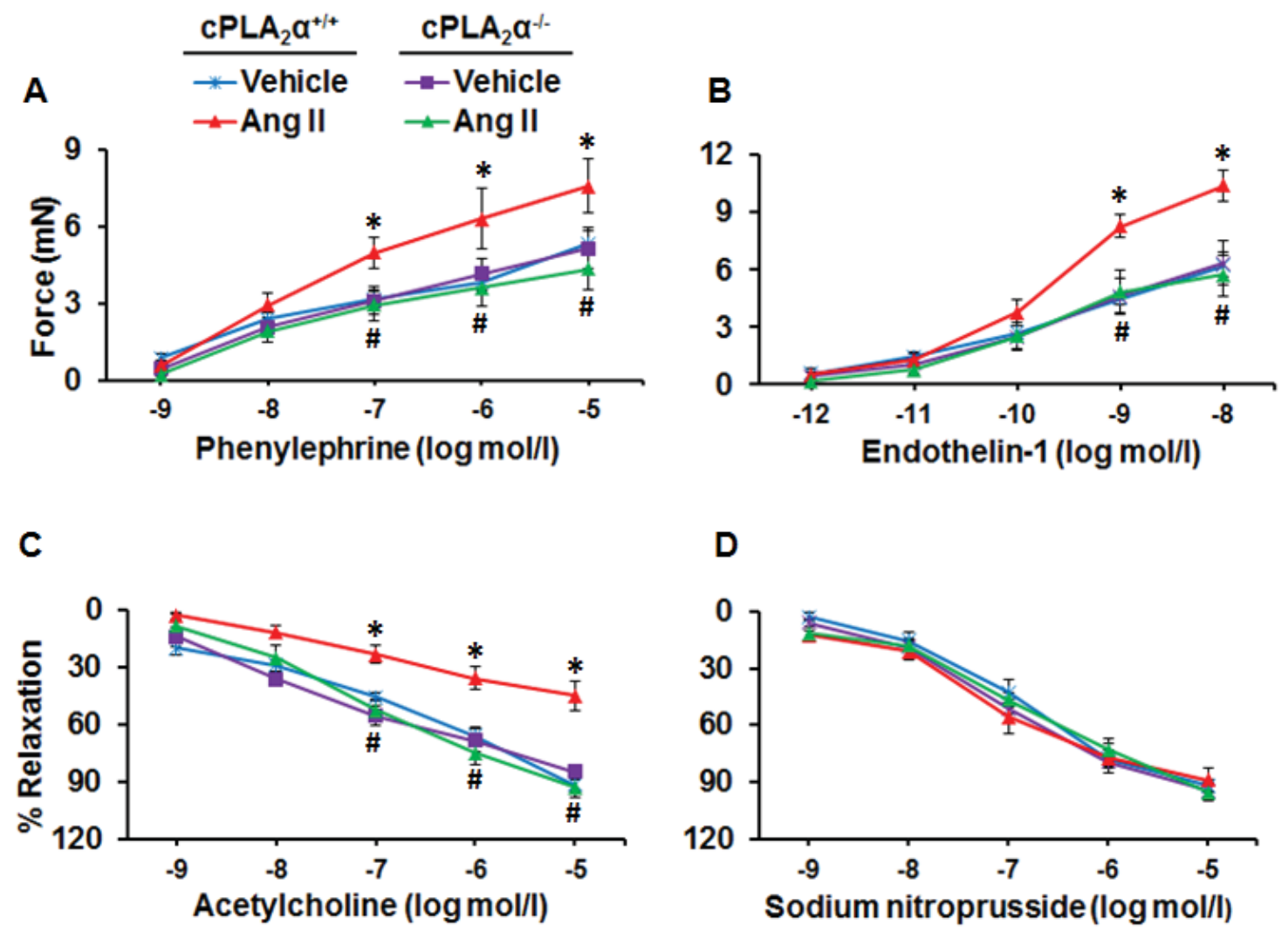

Figure 4.8 $\mathrm{CPLA}_{2} \alpha$ gene disruption prevents increased vascular reactivity and endothelial dysfunction in Ang II-induced hypertension

The vascular response of aorta to increasing concentrations of PE (A) ET-1 (B) The vascular response to increasing concentrations of Ach (endothelium-dependent relaxation (C) and SNP (endothelium-independent relaxation) (D) was examined in the thoracic aorta from animals in each of the groups.

${ }^{*} P<0.05 \mathrm{cPLA}_{2} \alpha^{+/+}$vehicle vs. $\mathrm{cPLA}_{2} \alpha^{+/+}$Ang II, \#P<0.05 $\mathrm{cPLA}_{2} \alpha^{+/+}$Ang II vs. $\mathrm{cPLA}_{2} \alpha^{-/-}$Ang II ( $\mathrm{n}=5$ for all experiments; data are expressed as mean $\left.\pm \mathrm{SEM}\right)$. 


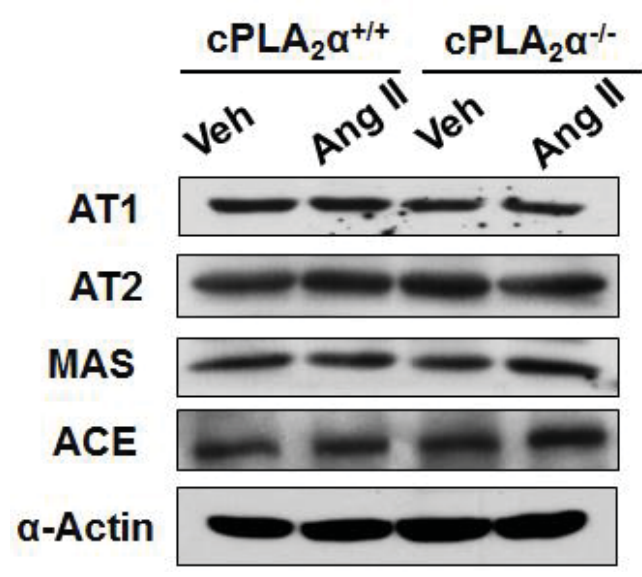

Figure 4.9 cPLA $_{2} \alpha$ gene disruption does not alter expression of AT1, AT2, MAS receptors and $\mathrm{ACE}$

Western blot analysis was performed on the heart homogenates with respective antibodies. Protein expression of these receptors and ACE was not altered ( $n=3$ for all experiments) 

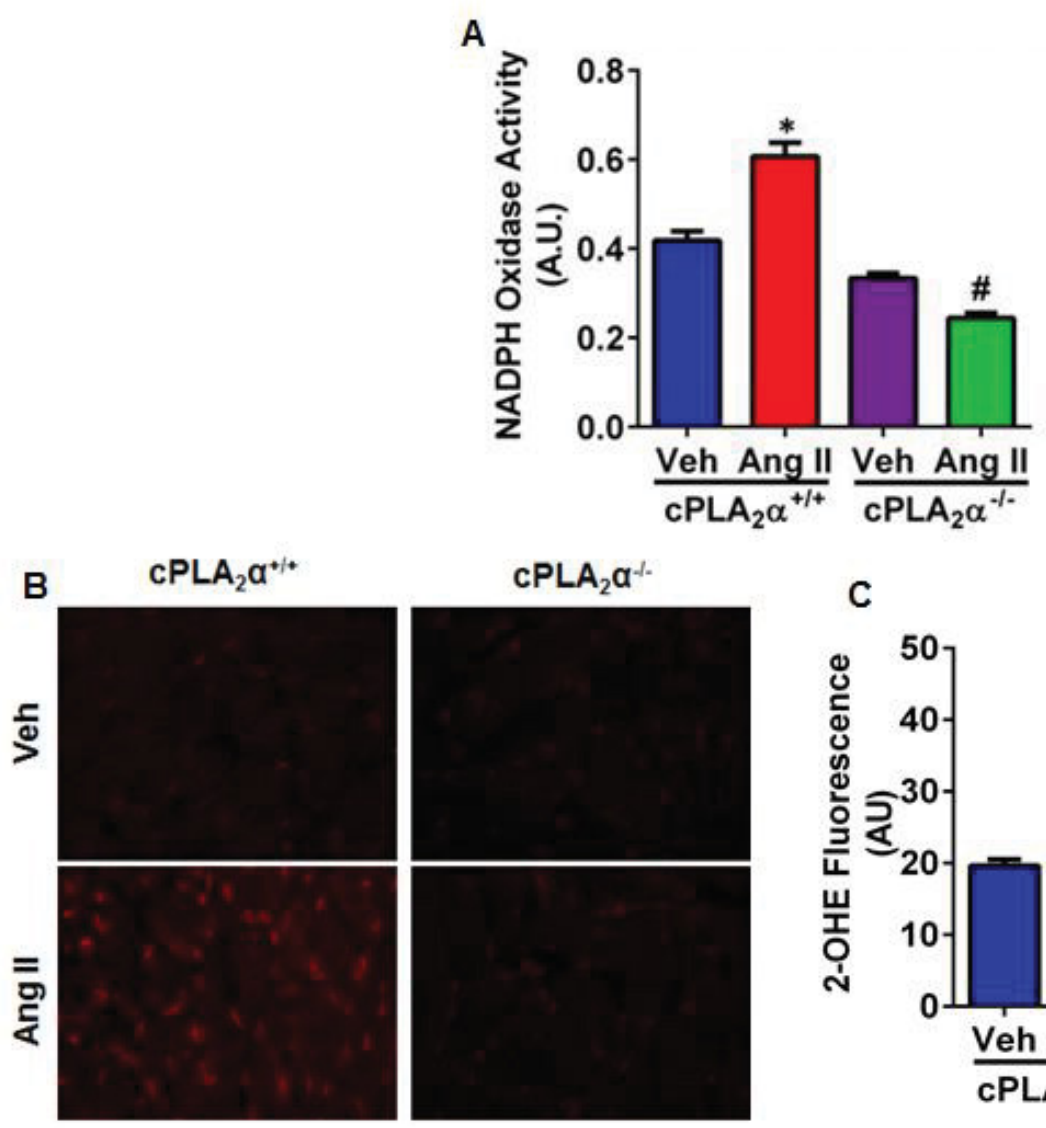

C
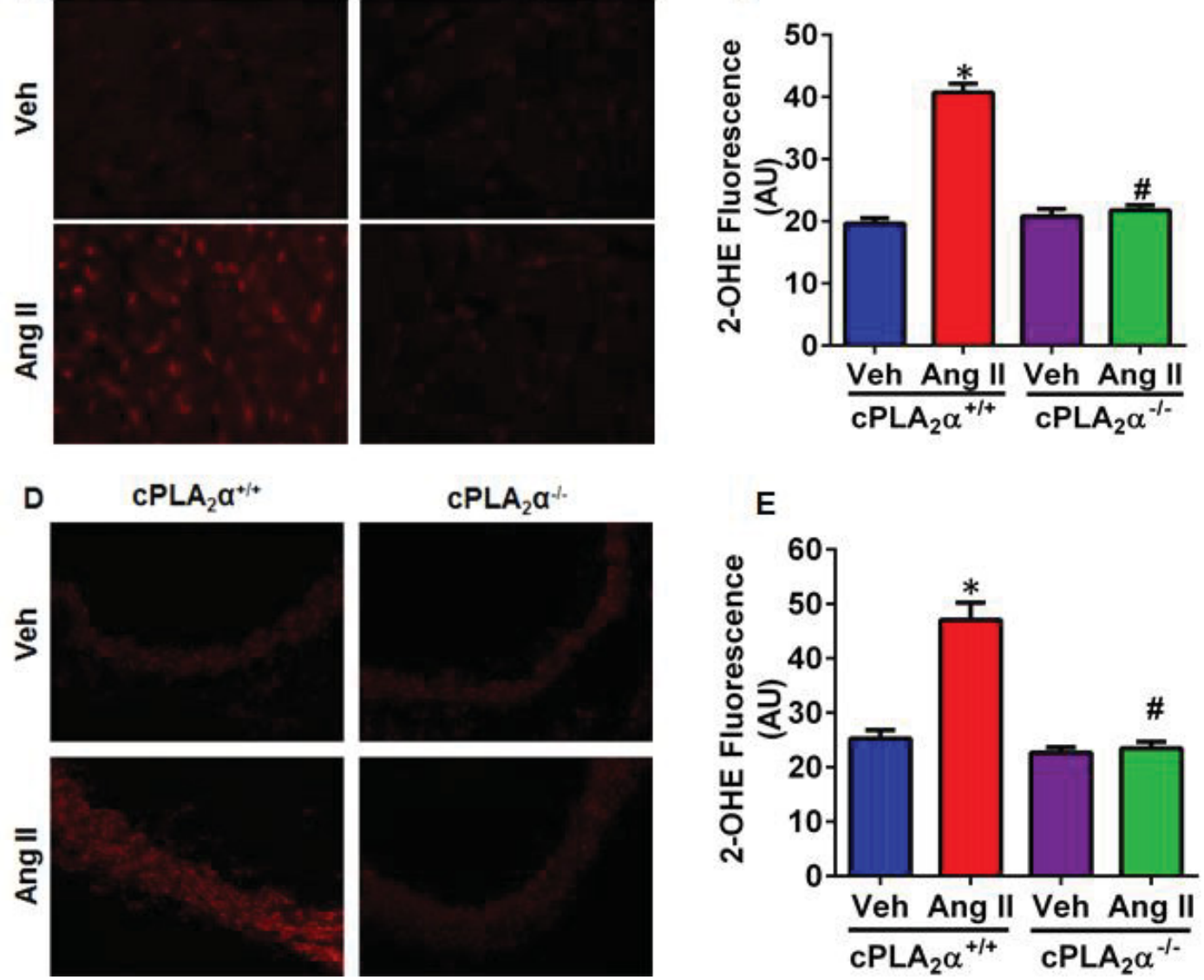

Figure 4.10 $\mathrm{cPLA}_{2} \alpha$ gene disruption protects against Ang II-induced cardiovascular oxidative stress

NADPH oxidase activity measured in kidney homogenate (A), ROS production determined by DHE staining in the heart $(\mathbf{B}, \mathbf{C})$ and aorta $(\mathbf{D}, \mathbf{E})$ quantified as fluorescence of $2-\mathrm{OHE}$

${ }^{*} P<0.05 \mathrm{cPLA}_{2} \alpha^{+/+}$vehicle vs. cPLA $2 \alpha^{+/+}$Ang II, ${ }^{\#} P<0.05 \mathrm{cPLA}_{2} \alpha^{+/+}$Ang II vs. cPLA $2 \alpha^{-/-}$ Ang II ( $\mathrm{n}=5$ for each group; data are expressed as mean $\pm \mathrm{SEM}$ ). 


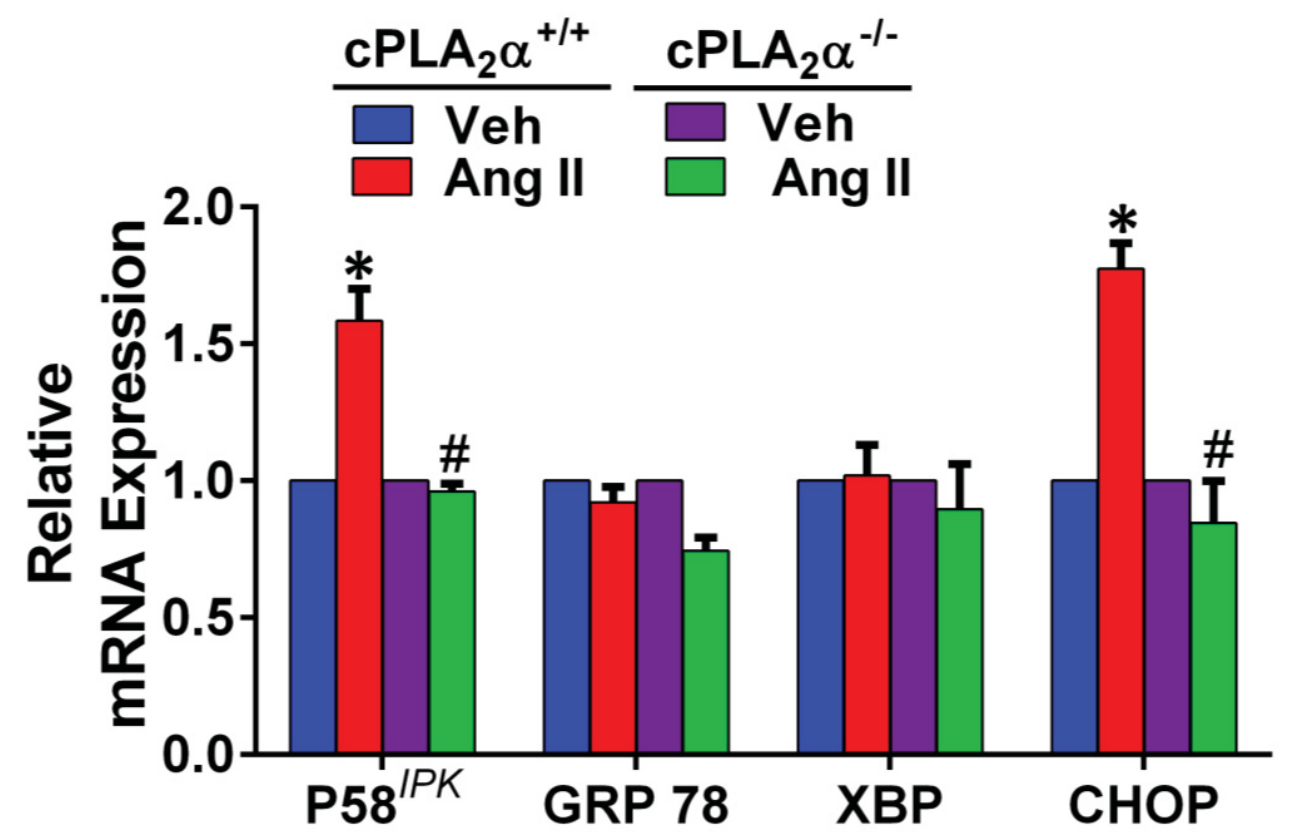

Figure 4.11 $\mathrm{CPLA}_{2} \alpha$ gene disruption prevents ER stress in Ang II-induced hypertension

RT-PCR analysis was performed using cardiac mRNA for various ER stress biomarkers: p58 ${ }^{I P K}$, GRP78, XBP, and CHOP.

${ }^{*} P<0.05 \mathrm{cPLA}_{2} \alpha^{+/+}$vehicle vs. cPLA $2 \alpha^{+/+}$Ang II, ${ }^{\#} P<0.05 \mathrm{cPLA}_{2} \alpha^{+/+}$Ang II vs. cPLA $2 \alpha^{-/-}$ Ang II ( $\mathrm{n}=4$ for all experiments; data are expressed as mean $\pm \mathrm{SEM})$. 


\subsubsection{2 $\mathrm{cPLA}_{2} \alpha$ Gene Disruption Prevents Ang II-Induced Phosphorylation of ERK1/2 and c-Src}

It is well established that, in VSMC, Ang II increases the production of ROS, and activity of ERK1/2 and cSrc that contributes to hypertrophy. ${ }^{59}$ ERK1/2 also promotes phosphorylation of $\mathrm{cPLA}_{2}{ }^{3}$ Ang II-infusion increased ERK1/2 (Figure 4.12A) and cSrc activity (Figure 4.12B) as measured by phosphorylation of these kinases in the heart tissue of $\mathrm{cPLA}_{2} \alpha^{+/+}$but not in $\mathrm{cPLA}_{2} \alpha^{-/-}$mice.

\subsection{Aim 2. To Demonstrate that $\mathrm{CPLA}_{2} \alpha$ Is Essential in Ang II-Induced Renal Pathophysiology Associated with Hypertension}

\subsection{1 $\mathrm{CPLA}_{2} \alpha$ Gene Disruption Prevents Against Ang II-Induced Altered Renal Hemodynamics}

Renal Doppler imaging was performed and renal artery resistive (Figure 4.13D) and pulsatility index (Figure 4.13E) were calculated as a measure of resistance and variability of blood velocity in the renal artery. These parameters are widely used to assess renal failure and extent of damage in humans. In the present study, Ang II infusion for 13 days increased renal vascular resistance and pulsatility index in cPLA $\alpha^{+/+}$but not in in $\mathrm{CPLA}_{2} \alpha^{-/-}$mice.

\subsection{2 $\mathrm{cPLA}_{2} \alpha$ Gene Disruption Prevents Ang II-Induced Renal Dysfunction}

Water intake and urine output were not different between $\mathrm{cPLA}_{2} \alpha^{+/+}$and $\mathrm{cPLA}_{2} \alpha^{-/-}$ mice. Infusion of Ang II for 13 days increased water intake (Figure 4.14A), urine output, (Figure 4.14B), decreased urine osmolality (Figure 4.14C), increased glomerular filtration rate as determined from creatinine clearance (Figure 4.14D), and caused proteinuria (Figure 4.14E) in $\mathrm{cPLA}_{2} \alpha^{+/+}$but not $\mathrm{cPLA}_{2} \alpha^{-/-}$mice.

\subsection{3 $\mathrm{cPLA}_{2} \alpha$ Gene Disruption Prevents Renal Fibrosis in the Kidney}

Increased interstitial staining of $\alpha$-SMA (Figure 4.15A) and TGF- $\beta$ (Figure 4.15B) indicators of interstitial fibrosis, was observed in renal sections from Ang IIinfused $\mathrm{cPLA}_{2} \alpha^{+/+}$but not in $\mathrm{cPLA}_{2} \alpha^{-/-}$mice. Masson's trichrome staining revealed increased collagen accumulation (intense blue staining) (Figure 4.15C) in the interstitial space in Ang II-infused $\mathrm{CPLA}_{2} \alpha^{+/+}$but not $\mathrm{cPLA}_{2} \alpha^{-/-}$mice. 

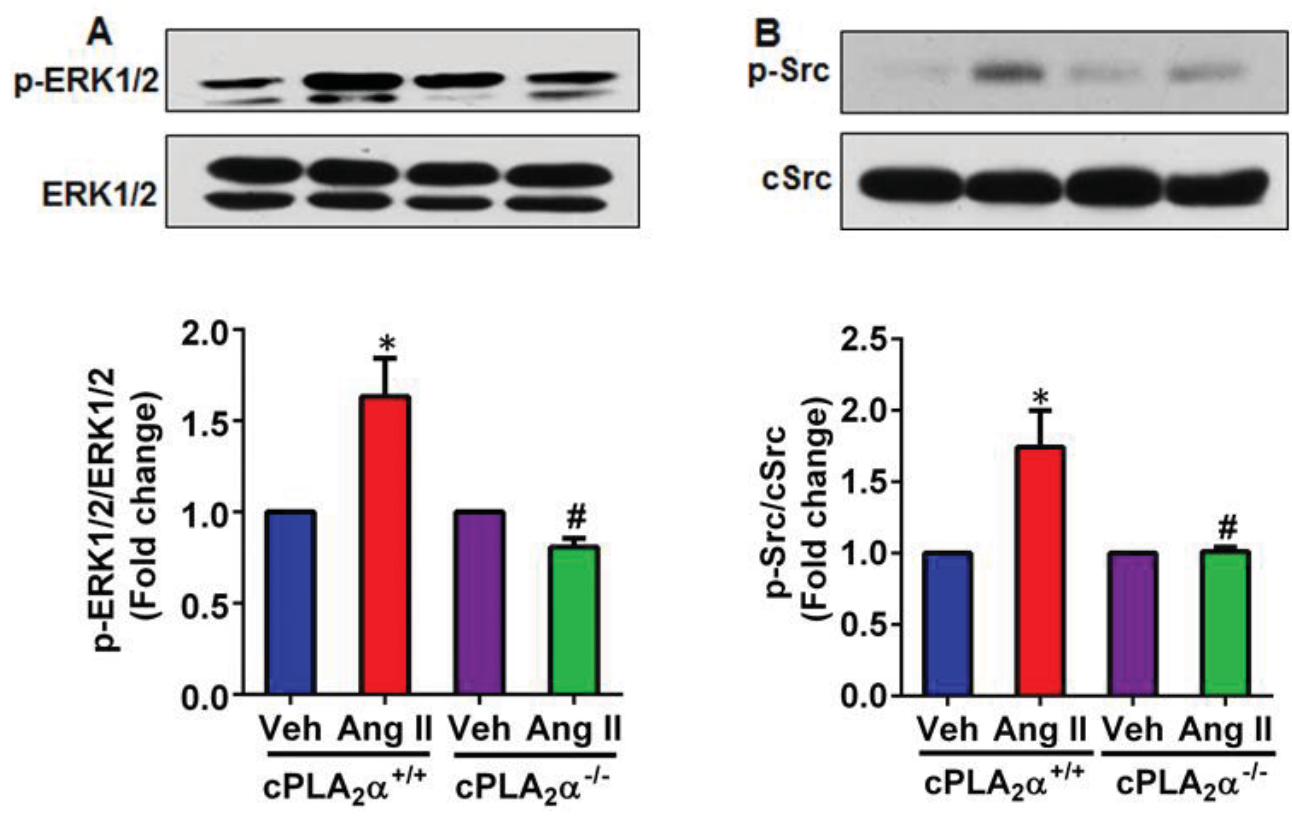

Figure 4.12 cPLA $_{2} \alpha$ gene disruption prevents Ang II-induced phosphorylation of ERK1/2 and cSrc

Erk1/2 (A) and cSrc (B) activities were measured in heart homogenates by Western blot analysis as described in the methods ( $\mathrm{n}=3$ for all experiments).

${ }^{*} P<0.05 \mathrm{cPLA}_{2} \alpha^{+/+}$vehicle vs. $\mathrm{cPLA}_{2} \alpha^{+/+}$Ang II, ${ }^{\#} P<0.05 \mathrm{cPLA}_{2} \alpha^{+/+}$Ang II vs. cPLA $2 \alpha^{-/-}$ Ang II 
A

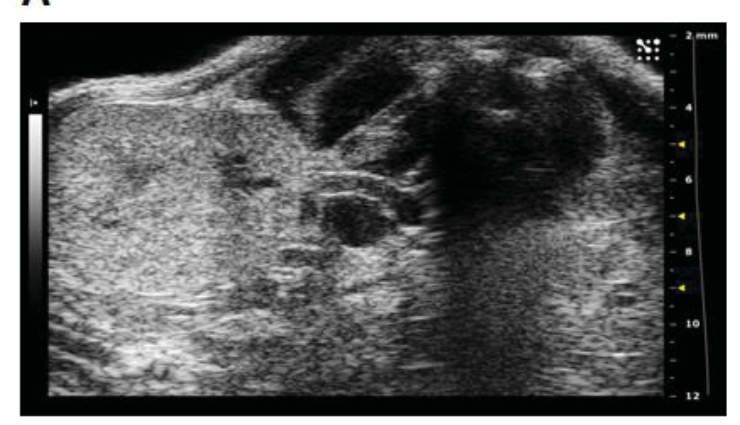

B

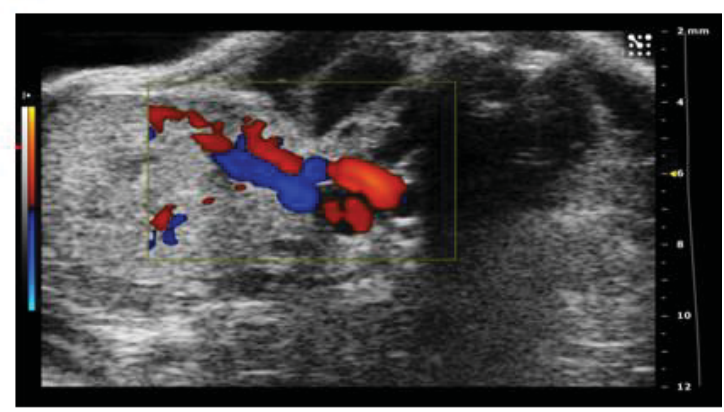

C
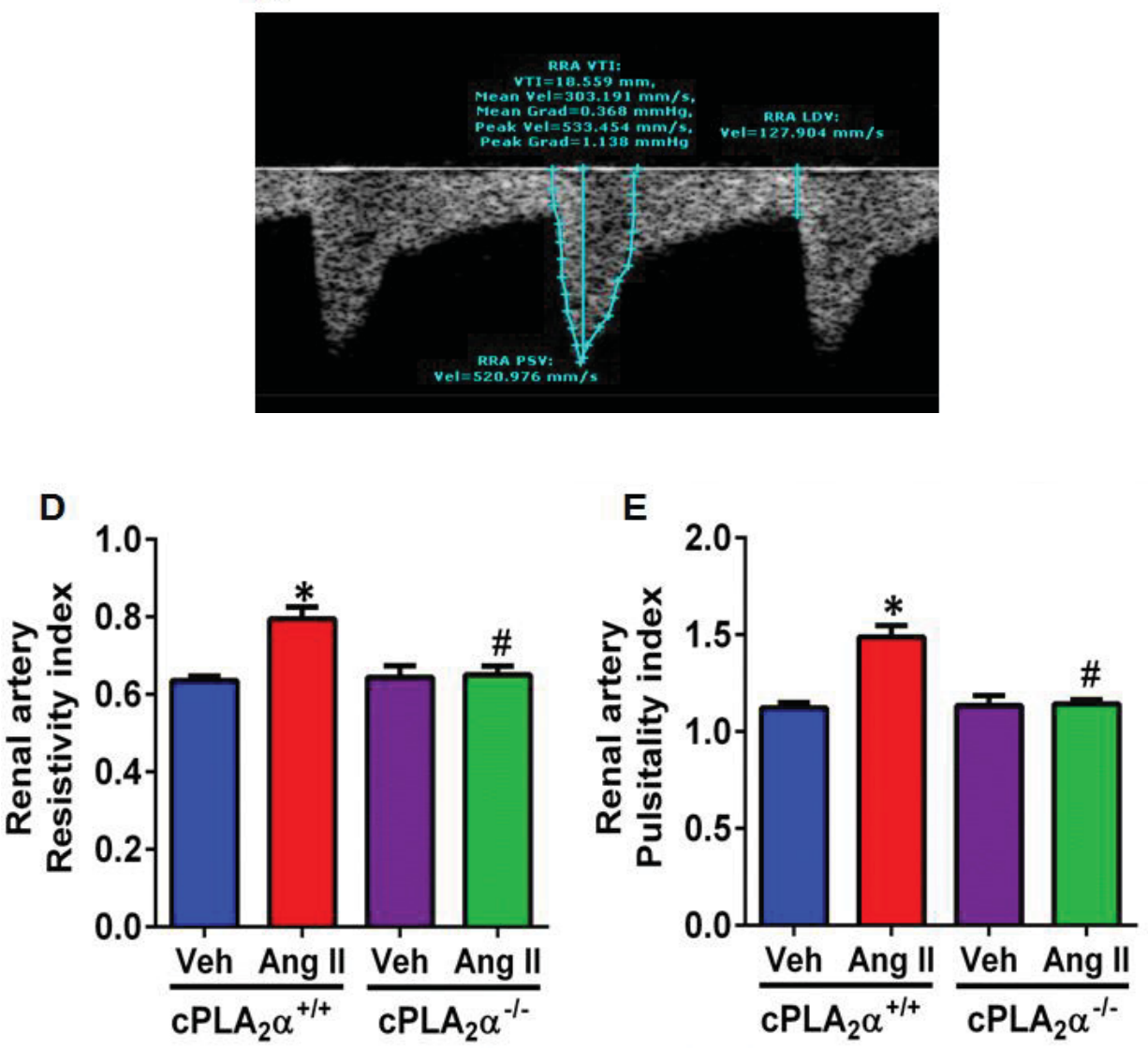

Figure 4.13 $\mathrm{cPLA}_{2} \alpha$ gene disruption prevents against Ang II-induced altered renal hemodynamics

Representative ultrasound B mode image of the kidney in transverse view (A) Color Doppler to visualize blood flow (B) Pulse wave Doppler mode (C) Renal artery resistive index (D) and renal artery pulsitality index (E) ${ }^{*} P<0.05 \mathrm{cPLA}_{2} \alpha^{+/+}$vehicle vs. cPLA $2 \alpha^{+/+}$Ang II, ${ }^{\#} P<0.05 \mathrm{cPLA}_{2} \alpha^{+/+}$Ang II vs. cPLA $2 \alpha^{-/-}$ Ang II ( $\mathrm{n}=4$ for all experiments; data are expressed as mean $\pm \mathrm{SEM})$ 
A

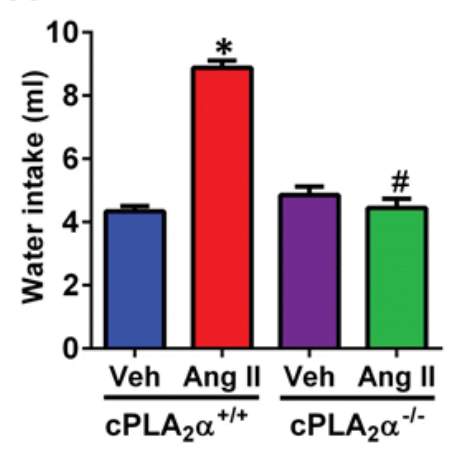

B

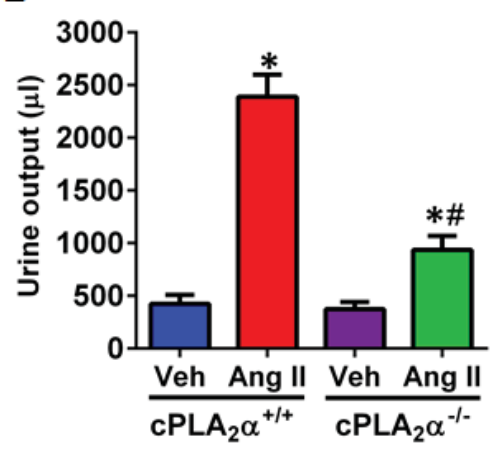

C

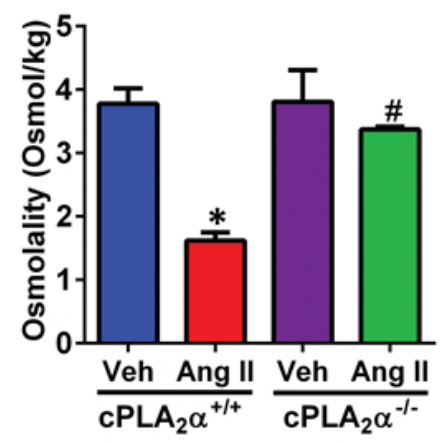

D

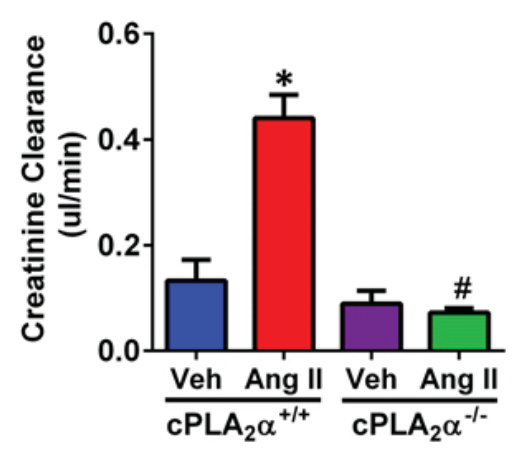

E

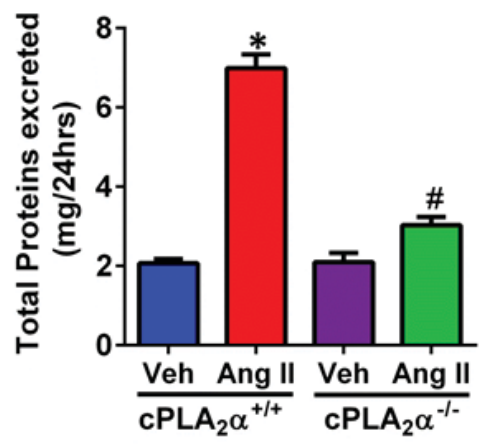

Figure 4.14 $\mathrm{cPLA}_{2} \alpha$ gene disruption prevents Ang II-induced renal dysfunction

Water intake (A), urine output (B) measured on day 13 of Ang II infusion, urine osmolality (C), creatinine clearance (D) and protein excretion in the urine (E) was measured

${ }^{*} P<0.05 \mathrm{cPLA}_{2} \alpha^{+/+}$vehicle vs. $\mathrm{cPLA}_{2} \alpha^{+/+}$Ang II, ${ }^{\#} P<0.05 \mathrm{cPLA}_{2} \alpha^{+/+}$Ang II vs. cPLA $2 \alpha^{-/-}$ $(n=6-10$ for all experiments; data are expressed as mean \pm SEM) 


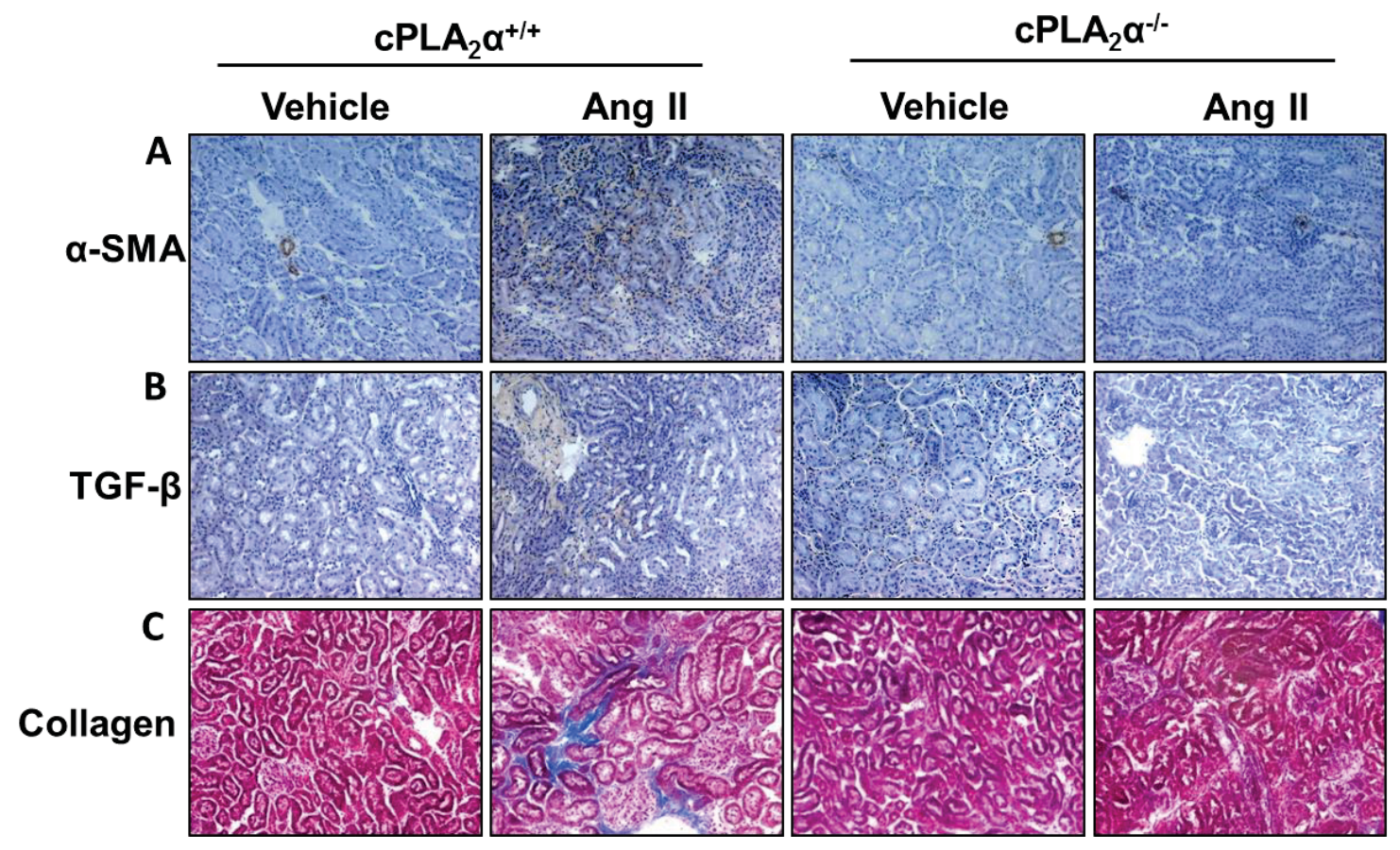

Figure 4.15 $\operatorname{cPLA}_{2} \alpha$ gene disruption prevents renal fibrosis in the kidney

Immunohistochemical analysis for $\alpha$-SMA (A), TGF- $\beta$ (B) and Masson's trichrome staining for collagen $(\mathbf{C})$ in renal sections. 


\subsection{4 $\mathrm{CPLA}_{2} \alpha$ Gene Disruption Prevents Renal Inflammation}

To determine the contribution of $\mathrm{cPLA}_{2} \alpha$ to inflammation associated with Ang IIinduced end organ damage, we examined the localization of $\mathrm{CD}^{+} \mathrm{T}$-lymphocytes and $\mathrm{F} 4 / 80^{+}$macrophages in the renal tissue. Ang II infusion resulted in increased accumulation of $\mathrm{CD}^{+} \mathrm{T}$ cells in the interstitium (Figure 4.16A) and glomerulus (Figure 4.16B) and infiltration of $\mathrm{F} 4 / 80^{+}$macrophages (Figure 4.16C) in the renal interstitium of $\mathrm{cPLA}_{2} \alpha^{+/+}$but not cPLA $2 \alpha^{-/-}$mice

\subsection{5 $\mathrm{cPLA}_{2} \alpha$ Gene Disruption Protects Against Ang II-Induced Renal Oxidative Stress}

Infusion of Ang II for 13 days increased renal NADPH oxidase activity (Figure 4.17A) and urinary TBARS (Figure 4.17B), a byproduct of lipid peroxidation in $\mathrm{cPLA}_{2} \alpha^{+/+}$but not in $\mathrm{cPLA}_{2} \alpha^{-/-}$mice. This data correlated with increased superoxide production in renal sections of $\mathrm{cPLA}_{2} \alpha^{+/+}$mice, as indicated by 2-OHE fluorescence intensity (Figure 4.17C, D). This increase was not observed in $\mathrm{CPLA}_{2} \alpha^{-/-}$mice infused with Ang II

\subsubsection{Protection Against Ang II-Induced Hypertension in $\operatorname{cPLA}_{2} \alpha^{-/-}$Mice Is Independent of Endothelin}

Ang II infusion increased endothelin levels (Figure 4.18) to the same extent in both $\mathrm{cPLA}_{2} \alpha^{+/+}$and $\mathrm{CPLA}_{2} \alpha^{-/-}$mice, however this did not reach significant difference demonstrating that reduced SBP in $\mathrm{CPLA}_{2} \alpha^{-/-}$mice after Ang II infusion is independent of endothelin. 


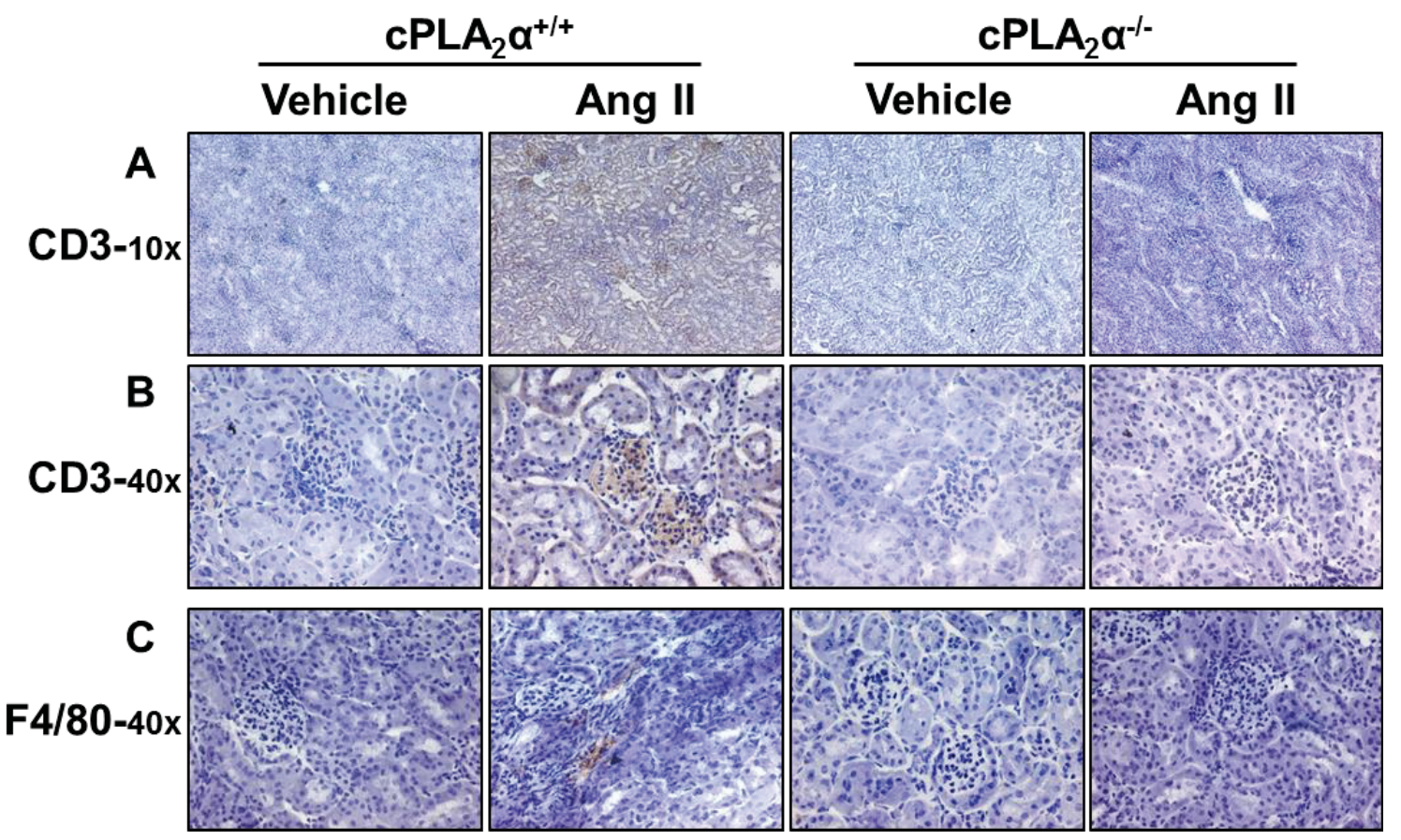

Figure 4.16 $\mathrm{cPLA}_{2} \alpha$ gene disruption prevents renal inflammation

$\mathrm{CD}^{+} \mathrm{T}$ cell staining in the interstitium (A) and glomerulus (B) and F4/80+ macrophages in the interstitium (C) of the kidney. 
A
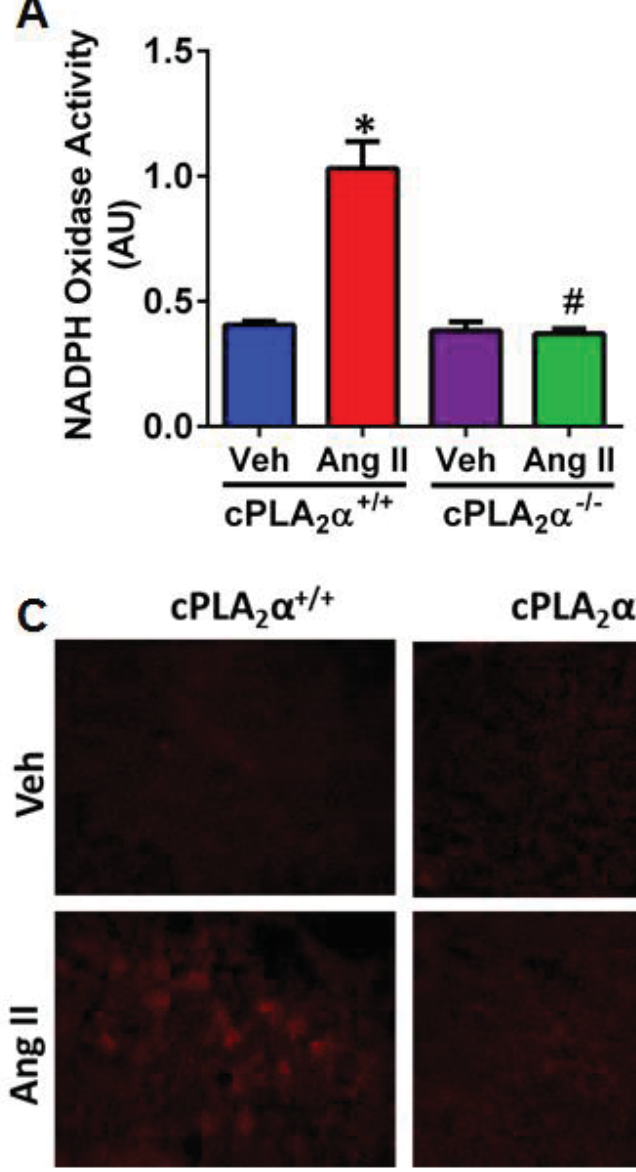

B

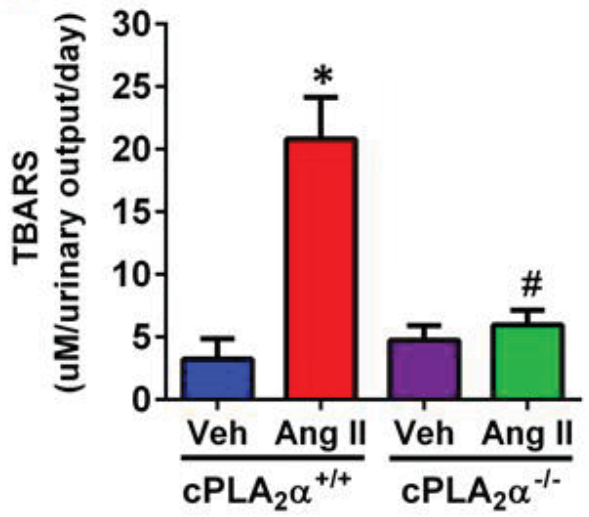

D

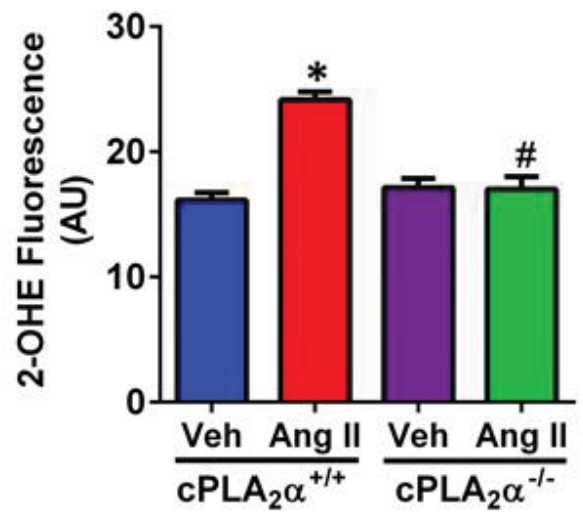

Figure 4.17 $\mathrm{CPLA}_{2} \alpha$ gene disruption protects against Ang II-induced renal oxidative stress

NADPH oxidase activity measured in kidney homogenate (A), urinary TBARS (B), ROS production determined by DHE staining (C) quantified as fluorescence of 2-OHE (D) (n $=5-6$ for all experiments; data are expressed as mean \pm SEM) 


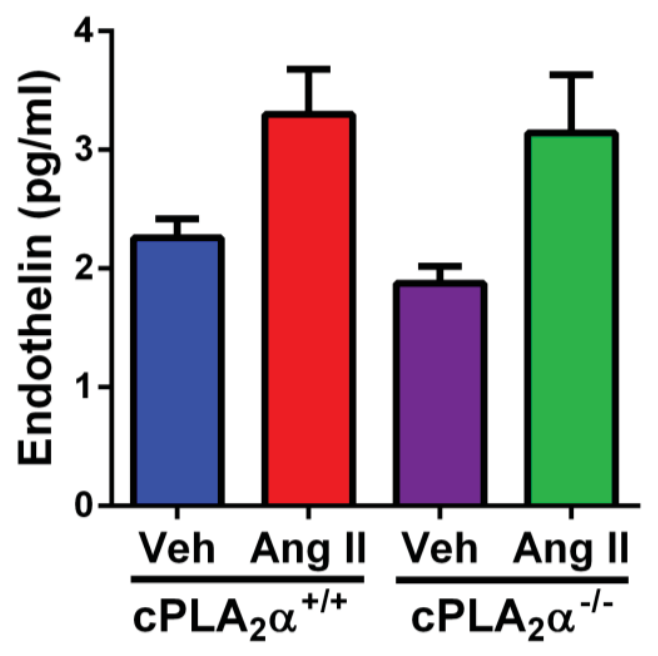

Figure 4.18 Protection against Ang II-induced hypertension in $\mathrm{cPLA}_{2} \alpha^{-/-}$mice is independent of endothelin

Endothelin levels measure by HPLC ( $\mathrm{n}=6$ for all experiments; data are expressed as mean \pm SEM) 


\section{CHAPTER 5. DISCUSSION}

\subsection{Aim 1. To Determine the Contribution of $\mathrm{CPLA}_{2} \alpha$ to Ang II-Induced Hypertension and Associated Cardiovascular Pathophysiology}

The novel finding of this study is the demonstration that $\mathrm{CPLA}_{2} \alpha$ is crucial for the development of Ang II-induced hypertension and associated cardiovascular dysfunction, hypertrophy, cardiac fibrosis, inflammation, oxidative stress, and activation of ERK1/2 and cSrc in mice. This conclusion is based on my finding that infusion of Ang II increased SBP in $\mathrm{cPLA}_{2} \alpha^{+/+}$mice and this was minimized by $\mathrm{cPLA}_{2} \alpha$ gene disruption. The selectivity of this effect of $\mathrm{cPLA}_{2} \alpha$ gene disruption in our mice was indicated by loss of cardiac expression of its mRNA but not that of other related PL enzymes: $\mathrm{SPLA}_{2} \alpha$, $\mathrm{cPLA}_{2} \beta$, and $\mathrm{cPLA}_{2} \gamma ; \operatorname{PLC} \beta 1,2,3$, and 4; and PLD1 and PLD2. The protein expression of PLA 2 but not PLC $\beta 2$, PLD1, or PLD2 was also absent in $\mathrm{cPLA}_{2} \alpha^{---}$mice. Since $\mathrm{cPLA}_{2} \alpha$ selectively catalyzes release of AA from tissue lipids ${ }^{227}$ and Ang II is known to activate $\mathrm{cPLA}_{2}$ to release $\mathrm{AA}, \mathrm{cPLA}_{2}$ appears to mediate the hypertensive effect of Ang II via AA release. Supporting this view was our finding that cPLA $\mathrm{A}_{2}$ activity, as indicated by its phosphorylation, was increased in the heart of $\mathrm{cPLA}_{2} \alpha^{+/+}$but not $\mathrm{cPLA}_{2} \alpha^{-/-}$mice. The induction of eicosanoid production by lipopolysaccharide and calcium ionophore A23187 in peritoneal macrophages and furosemide-induced PGE2 excretion was also abolished in $\mathrm{CPLA}_{2} \alpha^{-/-}$mice. ${ }^{204,228,229}$. In the present study, Ang II infusion increased the urinary output of PGEM. Moreover, administration of inhibitor of AA metabolism, ETYA, blocked Ang II-induced increase in SBP in $\mathrm{CPLA}_{2} \alpha^{+/+}$mice. Therefore, it appears that metabolites of AA with pro-hypertensive effects contribute to the development of hypertension caused by this peptide in these mice. Since cPLA ${ }_{2} \alpha$ gene disruption or ETYA did not alter basal BP, it appears that $\mathrm{cPLA}_{2} \alpha$ activation and release of AA and its metabolites are not required to maintain basal BP.

The increase in BP produced by Ang II in $\mathrm{CPLA}_{2} \alpha^{+/+}$mice was associated with cardiac dysfunction as indicated by decreased EF, FS, CO and increased EDV and ESV, cardiac hypertrophy as shown by increased LV mass. These events were minimized in $\mathrm{cPLA}_{2} \alpha^{-/ /}$mice, suggesting an essential role of $\mathrm{cPLA}_{2} \alpha^{+/+}$in cardiac dysfunction and hypertrophy. Moreover, in the present study, cardiac fibrosis and inflammation as indicated by increased intracardiac staining of $\alpha$-SMA myofibroblasts, TGF- $\beta$, as well as by increased infiltration of $\mathrm{F} 4 / 80^{+}$macrophages and $\mathrm{CD}^{+}{ }^{+} \mathrm{T}$ cells in Ang II-infused $\mathrm{cPLA}_{2} \alpha^{+/+}$mice were prevented in $\mathrm{CPLA}_{2} \alpha^{-/-}$mice. These findings suggest that $\mathrm{cPLA}_{2} \alpha / \mathrm{AA}$ also mediate cardiac fibrosis and inflammation associated with Ang IIinduced hypertension. $\mathrm{CPLA}_{2} \alpha$ was also found to be critical for increased vascular remodeling and reactivity associated with Ang II-induced hypertension characterized by an increase in various parameters such as media:lumen ratio, $\alpha$-SMA, deposition of collagen, as well as by increased contractile response of aorta to PE and ET-1 in $\mathrm{cPLA}_{2} \alpha^{+/+}$but not cPLA $2 \alpha^{-/-}$mice. Although the effect of Ang II on cardiovascular remodeling has been shown to be independent of an increase in $\mathrm{BP},{ }^{230-233}$ we cannot exclude the possibility that the protection against Ang II-induced cardiovascular remodeling in $\mathrm{cPLA}_{2} \alpha^{-/-}$mice could also be due to decreased BP. The precise mechanism 
by which increase in BP causes cardiovascular remodeling is not known. Since stretch can increase cPLA 2 activity and eicosanoid production ${ }^{234}$ and 20-HETE contributes to pressure-induced myogenic tone, ${ }^{235}$ it raises the possibility that the increased stretch associated with hypertension might also result in $\mathrm{cPLA}_{2} \alpha$ activation and generation of eicosanoids that contribute to Ang II-induced cardiovascular remodeling. Ang II-induced hypertension is also known to be associated with endothelial dysfunction. ${ }^{16}$ Our finding that Ang II-induced endothelial dysfunction, as indicated by diminished relaxation of aorta to ACh but not to SNP, an agent that acts directly on VSMCs, occurs selectively in $\mathrm{cPLA}_{2} \alpha^{+/+}$but not cPLA $2 \alpha^{-/-}$mice, suggests that $\mathrm{cPLA}_{2} \alpha$ is essential for endothelial dysfunction associated with Ang II-induced hypertension. Moreover, endothelial dysfunction in larger vessels is dependent on NO. ${ }^{236}$ Hypertension caused by the inhibitor of NO synthesis, L-NG-nitroarginine methyl ester, which has been attributed to increased activity of RAS and sympathetic nervous system, ${ }^{237,238}$ is also associated with endothelial dysfunction in the aorta. Both hypertension and endothelial dysfunction are prevented in cPLA $_{2} \alpha^{-/-}$mice. 9

The mechanism by which $\mathrm{cPLA}_{2} \alpha$ gene disruption protects against Ang IIinduced hypertension and cardiovascular remodeling, inflammation, increased vascular reactivity, and endothelial dysfunction could be due to alterations in expression of Ang II, Ang (1-7) receptors, and ACE enzyme. However, this possibility appears to be unlikely because the level of expression of AT1, AT2, Mas receptor and ACE enzyme examined in the heart were not different in $\mathrm{cPLA}_{2} \alpha^{-/-}$compared to $\mathrm{CPLA}_{2} \alpha^{+/+}$mice. Oxidative stress and activation of immune system have been implicated in various models of hypertension including Ang II-induced hypertension. ${ }^{239,240}$ In the present study, Ang II-induced hypertension was associated with increased oxidative stress, as shown by increased cardiac NADPH oxidase activity, ROS production in the heart and aorta, and cardiac infiltration of $\mathrm{F} 4 / 80^{+}$macrophages and $\mathrm{CD}^{+} \mathrm{T}$ lymphocytes in $\mathrm{CPLA}_{2} \alpha^{+/+}$mice. These changes were prevented in $\mathrm{CPLA}_{2} \alpha^{-/-}$mice, suggesting that increased oxidative stress and inflammation in Ang II-induced hypertension are dependent on $\mathrm{cPLA}_{2} \alpha$. Supporting this view, it has been shown that Ang II increases NADPH oxidase activity by activating cPLA $_{2}$ and release of AA in VSMCs. ${ }^{23,224}$ cPLA $_{2} \alpha$ generated AA has also been implicated in NADPH oxidase activation in human monocytes and myeloid cell line PLB-985. ${ }^{241,242}$ AA metabolites generated by COX, PGE2 via its actions on EP1 and EP3 receptors $^{243,244}$ and TXA2 $2^{245}$ contributes to Ang II-induced hypertension. AA metabolites formed by 12/15 LOX $^{127,246}$ and by CYP450 4A (20-HETE), ${ }^{247,248}$ also contribute to Ang II-induced hypertension. Therefore, protection against Ang II-induced hypertension and associated cardiovascular pathogenesis in $\mathrm{CPLA}_{2} \alpha^{-/-}$mice is most likely due to lack of AA release and generation of one or more metabolites that mediate hypertensive effects of Ang II. Supporting this conclusion was our finding that Ang II infusion increased the urinary excretion of PGEM in $\mathrm{CPLA}_{2} \alpha^{+/+}$but not $\mathrm{CPLA}_{2} \alpha^{-/-}$mice.

The site of pro-hypertensive eicosanoids generated by $\mathrm{cPLA}_{2} \alpha$ that participate in Ang II-induced hypertension is not known. Since cPLA $2 \alpha$ is ubiquitously distributed in various tissues and eicosanoids generated from AA act locally, it is possible that eicosanoids generated at the site of action of Ang II including the cardiovascular, renal, brain and cells of the immune system, could contribute to Ang II-induced hypertension. 
Recently, it has been shown that Ang II by stimulating expression of (pro)renin receptor in the rat renal medulla through COX2-generated PGE2, via stimulation of EP4 receptors increases renin release that partly contributes to Ang II-induced hypertension. ${ }^{249}$ Also mice lacking macrophage 12/15 LOX have been shown to be resistant to L-NAME or DOCA-salt induced hypertension. ${ }^{250}$ Ang II is known to cause hypertension by increasing oxidative stress in subfornical organ (SFO) of circumventricular organs and via its projections to $\mathrm{PVN}$ and from there to the brain stem, finally resulting in increased sympathetic activity. ${ }^{251} \mathrm{cPLA}_{2} \alpha$ is also present in the brain ${ }^{7,204}$ and intracerebroventricular administration of PGE2 increases sympathetic nervous activity, vasopressin release and $\mathrm{BP} .{ }^{252}$ The demonstration that the effect of Ang II in increasing BP is mediated by activation of the EP1 receptor by PGE2, formed by COX-1 and not COX-2 in SFO, most likely by release of AA, suggests involvement of $\mathrm{CPLA}_{2}{ }^{253}$ Therefore, it is possible that Ang II-induced hypertension in our study could be mediated by activation of $\mathrm{cPLA}_{2} \alpha$ in the SFO as well as in the cardiovascular and renal systems. Moreover, it has been reported that Ang II-salt hypertension, which is associated with increased sympathetic activity and increased plasma levels of norepinephrine, are minimized by inhibitor of COX-1, SC560 but not nemsulide, an inhibitor of COX 2 suggesting that $\mathrm{COX}-1$ derived prostanoids by activating sympathetic nervous system increase BP ${ }^{254}$ The oxidative stress produced by Ang II in SFO is mediated by ER stress, and inhibitors of ER stress minimize Ang II-induced hypertension. ${ }^{225}$ Activation of $\mathrm{CPLA}_{2}$ is associated with increased ER stress. ${ }^{255}$ Inhibitors of ER stress reduce BP in spontaneously hypertensive rats and the effect of endothelial-derived contractile factors, by suppressing $\mathrm{H}_{2} \mathrm{O}_{2}$ production and expression of COX-1 and ERK $1 / 2$ and $\mathrm{CPLA}_{2}$ phosphorylation. ${ }^{256}$ However, our demonstration that $\mathrm{CPLA}_{2} \alpha$ gene disruption prevented the cardiac expression of ER stress markers $\mathrm{p} 58^{I P K}$ and CHOP suggests that Ang II also increases ER stress in the heart, but $\mathrm{CPLA}_{2} \alpha$ acts upstream of ER stress and NADPH oxidase activity, most likely by generating AA/metabolites. The effect of vasoactive agents, including Ang II, to promote influx of calcium and translocation of $\mathrm{CPLA}_{2} \alpha$ to the nuclear envelope/ER, ${ }^{257}$ the site of AA metabolizing enzymes (COX, LOX, and CYP P450), ${ }^{258-260}$ raises the possibility that $\mathrm{CPLA}_{2} \alpha$ via AA release and its metabolism by these enzymes might regulate generation of ER stress and ROS production. In support of this view, 12/15-LOX has been implicated in ER stress in adipocytes, pancreatic islets, and rat liver. ${ }^{259}$

The increased ROS generated by Ang II promotes cardiovascular remodeling by activating one or more signaling molecules. ${ }^{59}$ Our finding that Ang II-induced hypertension was associated with increased cardiac ERK1/2 and cSrc activity in ${ }_{\mathrm{CPLA}} \alpha^{+/+}$but not in $\mathrm{cPLA}_{2} \alpha^{-/-}$mice suggests that these signaling molecules are most likely activated by oxidative stress produced by $\mathrm{CPLA}_{2} \alpha$-generated AA metabolites, thus contributing to cardiovascular remodeling.

In conclusion, the present study provides the first evidence that the selective release of AA by $\mathrm{cPLA}_{2} \alpha$ is crucial for the development of Ang II-induced hypertension and associated cardiovascular pathophysiological changes including cardiovascular remodeling, increased vascular reactivity, endothelial dysfunction, and cardiac inflammation. These effects are most likely mediated by oxidative ${ }^{16,59,166}$ and ER 
stress $^{225,256}$ generated by AA metabolism ${ }^{259}$ and predominantly by pro-hypertensive eicosanoids resulting in activation of one or more signaling molecules including ERK1/2 and cSrc.

However, further studies using tissue specific knockout of $\mathrm{cPLA}_{2} \alpha$ and AA metabolizing enzymes would allow assessment of their relative contribution in various tissues to Ang II- and other models of hypertension and associated pathogenesis.

\subsection{Aim 2. To Investigate if $\mathrm{CPLA}_{2} \alpha$ Is Essential for Renal Dysfunction and End Organ Damage Associated with Ang II-Induced Hypertension}

This study demonstrated that $\mathrm{cPLA}_{2} \alpha$ that selectively stimulates release of AA from tissue lipids is indispensable for renal dysfunction, inflammation, and end organ damage associated with Ang II-induced hypertension, most likely as a result of increased production and/or action predominantly of pro-hypertensive eicosanoids and generation of ROS. Eicosanoids generated from AA released by $\mathrm{cPLA}_{2}$, in various structures of the kidney by their direct vascular, as well as tubular-glomerular actions, and, more importantly by modulating and/or mediating the actions of various neurohumoral agents contribute to renal anti- and pro-hypertensive mechanisms. ${ }^{126,127,243,244,261-265}$ This study showed that the net effect of eicosanoids that contribute to renal pro-hypertensive mechanism and associated renal dysfunction and end organ damage predominates over those that participate in anti-hypertensive mechanisms in Ang II-induced hypertension. Infusion of Ang II increased SBP in $\mathrm{CPLA}_{2} \alpha^{+/+}$, but not in $\mathrm{CPLA}_{2} \alpha^{-/}$, mice. In the present study, Ang II infusion also increased renal cPLA 2 activity, as indicated by its phosphorylation, without altering its expression in $\mathrm{cPLA}_{2} \alpha^{+/+}$, but not $\mathrm{cPLA}_{2} \alpha^{-/-}$mice. This observation together with the demonstration that Ang II increases urinary output of AA metabolites in $\mathrm{cPLA}_{2} \alpha^{+/+}$, but not $\mathrm{CPLA}_{2} \alpha^{-/-}$mice, and $\mathrm{cPLA}_{2} \alpha$ gene disruption also inhibits the basal, as well as furosemide-induced, increase in urinary PGE2 excretion, ${ }^{229}$ suggest that eicosanoids generated by Ang II in the kidney are most likely due to AA release consequent to activation of $\mathrm{cPLA}_{2} \alpha$.

It has been shown that $\mathrm{cPLA}_{2}$ gene disruption does not alter renal function as indicated by lack of changes in serum electrolyte or creatinine concentration, glomerular filtration rate, and fractional $\mathrm{Na}^{+}$or $\mathrm{K}^{+}$excretion compared to $\mathrm{CPLA}_{2}{ }^{+/+}$mice; however, cPLA $_{2}$ gene disruption produces concentration defect in older $\mathrm{cPLA}_{2}{ }^{-/-}$mice $(>45$ weeks). ${ }^{229}$ In the present study, cPLA 2 gene disruption alone did not alter renal function in 9 to 10 week old mice or cause any structural changes. However, in the present study Ang II-induced increase in renal arterial resistance and pulsatility observed in $\mathrm{CPLA}_{2} \alpha^{+/+}$ mice was prevented in $\mathrm{cPLA}_{2} \alpha^{-/-}$mice. These observations suggest that one or more AA metabolites predominantly with pro-hypertensive effects mediate the increase in renal vascular resistance caused by Ang II in $\mathrm{cPLA}_{2}{ }^{+/+}$mice. Supporting this view is the report that inhibitor of AA metabolism ETYA acid attenuates Ang II-induced renal vasoconstriction $^{266}$ and the COX product, PGE2, via activation of EP1 and EP3 receptor, and $\mathrm{PGH} 2$ and thromboxane $\mathrm{A} 2$ via thromboxane-prostanoid receptor, contributes to

pressor actions of Ang II. ${ }^{245}$ A recent study demonstrated Ang II-mediated activation of 
EP4 receptor via COX-2 derived PGE2 increases expression of (pro)renin receptor locally in rat renal medulla and increases medullary and urinary activity of renin that partly contributes to Ang II-induced hypertension. ${ }^{267}$ Products of AA generated via LOX (12-HETE) and cytochrome P450 4A (20-HETE) also mediate Ang II-induced renal vasoconstriction. ${ }^{248,268,269}$ In the present study, infusion of Ang II for 13 days in $\mathrm{cPLA}_{2} \alpha^{+/+}$mice also increased water intake, urine output, and glomerular filtration rate; decreased urinary osmolality; and caused proteinuria in $\mathrm{cPLA}_{2} \alpha^{+/+}$mice. Since all these effects of Ang II were minimized in $\mathrm{CPLA}_{2} \alpha^{-/-}$mice, they are most likely mediated by AA metabolites that contribute predominantly to pro-hypertensive mechanisms. The cPLA $_{2} \alpha$-dependent dipsogenic effect of Ang II could be mediated by the central actions of AA metabolite, Tx A2, because Tx A2 receptor blocker inhibits and Tx A2 receptor activation enhances the effect of intracerebroventricularly administered Ang II. ${ }^{270}$ Ang II stimulates the production of eicosanoids with both pro- and antihypertensive actions, and the balance between their vascular, as well as tubular actions, most likely maintain renal homeostasis. ${ }^{126,127,248,261-265,271}$ Therefore, it appears that renal dysfunction associated with Ang II-induced hypertension is primarily due to loss of predominantly those eicosanoids that contribute to pro- and not anti-hypertensive mechanisms. Since nonsteroidal antiinflammatory COX-2 inhibitors or COX gene disruption produce renal dysfunction and hypertension in mice on a high salt diet due to loss of anti-hypertensive and renoprotective effect of PGI $2,{ }^{271}$ further studies in $\mathrm{CPLA}_{2} \alpha^{-/-}$mice on low and high salt diets and other models of hypertension would allow assessment of the role of anti-hypertensive eicosanoids including PGI2 and EETs in renal function.

$\mathrm{cPLA}_{2} \alpha$ is also present in immune cells, and AA released by its activation is metabolized into eicosanoids with pro- and anti-inflammatory properties and is able to generate cytokines/chemokines, which regulate both innate and adaptive immune responses. ${ }^{272-277}$ In this study, infusion of Ang II for 13 days in CPLA $_{2} \alpha^{+/+}$mice caused inflammation as demonstrated by increased renal infiltration of $\mathrm{F} 4 / 80^{+}$macrophages and $\mathrm{CD} 3{ }^{+} \mathrm{T}$ lymphocytes and damage as indicated by renal accumulation of $\alpha$-smooth muscle actin, TGF $\beta$, and collagen. Our findings that Ang II infusion failed to produce these effects in $\mathrm{cPLA}_{2} \alpha^{-/-}$mice suggest that AA released by $\mathrm{cPLA}_{2} \alpha$ activation results in production of predominantly pro-hypertensive eicosanoids that stimulate infiltration of macrophages and $\mathrm{CD}^{+} \mathrm{T}$ lymphocytes in the kidney and promote production of cytokines/chemokines and inflammation and renal fibrosis.

The effect of $\mathrm{cPLA}_{2} \alpha$ gene disruption to minimize Ang II-induced renal dysfunction, renal damage, and inflammation without altering basal renal function suggests that $\mathrm{CPLA}_{2} \alpha$ activity and hence the amount of AA released under basal physiological conditions is low and does not appear to generate a sufficient amount of eicosanoids to affect renal function. Supporting this view, it has been shown that, although $\mathrm{cPLA}_{2}$ is constitutively active, it requires influx of extracellular calcium for its translocation to the nuclear envelope and phosphorylation by one or more kinase for its maximal activity to release AA. ${ }^{187,272}$ Several vasoactive agents that increase influx of extracellular calcium, including Ang II, increase cPLA 2 activity. ${ }^{10,11,278,279}$ In the present study, Ang II increased cPLA 2 activity in the kidney, as measured by its phosphorylation and as shown from the elevated urinary excretion of AA metabolite PGEM in 
$\mathrm{cPLA}_{2} \alpha^{+/+}$, but not $\mathrm{CPLA}_{2} \alpha^{-/-}$, mice. Therefore, the increase in PLA $_{2}$ activity observed in ischemia, ${ }^{204,280}$ diabetic nephropathy, ${ }^{281}$ glomerulonephritis, ${ }^{282}$ and polycystic kidney disease $^{283}$ is most likely due to associated increase in the activity of various vasoactive systems including the renin-angiotensin system. ${ }^{284-287}$ Increased levels of Ang II would result in increased calcium influx in various renal cell types, AA release, and generation of eicosanoids that favor renal pro-hypertensive mechanisms and contribute to renal dysfunction, inflammation, and end-organ damage.

The mechanism by which $\mathrm{cPLA}_{2} \alpha$ gene disruption minimizes Ang II-induced renal dysfunction, inflammation, and end-organ damage could be the consequence of decreased BP. ${ }^{288}$ The mechanical stretch and inflammation, which are associated with hypertension, promote aortic stiffening via activation of $\mathrm{p} 38 \mathrm{MAPK}{ }^{289}$ The mechanical stretch increases $\mathrm{Ca}^{2+}$ influx via stress-operated $\mathrm{Ca}^{2+}$ channels, which is known to increase $\mathrm{CPLA}_{2}$ activity and generation of eicosanoids, ${ }^{234}$ and metabolites of AA increase p38 MAPK activity. ${ }^{290}$ Therefore, it is possible that the effect of mechanical stretch caused by high BP on cardiovascular remodeling, activation of immune cells, and endorgan damage might be mediated in part by pro-hypertensive eicosanoids. However, Ang II also produces cardiovascular and renal pathophysiological changes independent of increased BP. ${ }^{232,233}$ In transgenic rats carrying both human renin and angiotensinogen genes, treatment with triple therapy (hydralazine, reserpine, and hydrochlorothiazide) prevented increased BP but not end organ damage, inflammation, or cellular growth in the kidney. ${ }^{233}$ Therefore, the protection against Ang II-induced renal dysfunction, inflammation, and damage could also result from a pressure-independent mechanism. ET has been implicated in Ang II-induced hypertension and some of its renal actions. ${ }^{267,291}$ However, in our study, ET was unlikely to mediate $\mathrm{cPLA}_{2} \alpha$-dependent actions of Ang II because it produced an equally insignificant increase in the plasma levels of ET in $\mathrm{cPLA}_{2} \alpha^{-/-}$and $\mathrm{cPLA}_{2} \alpha^{+/+}$mice.

Ang II is known to increase oxidative stress, activate immune cells that release cytokines, and promote inflammation that have been implicated in the development of hypertension and end organ damage. ${ }^{15,292,293}$ These finding that CPLA $_{2} \alpha$ gene disruption prevented Ang II-induced increase in NADPH oxidase activity, generation of ROS and TBARS, byproducts of lipid peroxidation in the kidney, suggest that ROS/lipid peroxides generated by renal and immune cells by AA most likely contribute to renal dysfunction, inflammation, and end organ damage. Supporting this view are the reports that a) monocytes/macrophages and T cells express cPLA $_{2} \alpha^{273}$ and NADPH oxidase, ${ }^{241,294,295}$ b) $\mathrm{AA}$ is required for activation of NADPH oxidase and generation of ROS in monocyte/macrophages and VSMCs, ${ }^{12,241,294}$ and c) ROS and/or one or more AA metabolites stimulate release of cytokines that promote inflammation. ${ }^{296,297}$

In conclusion, this study demonstrated that $\mathrm{CPLA}_{2} \alpha$ is essential for the development of renal dysfunction, inflammation, and end organ damage associated with Ang II-induced hypertension. AA released by $\mathrm{cPLA}_{2} \alpha$ activation by Ang II, most likely via generation of pro-hypertensive eicosanoids, and ROS/lipid peroxides promote renal dysfunction, activation of immune cells leading to inflammation, and end- organ damage. Therefore, $\mathrm{cPLA}_{2} \alpha$ could serve as a potential novel target for developing therapeutic 
agents for treating hypertension and associated renal dysfunction and end organ damage. Moreover, the development of water-soluble selective $\mathrm{CPLA}_{2} \alpha$ inhibitors would allow further assessment of its physiological and pathophysiological significance in kidney diseases and other models of hypertension 


\section{CHAPTER 6. CONCLUSION}

This study has demonstrated that $\mathrm{cPLA}_{2} \alpha$ is essential for the development of Ang II-induced hypertension and associated cardiovascular remodeling, cardiac and endothelial dysfunction, and increased vascular reactivity. Cardiac oxidative and ER stress and inflammation associated with Ang II-induced hypertension also depends on $\mathrm{cPLA}_{2} \alpha$. Ang II-induced cardiac dysfunction, remodeling, and inflammation that depend on $\mathrm{cPLA}_{2} \alpha$ are most likely mediated by ERK1/2 and cSrc. My study provides novel information on the mechanism of Ang II-induced hypertension and associated cardiovascular pathophysiological changes, whereby cPLA ${ }_{2} \alpha$-generated AA is crucial for Ang II-induced hypertension.

These findings also suggest that $\mathrm{cPLA}_{2} \alpha$ gene disruption in mice minimizes Ang II-induced increase in renal vascular resistance and renal dysfunction, inflammation, and end organ damage.cPLA ${ }_{2} \alpha$ gene disruption also prevents the effect of Ang II to increase renal NADPH oxidase activity, ROS, and TBARS production. $\mathrm{cPLA}_{2} \alpha$ plays a critical role in renal dysfunction, inflammation, and end-organ damage associated with Ang IIinduced hypertension, most likely as a result of release of AA and generation of prohypertensive eicosanoids and ROS/lipid peroxides.

This study and the work of other investigators that has been discussed in this dissertation has led us to propose the following mechanism of $\mathrm{CPLA}_{2} \alpha$ dependent Ang IIinduced hypertension and associated pathophysiology. (Figure 6.1) AA and or its metabolites generated via $\mathrm{cPLA}_{2} \alpha$, activates the immune system resulting in immune cell infiltration and inflammation in cardiovascular and renal tissues. Cytokines released by these infiltrating cells, results in elevation of BP and also ROS production. The metabolites of AA may also cause ER stress which is known to promote ROS production resulting in hypertension. ROS, via activation of second messenger systems, ERK1/2 and cSrc results in cardiovascular and renal hypertrophy and dysfunction promoting hypertension. Hypertension may in turn exacerbate end organ dysfunction and damage.

These observations raise the possibility that $\mathrm{cPLA}_{2} \alpha$ could serve as a target for developing novel therapeutic agents to treat hypertension and associated renal dysfunction and end organ damage. 


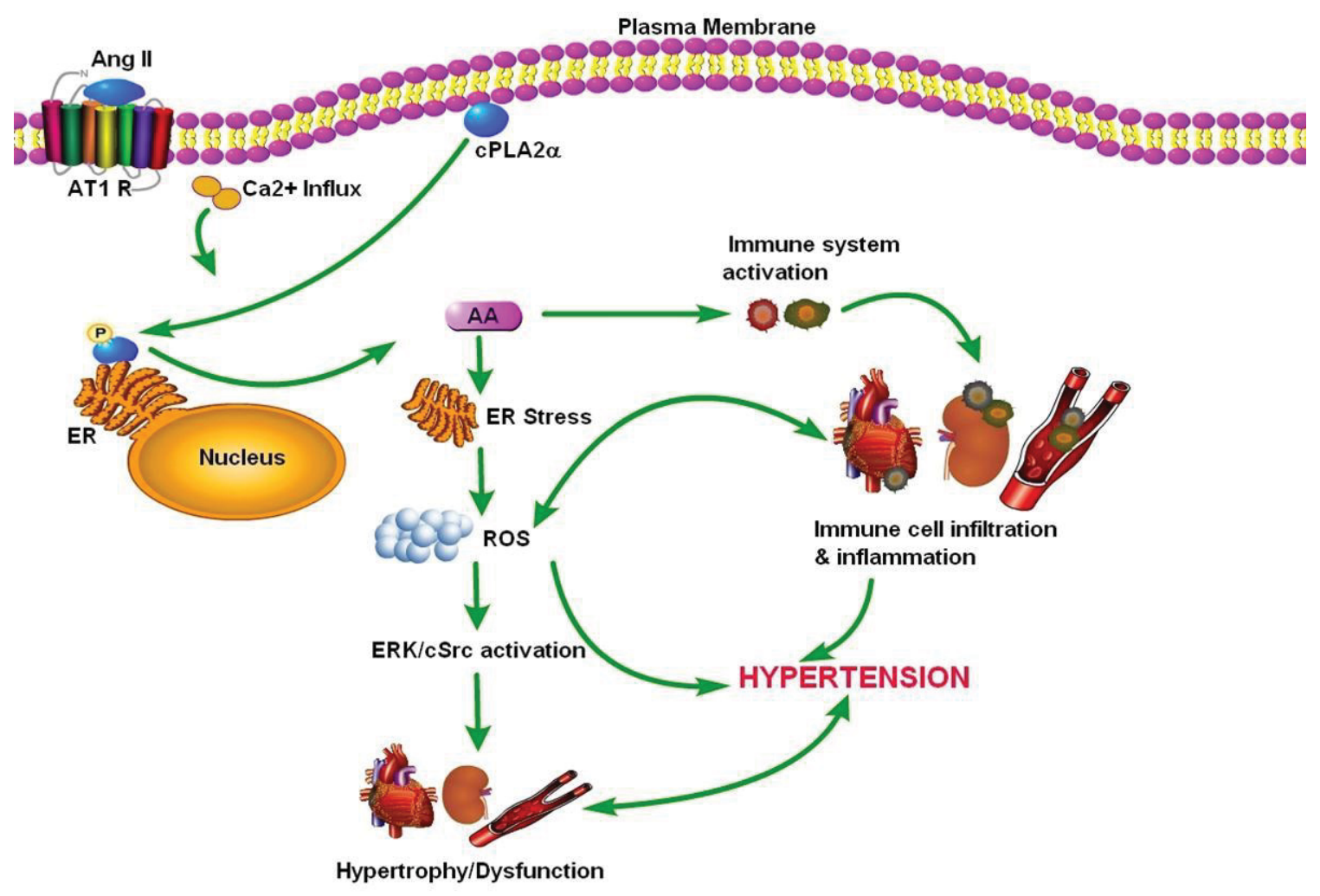

Figure 6.1 Proposed mechanism of $\mathrm{cPLA}_{2} \alpha$ dependent Ang II-induced hypertension and associated pathophysiology 


\section{LIST OF REFERENCES}

1. Members WG, Roger VL, Go AS, Lloyd-Jones DM, Benjamin EJ, Berry JD, Borden WB, Bravata DM, Dai S, Ford ES, Fox CS, Fullerton HJ, Gillespie C, Hailpern SM, Heit JA, Howard VJ, Kissela BM, Kittner SJ, Lackland DT, Lichtman JH, Lisabeth LD, Makuc DM, Marcus GM, Marelli A, Matchar DB, Moy CS, Mozaffarian D, Mussolino ME, Nichol G, Paynter NP, Soliman EZ, Sorlie PD, Sotoodehnia N, Turan TN, Virani SS, Wong ND, Woo D, Turner MB. Heart Disease and Stroke Statistics-2012 Update: A Report From the American Heart Association. Circulation 2012; 125(1): e2-e220.

2. Murakami M, Taketomi Y, Miki Y, Sato H, Hirabayashi T, Yamamoto K. Recent progress in phospholipase A(2) research: from cells to animals to humans. Prog Lipid Res 2011; 50(2): 152-192.

3. Leslie CC. Properties and Regulation of Cytosolic Phospholipase A2. Journal of Biological Chemistry 1997; 272(27): 16709-16712.

4. Hirabayashi T, Kume K, Hirose K, Yokomizo T, Iino M, Itoh H, Shimizu T. Critical duration of intracellular $\mathrm{Ca} 2+$ response required for continuous translocation and activation of cytosolic phospholipase A2. J Biol Chem 1999; 274(8): 5163-5169.

5. Hefner Y, Borsch-Haubold AG, Murakami M, Wilde JI, Pasquet S, Schieltz D, Ghomashchi F, Yates JR, 3rd, Armstrong CG, Paterson A, Cohen P, Fukunaga R, Hunter T, Kudo I, Watson SP, Gelb MH. Serine 727 phosphorylation and activation of cytosolic phospholipase A2 by MNK1-related protein kinases. $J$ Biol Chem 2000; 275(48): 37542-37551.

6. Muthalif MM, Hefner Y, Canaan S, Harper J, Zhou H, Parmentier JH, Aebersold $\mathrm{R}$, Gelb MH, Malik KU. Functional interaction of calcium-/calmodulin-dependent protein kinase II and cytosolic phospholipase A(2). J Biol Chem 2001; 276(43): 39653-39660.

7. Linkous A, Yazlovitskaya E. Cytosolic phospholipase A2 as a mediator of disease pathogenesis. Cell Microbiol 2010; 12(10): 1369-1377.

8. Kawaguchi H, Yasuda H. Increased phospholipase A2 activity in the kidney of spontaneously hypertensive rats. Arch Biochem Biophys 1986; 248(1): 401-407.

9. Tanaka K, Yamamoto Y, Ogino K, Tsujimoto S, Saito M, Uozumi N, Shimizu T, Hisatome I. Cytosolic phospholipase A2alpha contributes to blood pressure increases and endothelial dysfunction under chronic NO inhibition. Arterioscler Thromb Vasc Biol 2011; 31(5): 1133-1138. 
10. Muthalif MM, Benter IF, Uddin MR, Harper JL, Malik KU. Signal Transduction Mechanisms Involved in Angiotensin-(1-7)-Stimulated Arachidonic Acid Release and Prostanoid Synthesis in Rabbit Aortic Smooth Muscle Cells. Journal of Pharmacology and Experimental Therapeutics 1998; 284(1):388-398.

11. Muthalif MM, Benter IF, Uddin MR, Malik KU. Calcium/Calmodulin-dependent Protein Kinase II $\alpha$ Mediates Activation of Mitogen-activated Protein Kinase and Cytosolic Phospholipase A2 in Norepinephrine-induced Arachidonic Acid Release in Rabbit Aortic Smooth Muscle Cells. Journal of Biological Chemistry 1996; 271(47): 30149-30157.

12. Yaghini FA, Song CY, Lavrentyev EN, Ghafoor HU, Fang XR, Estes AM, Campbell WB, Malik KU. Angiotensin II-induced vascular smooth muscle cell migration and growth are mediated by cytochrome P450 1B1-dependent superoxide generation. Hypertension 2010; 55(6): 1461-1467.

13. Jennings BL, Anderson LJ, Estes AM, Yaghini FA, Fang XR, Porter J, Gonzalez FJ, Campbell WB, Malik KU. Cytochrome P450 1B1 contributes to renal dysfunction and damage caused by angiotensin II in mice. Hypertension 2012; 59(2): 348-354.

14. Jennings BL, Sahan-Firat S, Estes AM, Das K, Farjana N, Fang XR, Gonzalez FJ, Malik KU. Cytochrome P450 1B1 contributes to angiotensin II-induced hypertension and associated pathophysiology. Hypertension 2010; 56(4): 667674.

15. Harrison DG, Guzik TJ, Lob HE, Madhur MS, Marvar PJ, Thabet SR, Vinh A, Weyand CM. Inflammation, immunity, and hypertension. Hypertension 2011; 57(2): 132-140.

16. Rajagopalan S, Kurz S, Munzel T, Tarpey M, Freeman BA, Griendling KK, Harrison DG. Angiotensin II-mediated hypertension in the rat increases vascular superoxide production via membrane NADH/NADPH oxidase activation. Contribution to alterations of vasomotor tone. J Clin Invest 1996; 97(8): 19161923.

17. Xu H, Fink GD, Galligan JJ. Nitric oxide-independent effects of tempol on sympathetic nerve activity and blood pressure in DOCA-salt rats. Am J Physiol Heart Circ Physiol 2002; 283(3): H885-892.

18. Kamiya A, Michikami D, Fu Q, Niimi Y, Iwase S, Mano T, Suzumura A. Static handgrip exercise modifies arterial baroreflex control of vascular sympathetic outflow in humans. Am J Physiol Regul Integr Comp Physiol 2001; 281(4): R1134-1139. 
19. Thrasher TN, Chen HG, Keil LC. Arterial baroreceptors control plasma vasopressin responses to graded hypotension in conscious dogs. Am J Physiol Regul Integr Comp Physiol 2000; 278(2): R469-475.

20. Morrison SF, Cao WH. Different adrenal sympathetic preganglionic neurons regulate epinephrine and norepinephrine secretion. Am J Physiol Regul Integr Comp Physiol 2000; 279(5): R1763-1775.

21. Zhang J, Mifflin SW. Subthreshold aortic nerve inputs to neurons in nucleus of the solitary tract. Am J Physiol Regul Integr Comp Physiol 2000; 278(6): R15951604.

22. Stauss HM. Baroreceptor reflex function. Am J Physiol Regul Integr Comp Physiol 2002; 283(2): R284-286.

23. Barman SM, Gebber GL, Orer HS. Medullary lateral tegmental field: an important source of basal sympathetic nerve discharge in the cat. Am J Physiol Regul Integr Comp Physiol 2000; 278(4): R995-R1004.

24. Gebber GL, Zhong S, Lewis C, Barman SM. Defenselike patterns of spinal sympathetic outflow involving the $10-\mathrm{Hz}$ and cardiac-related rhythms. Am J Physiol Regul Integr Comp Physiol 2000; 278(6): R1616-1626.

25. Mayorov DN, Head GA. Influence of rostral ventrolateral medulla on renal sympathetic baroreflex in conscious rabbits. Am J Physiol Regul Integr Comp Physiol 2001; 280(2): R577-587.

26. Farah VM, Moreira ED, Irigoyen MC, Krieger EM. Baroreflex depression persists in the early phase after hypertension reversal. Am J Physiol Regul Integr Comp Physiol 2001; 280(6): R1620-1626.

27. Rector DM, Richard CA, Staba RJ, Harper RM. Sleep states alter ventral medullary surface responses to blood pressure challenges. Am J Physiol Regul Integr Comp Physiol 2000; 278(4): R1090-1098.

28. Irigoyen MC, Moreira ED, Werner A, Ida F, Pires MD, Cestari IA, Krieger EM. Aging and baroreflex control of RSNA and heart rate in rats. Am J Physiol Regul Integr Comp Physiol 2000; 279(5): R1865-1871.

29. Massett MP, Lewis SJ, Stauss HM, Kregel KC. Vascular reactivity and baroreflex function during hyperthermia in conscious rats. Am J Physiol Regul Integr Comp Physiol 2000; 279(4): R1282-1289.

30. Hines T. Baroreceptor afferent discharge in the pregnant rat. Am J Physiol Regul Integr Comp Physiol 2000; 278(6): R1433-1440. 
31. Abboud FM. The sympathetic system in hypertension. State-of-the-art review. Hypertension 1982; 4(3 Pt 2): 208-225.

32. Piepho RW, Beal J. An overview of antihypertensive therapy in the 20th century. J Clin Pharmacol 2000; 40(9): 967-977.

33. Ferrario CM. Role of angiotensin II in cardiovascular disease therapeutic implications of more than a century of research. J Renin Angiotensin Aldosterone Syst 2006; 7(1): 3-14.

34. Skeggs LT, Jr., Kahn JR, Lentz K, Shumway NP. The preparation, purification, and amino acid sequence of a polypeptide renin substrate. $J$ Exp Med 1957;

106(3): 439-453.

35. Laragh JH, Sealey JE. Renin-Angiotensin-Aldosterone System and the Renal Regulation of Sodium, Potassium, and Blood Pressure Homeostasis. In, Comprehensive Physiology. John Wiley \& Sons, Inc., 2010.

36. Atlas SA. The renin-angiotensin aldosterone system: pathophysiological role and pharmacologic inhibition. J Manag Care Pharm 2007; 13(8 Suppl B): 9-20.

37. Brown MJ. Direct renin inhibition - a new way of targeting the renin system. Journal of Renin-Angiotensin-Aldosterone System 2006; 7(2 suppl): S7-S11.

38. Carey RM, Siragy HM. Newly recognized components of the renin-angiotensin system: potential roles in cardiovascular and renal regulation. Endocr Rev 2003; 24(3): 261-271.

39. Conti S, Cassis P, Benigni A. Aging and the Renin-Angiotensin System. Hypertension 2012; 60(4): 878-883.

40. Reudelhuber TL. The renin-angiotensin system: peptides and enzymes beyond angiotensin II. Curr Opin Nephrol Hypertens 2005; 14(2): 155-159.

41. Stanton A. Therapeutic potential of renin inhibitors in the management of cardiovascular disorders. Am J Cardiovasc Drugs 2003; 3(6): 389-394.

42. Danilczyk U, Penninger JM. Angiotensin-Converting Enzyme II in the Heart and the Kidney. Circ Res 2006; 98(4): 463-471.

43. Carey RM, Wang Z-Q, Siragy HM. Role of the Angiotensin Type 2 Receptor in the Regulation of Blood Pressure and Renal Function. Hypertension 2000; 35(1): 155-163. 
44. Higuchi S, Ohtsu H, Suzuki H, Shirai H, Frank GD, Eguchi S. Angiotensin II signal transduction through the AT1 receptor: novel insights into mechanisms and pathophysiology. Clinical Science 2007; 112(8): 417-428.

45. de Gasparo M, Catt KJ, Inagami T, Wright JW, Unger T. International union of pharmacology. XXIII. The angiotensin II receptors. Pharmacol Rev 2000; 52(3): 415-472.

46. Nickenig G, Jung O, Strehlow K, Zolk O, Linz W, Scholkens BA, Bohm M. Hypercholesterolemia is associated with enhanced angiotensin AT1-receptor expression. Am J Physiol 1997; 272(6 Pt 2): H2701-2707.

47. Banday AA, Siddiqui AH, Menezes MM, Hussain T. Insulin treatment enhances AT1 receptor function in OK cells. Am J Physiol Renal Physiol 2005; 288(6): 15.

48. Griendling KK, Ushio-Fukai M, Lassegue B, Alexander RW. Angiotensin II signaling in vascular smooth muscle. New concepts. Hypertension. 1997 Jan;29(1 Pt 2):366-73.

49. Eguchi S, Frank GD, Mifune M, Inagami T. Metalloprotease-dependent ErbB ligand shedding in mediating EGFR transactivation and vascular remodelling. Biochem Soc Trans 2003; 31(Pt 6): 1198-1202.

50. Yin G, Yan C, Berk BC. Angiotensin II signaling pathways mediated by tyrosine kinases. Int J Biochem Cell Biol 2003; 35(6): 780-783.

51. Suzuki H, Motley ED, Frank GD, Utsunomiya H, Eguchi S. Recent progress in signal transduction research of the angiotensin II type-1 receptor: protein kinases, vascular dysfunction and structural requirement. Curr Med Chem Cardiovasc Hematol Agents 2005; 3(4): 305-322.

52. Yan C, Kim D, Aizawa T, Berk BC. Functional interplay between angiotensin II and nitric oxide: cyclic GMP as a key mediator. Arterioscler Thromb Vasc Biol 2003; 23(1): 26-36.

53. Touyz RM, Schiffrin EL. Signal transduction mechanisms mediating the physiological and pathophysiological actions of angiotensin II in vascular smooth muscle cells. Pharmacol Rev 2000; 52(4): 639-672.

54. Seshiah PN, Weber DS, Rocic P, Valppu L, Taniyama Y, Griendling KK. Angiotensin II stimulation of $\mathrm{NAD}(\mathrm{P}) \mathrm{H}$ oxidase activity: upstream mediators. Circ Res 2002; 91(5): 406-413. 
55. Touyz RM, Yao G, Quinn MT, Pagano PJ, Schiffrin EL. p47phox associates with the cytoskeleton through cortactin in human vascular smooth muscle cells: role in NAD(P)H oxidase regulation by angiotensin II. Arterioscler Thromb Vasc Biol 2005; 25(3): 512-518.

56. Gryglewski RJ, Palmer RM, Moncada S. Superoxide anion is involved in the breakdown of endothelium-derived vascular relaxing factor. Nature 1986; 320(6061): 454-456.

57. Rubanyi GM, Vanhoutte PM. Superoxide anions and hyperoxia inactivate endothelium-derived relaxing factor. Am J Physiol 1986; 250 (5 Pt 2): H822-827.

58. Marui N, Offermann MK, Swerlick R, Kunsch C, Rosen CA, Ahmad M, Alexander RW, Medford RM. Vascular cell adhesion molecule-1 (VCAM-1) gene transcription and expression are regulated through an antioxidant-sensitive mechanism in human vascular endothelial cells. J Clin Invest 1993; 92(4): 18661874.

59. Mehta PK, Griendling KK. Angiotensin II cell signaling: physiological and pathological effects in the cardiovascular system. Am J Physiol Cell Physiol 2007; 292(1): C82-97.

60. Sugden PH, Clerk A. Regulation of the ERK subgroup of MAP kinase cascades through G protein-coupled receptors. Cell Signal 1997; 9(5): 337-351.

61. Taniyama Y, Ushio-Fukai M, Hitomi H, Rocic P, Kingsley MJ, Pfahnl C, Weber DS, Alexander RW, Griendling KK. Role of p38 MAPK and MAPKAPK-2 in angiotensin II-induced Akt activation in vascular smooth muscle cells. Am J Physiol Cell Physiol 2004; 287(2): 14.

62. Touyz RM, He G, Deng LY, Schiffrin EL. Role of extracellular signal-regulated kinases in angiotensin II-stimulated contraction of smooth muscle cells from human resistance arteries. Circulation 1999; 99(3): 392-399.

63. Allen RT, Krueger KD, Dhume A, Agrawal DK. Sustained Akt/PKB activation and transient attenuation of c-jun $\mathrm{N}$-terminal kinase in the inhibition of apoptosis by IGF-1 in vascular smooth muscle cells. Apoptosis 2005; 10(3): 525-535.

64. Lim SY, Kim YS, Ahn Y, Jeong MH, Hong MH, Joo SY, Nam KI, Cho JG, Kang PM, Park JC. The effects of mesenchymal stem cells transduced with Akt in a porcine myocardial infarction model. Cardiovasc Res 2006; 70(3): 530-542.

65. Nishimura K, Li W, Hoshino Y, Kadohama T, Asada H, Ohgi S, Sumpio BE. Role of AKT in cyclic strain-induced endothelial cell proliferation and survival. Am J Physiol Cell Physiol 2006; 290(3): C812-821. 
66. Rocic P, Jo H, Lucchesi PA. A role for PYK2 in ANG II-dependent regulation of the PHAS-1-eIF4E complex by multiple signaling cascades in vascular smooth muscle. Am J Physiol Cell Physiol 2003; 285(6): 30.

67. Touyz RM. Reactive oxygen species and angiotensin II signaling in vascular cells -- implications in cardiovascular disease. Braz J Med Biol Res 2004; 37(8): 1263 1273.

68. Ishida M, Ishida T, Thomas SM, Berk BC. Activation of extracellular signalregulated kinases (ERK1/2) by angiotensin II is dependent on c-Src in vascular smooth muscle cells. Circ Res 1998; 82(1): 7-12.

69. Touyz RM, Yao G, Viel E, Amiri F, Schiffrin EL. Angiotensin II and endothelin1 regulate MAP kinases through different redox-dependent mechanisms in human vascular smooth muscle cells. J Hypertens 2004; 22(6): 1141-1149.

70. Sabri A, Govindarajan G, Griffin TM, Byron KL, Samarel AM, Lucchesi PA. Calcium- and protein kinase C-dependent activation of the tyrosine kinase PYK2 by angiotensin II in vascular smooth muscle. Circ Res 1998; 83(8): 841-851.

71. Ishida T, Ishida M, Suero J, Takahashi M, Berk BC. Agonist-stimulated cytoskeletal reorganization and signal transduction at focal adhesions in vascular smooth muscle cells require c-Src. J Clin Invest 1999; 103(6): 789-797.

72. Kyriakis JM, Avruch J. Mammalian mitogen-activated protein kinase signal transduction pathways activated by stress and inflammation. Physiol Rev 2001; 81(2): 807-869.

73. Li C, Hu Y, Sturm G, Wick G, Xu Q. Ras/Rac-Dependent activation of p38 mitogen-activated protein kinases in smooth muscle cells stimulated by cyclic strain stress. Arterioscler Thromb Vasc Biol 2000; 20(3): E1-9.

74. Bilato C, Pauly RR, Melillo G, Monticone R, Gorelick-Feldman D, Gluzband YA, Sollott SJ, Ziman B, Lakatta EG, Crow MT. Intracellular signaling pathways required for rat vascular smooth muscle cell migration. Interactions between basic fibroblast growth factor and platelet-derived growth factor. J Clin Invest 1995; 96(4): 1905-1915.

75. Linseman DA, Benjamin CW, Jones DA. Convergence of angiotensin II and platelet-derived growth factor receptor signaling cascades in vascular smooth muscle cells. J Biol Chem 1995; 270(21): 12563-12568.

76. Hollenberg MD. Tyrosine kinase pathways and the regulation of smooth muscle contractility. Trends Pharmacol Sci 1994; 15(4): 108-114. 
77. Ushio-Fukai M, Griendling KK, Becker PL, Hilenski L, Halleran S, Alexander RW. Epidermal growth factor receptor transactivation by angiotensin II requires reactive oxygen species in vascular smooth muscle cells. Arterioscler Thromb Vasc Biol 2001; 21(4): 489-495.

78. Prenzel N, Zwick E, Daub H, Leserer M, Abraham R, Wallasch C, Ullrich A. EGF receptor transactivation by G-protein-coupled receptors requires metalloproteinase cleavage of proHB-EGF. Nature 1999; 402(6764): 884-888.

79. Kagiyama S, Eguchi S, Frank GD, Inagami T, Zhang YC, Phillips MI. Angiotensin II-induced cardiac hypertrophy and hypertension are attenuated by epidermal growth factor receptor antisense. Circulation 2002; 106(8): 909-912.

80. Hall JE, Granger JP, do Carmo JM, da Silva AA, Dubinion J, George E, Hamza S, Speed J, Hall ME. Hypertension: Physiology and Pathophysiology. In, Comprehensive Physiology. John Wiley \& Sons, Inc., 2012.

81. Hall JE. Control of sodium excretion by angiotensin II: intrarenal mechanisms and blood pressure regulation. Am J Physiol 1986; 250(6 Pt 2): R960-972.

82. Hall JE, Brands MW, Henegar JR. Angiotensin II and long-term arterial pressure regulation: the overriding dominance of the kidney. J Am Soc Nephrol 1999;

10(12): S258-265.

83. John EH, Joey PG. Regulation of Fluid and Electrolyte Balance in Hypertension. In, Hypertension. CRC Press, 2005, pp 121-141.

84. Vinay Kumar AKA, Jon C. Aster, Nelson Fausto. Robbins \& Cotran Pathologic Basis of Disease, 8th edn. Saunders, 2009,page 496.

85. Calhoun DA, Nishizaka MK, Zaman MA, Thakkar RB, Weissmann P. Hyperaldosteronism among black and white subjects with resistant hypertension. Hypertension 2002; 40(6): 892-896.

86. Fuller PJ, Young MJ. Mechanisms of mineralocorticoid action. Hypertension 2005; 46(6): 1227-1235.

87. Funder JW. Reconsidering the roles of the mineralocorticoid receptor. Hypertension 2009; 53(2): 286-290.

88. Kohan DE. The renal medullary endothelin system in control of sodium and water excretion and systemic blood pressure. Curr Opin Nephrol Hypertens 2006; 15(1): 34-40.

89. Schiffrin EL. Vascular endothelin in hypertension. Vascul Pharmacol 2005; 43(1): 19-29. 
90. Gariepy CE, Ohuchi T, Williams SC, Richardson JA, Yanagisawa M. Saltsensitive hypertension in endothelin-B receptor-deficient rats. J Clin Invest 2000; 105(7): 925-933.

91. Quaschning T, Rebhan B, Wunderlich C, Wanner C, Richter CM, Pfab T, Bauer C, Kraemer-Guth A, Galle J, Yanagisawa M, Hocher B. Endothelin B receptordeficient mice develop endothelial dysfunction independently of salt loading. $J$ Hypertens 2005; 23(5): 979-985.

92. Taniyama Y, Griendling KK. Reactive oxygen species in the vasculature: molecular and cellular mechanisms. Hypertension 2003; 42(6): 1075-1081.

93. Harrison DG, Widder J, Grumbach I, Chen W, Weber M, Searles C. Endothelial mechanotransduction, nitric oxide and vascular inflammation. J Intern Med 2006; 259(4): 351-363.

94. Touyz RM. Molecular and cellular mechanisms in vascular injury in hypertension: role of angiotensin II. Curr Opin Nephrol Hypertens 2005; 14(2): 125-131.

95. Mueller CF, Laude K, McNally JS, Harrison DG. ATVB in focus: redox mechanisms in blood vessels. Arterioscler Thromb Vasc Biol 2005; 25(2): 274278.

96. Fukui T, Ishizaka N, Rajagopalan S, Laursen JB, Capers Qt, Taylor WR, Harrison DG, de Leon H, Wilcox JN, Griendling KK. p22phox mRNA expression and NADPH oxidase activity are increased in aortas from hypertensive rats. Circ Res 1997; 80(1): 45-51.

97. Virdis A, Neves MF, Amiri F, Touyz RM, Schiffrin EL. Role of NAD(P)H oxidase on vascular alterations in angiotensin II-infused mice. J Hypertens 2004; 22(3): 535-542.

98. Landmesser U, Cai H, Dikalov S, McCann L, Hwang J, Jo H, Holland SM, Harrison DG. Role of p47(phox) in vascular oxidative stress and hypertension caused by angiotensin II. Hypertension 2002; 40(4): 511-515.

99. Babior BM. NADPH oxidase. Curr Opin Immunol 2004; 16(1): 42-47.

100. Chabrashvili T, Tojo A, Onozato ML, Kitiyakara C, Quinn MT, Fujita T, Welch WJ, Wilcox CS. Expression and cellular localization of classic NADPH oxidase subunits in the spontaneously hypertensive rat kidney. Hypertension 2002; 39(2): 269-274.

101. Kitiyakara C, Wilcox CS. Antioxidants for hypertension. Curr Opin Nephrol Hypertens 1998; 7(5): 531-538. 
102. Houston MC. Nutraceuticals, vitamins, antioxidants, and minerals in the prevention and treatment of hypertension. Prog Cardiovasc Dis 2005; 47(6): 396449.

103. Touyz RM, Schiffrin EL. Reactive oxygen species in vascular biology: implications in hypertension. Histochem Cell Biol 2004; 122(4): 339-352.

104. Welch WJ. Intrarenal oxygen and hypertension. Clin Exp Pharmacol Physiol 2006; 33(10): 1002-1005.

105. Redon J, Oliva MR, Tormos C, Giner V, Chaves J, Iradi A, Saez GT. Antioxidant activities and oxidative stress byproducts in human hypertension. Hypertension 2003; 41(5): 1096-1101.

106. Li JM, Wheatcroft S, Fan LM, Kearney MT, Shah AM. Opposing roles of p47phox in basal versus angiotensin II-stimulated alterations in vascular O2production, vascular tone, and mitogen-activated protein kinase activation. Circulation 2004; 109(10): 1307-1313.

107. Jung O, Schreiber JG, Geiger H, Pedrazzini T, Busse R, Brandes RP. gp91phoxcontaining NADPH oxidase mediates endothelial dysfunction in renovascular hypertension. Circulation 2004; 109(14): 1795-1801.

108. Modlinger P, Chabrashvili T, Gill PS, Mendonca M, Harrison DG, Griendling KK, Li M, Raggio J, Wellstein A, Chen Y, Welch WJ, Wilcox CS. RNA silencing in vivo reveals role of $\mathrm{p} 22 \mathrm{phox}$ in rat angiotensin slow pressor response. Hypertension 2006; 47(2): 238-244.

109. Laude K, Cai H, Fink B, Hoch N, Weber DS, McCann L, Kojda G, Fukai T, Schmidt HH, Dikalov S, Ramasamy S, Gamez G, Griendling KK, Harrison DG. Hemodynamic and biochemical adaptations to vascular smooth muscle overexpression of p22phox in mice. Am J Physiol Heart Circ Physiol 2005; 288(1): 7 .

110. Luscher TF, Raij L, Vanhoutte PM. Endothelium-dependent vascular responses in normotensive and hypertensive Dahl rats. Hypertension 1987; 9(2): 157-163.

111. Luscher TF, Vanhoutte PM. Endothelium-dependent contractions to acetylcholine in the aorta of the spontaneously hypertensive rat. Hypertension 1986; 8(4): 344348.

112. Endemann DH, Schiffrin EL. Endothelial dysfunction. J Am Soc Nephrol 2004; 15(8): 1983-1992. 
113. Huang PL, Huang Z, Mashimo H, Bloch KD, Moskowitz MA, Bevan JA, Fishman MC. Hypertension in mice lacking the gene for endothelial nitric oxide synthase. Nature 1995; 377(6546): 239-242.

114. Arnal JF, el Amrani AI, Chatellier G, Menard J, Michel JB. Cardiac weight in hypertension induced by nitric oxide synthase blockade. Hypertension 1993; 22(3): 380-387.

115. Podjarny E, Hasdan G, Bernheim J, Rashid G, Green J, Korzets Z. Effect of chronic tetrahydrobiopterin supplementation on blood pressure and proteinuria in 5/6 nephrectomized rats. Nephrol Dial Transplant 2004; 19(9): 2223-2227.

116. Fortepiani LA, Reckelhoff JF. Treatment with tetrahydrobiopterin reduces blood pressure in male SHR by reducing testosterone synthesis. Am J Physiol Regul Integr Comp Physiol 2005; 288(3): 16.

117. Shinozaki K, Nishio Y, Okamura T, Yoshida Y, Maegawa H, Kojima H, Masada M, Toda N, Kikkawa R, Kashiwagi A. Oral administration of tetrahydrobiopterin prevents endothelial dysfunction and vascular oxidative stress in the aortas of insulin-resistant rats. Circ Res 2000; 87(7): 566-573.

118. Ihlemann N, Rask-Madsen C, Perner A, Dominguez H, Hermann T, Kober L, Torp-Pedersen C. Tetrahydrobiopterin restores endothelial dysfunction induced by an oral glucose challenge in healthy subjects. Am J Physiol Heart Circ Physiol 2003; 285(2): 1 .

119. McEniery CM, Schmitt M, Qasem A, Webb DJ, Avolio AP, Wilkinson IB, Cockcroft JR. Nebivolol increases arterial distensibility in vivo. Hypertension 2004; 44(3): 305-310.

120. Cai H, Harrison DG. Endothelial dysfunction in cardiovascular diseases: the role of oxidant stress. Circ Res 2000; 87(10): 840-844.

121. Dzau VJ. Theodore Cooper Lecture: Tissue angiotensin and pathobiology of vascular disease: a unifying hypothesis. Hypertension. 2001 Apr;37(4):1047-52.

122. Alexander RW. Theodore Cooper Memorial Lecture. Hypertension and the pathogenesis of atherosclerosis. Oxidative stress and the mediation of arterial inflammatory response: a new perspective. Hypertension 1995; 25(2): 155-161.

123. Schulman IH, Zhou MS, Raij L. Nitric oxide, angiotensin II, and reactive oxygen species in hypertension and atherogenesis. Curr Hypertens Rep 2005; 7(1): 61-67.

124. Perticone F, Ceravolo R, Candigliota M, Ventura G, Iacopino S, Sinopoli F, Mattioli PL. Obesity and body fat distribution induce endothelial dysfunction by oxidative stress: protective effect of vitamin C. Diabetes 2001; 50(1): 159-165. 
125. Taddei S, Virdis A, Ghiadoni L, Magagna A, Salvetti A. Vitamin C improves endothelium-dependent vasodilation by restoring nitric oxide activity in essential hypertension. Circulation 1998; 97(22): 2222-2229.

126. McGiff JC. Prostaglandins, prostacyclin, and thromboxanes. Annu Rev Pharmacol Toxicol 1981; 21: 479-509.

127. Nasjletti A. Arthur C. Corcoran Memorial Lecture. The role of eicosanoids in angiotensin-dependent hypertension. Hypertension. 1998 Jan;31(1 Pt 2):194-200.

128. McGiff JC, Quilley J. 20-hydroxyeicosatetraenoic acid and epoxyeicosatrienoic acids and blood pressure. Curr Opin Nephrol Hypertens 2001; 10(2): 231-237.

129. Chawengsub Y, Gauthier KM, Campbell WB. Role of arachidonic acid lipoxygenase metabolites in the regulation of vascular tone. Am J Physiol Heart Circ Physiol 2009; 297(2): 12.

130. Imig JD, Hammock BD. Soluble epoxide hydrolase as a therapeutic target for cardiovascular diseases. Nat Rev Drug Discov 2009; 8(10): 794-805.

131. Miller MJS QJ, McGiff JC. Eicosanoid-dependent mechanisms and the regulation of blood pressure. Amsterdam, Netherlands: Elsevier Science Publishers BV, 1986.

132. Mistry M, Nasjletti A. Prostanoids as mediators of prohypertensive and antihypertensive mechanisms. Am J Med Sci 1988; 295(4): 263-267.

133. Carmines PK, Bell PD, Roman RJ, Work J, Navar LG. Prostaglandins in the sodium excretory response to altered renal arterial pressure in dogs. Am J Physiol 1985; 248(1 Pt 2): F8-14.

134. Romero JC, Strong CG. The effect of indomethacin blockade of prostaglandin synthesis on blood pressure of normal rabbits and rabbits with renovascular hypertension. Circ Res 1977; 40(1): 35-41.

135. Diz DI, Baer PG, Nasjletti A. Angiotensin II-induced hypertension in the rat. Effects on the plasma concentration, renal excretion, and tissue release of prostaglandins. J Clin Invest 1983; 72(2): 466-477.

136. Henrich WL. Role of prostaglandins in renin secretion. Kidney Int 1981; 19(6): 822-830.

137. Jackson EK, Oates JA, Branch RA. Indomethacin decreases arterial blood pressure and plasma renin activity in rats with aortic ligation. Circ Res 1981; 49(1): 180-185. 
138. Vanhoutte PM. Endothelium and control of vascular function. State of the Art lecture. Hypertension 1989; 13(6 Pt 2): 658-667.

139. Welch WJ AN, and Wilcox CS. Mechanism of hypertension during prolonged infusion of thromboxane mimetic. Eur J Int Med 1992; 2: 277-280.

140. Himmelstein SI, Klotman PE. The role of thromboxane in two-kidney, one-clip Goldblatt hypertension in rats. Am J Physiol 1989; 257(2 Pt 2): F190-196.

141. Keen HL, Brands MW, Smith MJ, Jr., Shek EW, Hall JE. Thromboxane is required for full expression of angiotensin hypertension in rats. Hypertension 1997; 29(1 Pt 2): 310-314.

142. Funk CD, Cyrus T. 12/15-lipoxygenase, oxidative modification of LDL and atherogenesis. Trends Cardiovasc Med 2001; 11(3-4): 116-124.

143. Kuhn H, Chaitidis P, Roffeis J, Walther M. Arachidonic Acid metabolites in the cardiovascular system: the role of lipoxygenase isoforms in atherogenesis with particular emphasis on vascular remodeling. J Cardiovasc Pharmacol 2007; 50(6): 609-620.

144. Stern N, Nozawa K, Kisch E, Tuck ML, Golub M, Eggena P, Knoll E. Tonic inhibition of renin secretion by the 12 lipoxygenase pathway: augmentation by high salt intake. Endocrinology 1996; 137(5): 1878-1884.

145. Lin L, Balazy M, Pagano PJ, Nasjletti A. Expression of prostaglandin H2mediated mechanism of vascular contraction in hypertensive rats. Relation to lipoxygenase and prostacyclin synthase activities. Circ Res 1994; 74(2): 197-205.

146. Salmon JA, Smith DR, Flower RJ, Moncada S, Vane JR. Further studies on the enzymatic conversion of prostaglandin endoperoxide into prostacyclin by porcine aorta microsomes. Biochim Biophys Acta 1978; 523(1): 250-262.

147. Stern N, Golub M, Nozawa K, Berger M, Knoll E, Yanagawa N, Natarajan R, Nadler JL, Tuck ML. Selective inhibition of angiotensin II-mediated vasoconstriction by lipoxygenase blockade. Am J Physiol 1989; 257(2 Pt 2): H434-443.

148. Stern N, Nozawa K, Golub M, Eggena P, Knoll E, Tuck ML. The lipoxygenase inhibitor phenidone is a potent hypotensive agent in the spontaneously hypertensive rat. Am J Hypertens 1993; 6(1): 52-58.

149. Natarajan R, Gu JL, Rossi J, Gonzales N, Lanting L, Xu L, Nadler J. Elevated glucose and angiotensin II increase 12-lipoxygenase activity and expression in porcine aortic smooth muscle cells. Proc Natl Acad Sci U S A 1993; 90(11): 4947-4951. 
150. Nozawa K, Tuck ML, Golub M, Eggena P, Nadler JL, Stern N. Inhibition of lipoxygenase pathway reduces blood pressure in renovascular hypertensive rats. Am J Physiol 1990; 259(6 Pt 2): H1774-1780.

151. McGiff JC. Cytochrome P-450 metabolism of arachidonic acid. Annu Rev Pharmacol Toxicol 1991; 31: 339-369.

152. Sacerdoti D, Escalante B, Abraham NG, McGiff JC, Levere RD, Schwartzman ML. Treatment with tin prevents the development of hypertension in spontaneously hypertensive rats. Science 1989; 243(4889): 388-390.

153. Capdevila JH, Falck JR. Biochemical and molecular characteristics of the cytochrome P450 arachidonic acid monooxygenase. Prostaglandins Other Lipid Mediat 2000; 62(3): 271-292.

154. Capdevila JH, Falck JR, Harris RC. Cytochrome P450 and arachidonic acid bioactivation. Molecular and functional properties of the arachidonate monooxygenase. J Lipid Res 2000; 41(2): 163-181.

155. Cohen RA, Vanhoutte PM. Endothelium-dependent hyperpolarization. Beyond nitric oxide and cyclic GMP. Circulation 1995; 92(11): 3337-3349.

156. Roman RJ, Maier KG, Sun CW, Harder DR, Alonso-Galicia M. Renal and cardiovascular actions of 20-hydroxyeicosatetraenoic acid and epoxyeicosatrienoic acids. Clin Exp Pharmacol Physiol 2000; 27(11): 855-865.

157. Imig JD. Epoxide hydrolase and epoxygenase metabolites as therapeutic targets for renal diseases. Am J Physiol Renal Physiol 2005; 289(3): F496-503.

158. Maier KG, Roman RJ. Cytochrome P450 metabolites of arachidonic acid in the control of renal function. Curr Opin Nephrol Hypertens 2001; 10(1): 81-87.

159. Wang H, Lin L, Jiang J, Wang Y, Lu ZY, Bradbury JA, Lih FB, Wang DW, Zeldin DC. Up-regulation of endothelial nitric-oxide synthase by endotheliumderived hyperpolarizing factor involves mitogen-activated protein kinase and protein kinase C signaling pathways. J Pharmacol Exp Ther 2003; 307(2): 753764.

160. Xiao B, Li X, Yan J, Yu X, Yang G, Xiao X, Voltz JW, Zeldin DC, Wang DW. Overexpression of Cytochrome P450 Epoxygenases Prevents Development of Hypertension in Spontaneously Hypertensive Rats by Enhancing Atrial Natriuretic Peptide. Journal of Pharmacology and Experimental Therapeutics 2010; 334(3): 784-794. 
161. Capdevila JH, Pidkovka N, Mei S, Gong Y, Falck JR, Imig JD, Harris RC, Wang W. The Cyp2c44 epoxygenase regulates epithelial sodium channel activity and the blood pressure responses to increased dietary salt. J Biol Chem 2014; 289(7): 4377-4386.

162. Malik KU, Jennings BL, Yaghini FA, Sahan-Firat S, Song CY, Estes AM, Fang XR. Contribution of cytochrome P450 1B1 to hypertension and associated pathophysiology: A novel target for antihypertensive agents. Prostaglandins \& Other Lipid Mediators 2012; 98(3-4): 69-74.

163. Jennings BL, Estes AM, Anderson LJ, Fang XR, Yaghini FA, Fan Z, Gonzalez FJ, Campbell WB, Malik KU. Cytochrome P450 1B1 gene disruption minimizes deoxycorticosterone acetate-salt-induced hypertension and associated cardiac dysfunction and renal damage in mice. Hypertension 2012; 60(6): 1510-1516.

164. Sahan-Firat S, Jennings BL, Yaghini FA, Song CY, Estes AM, Fang XR, Farjana N, Khan AI, Malik KU. 2,3',4,5'-Tetramethoxystilbene prevents deoxycorticosterone-salt-induced hypertension: contribution of cytochrome P-450 1B1. Am J Physiol Heart Circ Physiol 2010; 299(6): 17.

165. Smith RL, Weidemann MJ. Reactive oxygen production associated with arachidonic acid metabolism by peritoneal macrophages. Biochem Biophys Res Commun 1980; 97(3): 973-980.

166. Touyz RM. Reactive oxygen species, vascular oxidative stress, and redox signaling in hypertension: what is the clinical significance? Hypertension 2004; 44(3): 248-252.

167. Okuda T, Grollman A. Passive transfer of autoimmune induced hypertension in the rat by lymph node cells. Tex Rep Biol Med 1967; 25(2): 257-264.

168. Svendsen UG. The role of thymus for the development and prognosis of hypertension and hypertensive vascular disease in mice following renal infarction. Acta Pathol Microbiol Scand A 1976; 84(3): 235-243.

169. Ba D, Takeichi N, Kodama T, Kobayashi H. Restoration of T cell depression and suppression of blood pressure in spontaneously hypertensive rats (SHR) by thymus grafts or thymus extracts. J Immunol 1982; 128(3): 1211-1216.

170. Guzik TJ, Hoch NE, Brown KA, McCann LA, Rahman A, Dikalov S, Goronzy J, Weyand C, Harrison DG. Role of the T cell in the genesis of angiotensin IIinduced hypertension and vascular dysfunction. J Exp Med 2007; 204(10): 24492460 . 
171. Mattson DL, Lund H, Guo C, Rudemiller N, Geurts AM, Jacob H. Genetic mutation of recombination activating gene 1 in Dahl salt-sensitive rats attenuates hypertension and renal damage. Am J Physiol Regul Integr Comp Physiol 2013; 304(6): 30 .

172. Broere F, Apasov S, Sitkovsky M, Eden W. A2 T cell subsets and T cell-mediated immunity. In Nijkamp FP, Parnham MJ (eds), Principles of Immunopharmacology. Birkhäuser Basel, 2011, pp 15-27.

173. Eid RE, Rao DA, Zhou J, Lo SF, Ranjbaran H, Gallo A, Sokol SI, Pfau S, Pober JS, Tellides G. Interleukin-17 and interferon-gamma are produced concomitantly by human coronary artery-infiltrating $T$ cells and act synergistically on vascular smooth muscle cells. Circulation 2009; 119(10): 1424-1432.

174. Tesmer LA, Lundy SK, Sarkar S, Fox DA. Th17 cells in human disease. Immunol Rev 2008; 223: 87-113.

175. Madhur MS, Lob HE, McCann LA, Iwakura Y, Blinder Y, Guzik TJ, Harrison DG. Interleukin 17 promotes angiotensin II-induced hypertension and vascular dysfunction. Hypertension 2010; 55(2): 500-507.

176. Marko L, Kvakan H, Park JK, Qadri F, Spallek B, Binger KJ, Bowman EP, Kleinewietfeld M, Fokuhl V, Dechend R, Muller DN. Interferon-gamma signaling inhibition ameliorates angiotensin II-induced cardiac damage. Hypertension 2012; 60(6): 1430-1436.

177. Muller DN, Shagdarsuren E, Park J-K, Dechend R, Mervaala E, Hampich F, Fiebeler A, Ju X, Finckenberg P, Theuer J, Viedt C, Kreuzer J, Heidecke H, Haller H, Zenke M, Luft FC. Immunosuppressive Treatment Protects Against Angiotensin II-Induced Renal Damage. The American journal of pathology 2002; 161(5): 1679-1693.

178. Zhang W, Wang W, Yu H, Zhang Y, Dai Y, Ning C, Tao L, Sun H, Kellems RE, Blackburn MR, Xia Y. Interleukin 6 underlies angiotensin II-induced hypertension and chronic renal damage. Hypertension 2012; 59(1): 136-144.

179. Seaberg EC, Munoz A, Lu M, Detels R, Margolick JB, Riddler SA, Williams CM, Phair JP. Association between highly active antiretroviral therapy and hypertension in a large cohort of men followed from 1984 to 2003. AIDS 2005; 19(9): 953-960.

180. Herrera J, Ferrebuz A, MacGregor EG, Rodriguez-Iturbe B. Mycophenolate mofetil treatment improves hypertension in patients with psoriasis and rheumatoid arthritis. J Am Soc Nephrol 2006; 17(12 Suppl 3): S218-225. 
181. Murakami M, Kudo I. Phospholipase A2. Journal of Biochemistry 2002; 131(3): 285-292.

182. Clark JD, Lin LL, Kriz RW, Ramesha CS, Sultzman LA, Lin AY, Milona N, Knopf JL. A novel arachidonic acid-selective cytosolic PLA2 contains a $\mathrm{Ca}(2+)-$ dependent translocation domain with homology to PKC and GAP. Cell 1991; 65(6): 1043-1051.

183. Kramer RM, Checani GC, Deykin A, Pritzker CR, Deykin D. Solubilization and properties of $\mathrm{Ca} 2+$-dependent human platelet phospholipase A2. Biochim Biophys Acta 1986; 878(3): 394-403.

184. Dessen A, Tang J, Schmidt H, Stahl M, Clark JD, Seehra J, Somers WS. Crystal structure of human cytosolic phospholipase A2 reveals a novel topology and catalytic mechanism. Cell 1999; 97(3): 349-360.

185. Nalefski EA, Sultzman LA, Martin DM, Kriz RW, Towler PS, Knopf JL, Clark JD. Delineation of two functionally distinct domains of cytosolic phospholipase $\mathrm{A} 2$, a regulatory $\mathrm{Ca}(2+)$-dependent lipid-binding domain and a $\mathrm{Ca}(2+)-$ independent catalytic domain. J Biol Chem 1994; 269(27): 18239-18249.

186. Evans JH, Leslie CC. The cytosolic phospholipase A2 catalytic domain modulates association and residence time at Golgi membranes. J Biol Chem 2004; 279(7): 6005-6016.

187. Clark JD, Schievella AR, Nalefski EA, Lin LL. Cytosolic phospholipase A2. J Lipid Mediat Cell Signal 1995; 12(2-3): 83-117.

188. Ghosh M, Tucker DE, Burchett SA, Leslie CC. Properties of the Group IV phospholipase A2 family. Prog Lipid Res 2006; 45(6): 487-510.

189. Perisic O, Fong S, Lynch DE, Bycroft M, Williams RL. Crystal structure of a calcium-phospholipid binding domain from cytosolic phospholipase A2. J Biol Chem 1998; 273(3): 1596-1604.

190. Nalefski EA, Slazas MM, Falke JJ. Ca2+-signaling cycle of a membrane-docking C2 domain. Biochemistry 1997; 36(40): 12011-12018.

191. Ball A, Nielsen R, Gelb MH, Robinson BH. Interfacial membrane docking of cytosolic phospholipase A2 $\mathrm{C} 2$ domain using electrostatic potential-modulated spin relaxation magnetic resonance. Proc Natl Acad Sci U S A 1999; 96(12): 6637-6642.

192. Xu GY, McDonagh T, Yu HA, Nalefski EA, Clark JD, Cumming DA. Solution structure and membrane interactions of the $\mathrm{C} 2$ domain of cytosolic phospholipase A2. J Mol Biol 1998; 280(3): 485-500. 
193. Davletov B, Perisic O, Williams RL. Calcium-dependent membrane penetration is a hallmark of the $\mathrm{C} 2$ domain of cytosolic phospholipase $\mathrm{A} 2$ whereas the $\mathrm{C} 2 \mathrm{~A}$ domain of synaptotagmin binds membranes electrostatically. J Biol Chem 1998; 273(30): 19093-19096.

194. Perisic O, Paterson HF, Mosedale G, Lara-Gonzalez S, Williams RL. Mapping the phospholipid-binding surface and translocation determinants of the $\mathrm{C} 2$ domain from cytosolic phospholipase A2. J Biol Chem 1999; 274(21): 14979-14987.

195. Leslie CC, Gangelhoff TA, Gelb MH. Localization and function of cytosolic phospholipase A2alpha at the Golgi. Biochimie 2010; 92(6): 620-626.

196. Dennis EA, Cao J, Hsu YH, Magrioti V, Kokotos G. Phospholipase A2 enzymes: physical structure, biological function, disease implication, chemical inhibition, and therapeutic intervention. Chem Rev 2011; 111(10): 6130-6185.

197. Tucker DE, Ghosh M, Ghomashchi F, Loper R, Suram S, John BS, Girotti M, Bollinger JG, Gelb MH, Leslie CC. Role of phosphorylation and basic residues in the catalytic domain of cytosolic phospholipase A2alpha in regulating interfacial kinetics and binding and cellular function. $J$ Biol Chem 2009; 284(14): 95969611.

198. Das S, Rafter JD, Kim KP, Gygi SP, Cho W. Mechanism of group IVA cytosolic phospholipase $\mathrm{A}(2)$ activation by phosphorylation. J Biol Chem 2003; 278(42): 41431-41442.

199. Pavicevic Z, Leslie CC, Malik KU. cPLA2 phosphorylation at serine-515 and serine-505 is required for arachidonic acid release in vascular smooth muscle cells. J Lipid Res 2008; 49(4): 724-737.

200. Muthalif MM, Benter IF, Karzoun N, Fatima S, Harper J, Uddin MR, Malik KU. 20-Hydroxyeicosatetraenoic acid mediates calcium/calmodulin-dependent protein kinase II-induced mitogen-activated protein kinase activation in vascular smooth muscle cells. Proc Natl Acad Sci U S A 1998; 95(21): 12701-12706.

201. Tian W, Wijewickrama GT, Kim JH, Das S, Tun MP, Gokhale N, Jung JW, Kim $\mathrm{KP}$, Cho W. Mechanism of regulation of group IVA phospholipase A2 activity by Ser727 phosphorylation. J Biol Chem 2008; 283(7):3960-3971.

202. Nakatani N, Uozumi N, Kume K, Murakami M, Kudo I, Shimizu T. Role of cytosolic phospholipase A2 in the production of lipid mediators and histamine release in mouse bone-marrow-derived mast cells. Biochem J 2000; 352(2): 311317. 
203. Uozumi N, Kume K, Nagase T, Nakatani N, Ishii S, Tashiro F, Komagata Y, Maki K, Ikuta K, Ouchi Y, Miyazaki J-i, Shimizu T. Role of cytosolic phospholipase A2 in allergic response and parturition. Nature 1997; 390(6660): 618-622.

204. Bonventre JV, Huang Z, Taheri MR, O'Leary E, Li E, Moskowitz MA, Sapirstein A. Reduced fertility and postischaemic brain injury in mice deficient in cytosolic phospholipase A2. Nature 1997; 390(6660): 622-625.

205. Fujishima H, Sanchez Mejia RO, Bingham CO, Lam BK, Sapirstein A, Bonventre JV, Austen KF, Arm JP. Cytosolic phospholipase A2 is essential for both the immediate and the delayed phases of eicosanoid generation in mouse bone marrow-derived mast cells. Proceedings of the National Academy of Sciences 1999; 96(9): 4803-4807.

206. Nagase T, Uozumi N, Ishii S, Kume K, Izumi T, Ouchi Y, Shimizu T. Acute lung injury by sepsis and acid aspiration: a key role for cytosolic phospholipase A2. Nat Immunol 2000; 1(1): 42-46.

207. Nagase T, Uozumi N, Ishii S, Kita Y, Yamamoto H, Ohga E, Ouchi Y, Shimizu T. A pivotal role of cytosolic phospholipase A(2) in bleomycin-induced pulmonary fibrosis. Nat Med 2002; 8(5): 480-484.

208. Yao C, Sakata D, Esaki Y, Li Y, Matsuoka T, Kuroiwa K, Sugimoto Y, Narumiya S. Prostaglandin E2-EP4 signaling promotes immune inflammation through TH1 cell differentiation and TH17 cell expansion. Nat Med 2009; 15(6): 633-640.

209. Kihara Y, Matsushita T, Kita Y, Uematsu S, Akira S, Kira J-i, Ishii S, Shimizu T. Targeted lipidomics reveals mPGES-1-PGE2 as a therapeutic target for multiple sclerosis. Proceedings of the National Academy of Sciences 2009; 106(51): 21807-21812.

210. Kihara Y, Yokomizo T, Kunita A, Morishita Y, Fukayama M, Ishii S, Shimizu T. The leukotriene B4 receptor, BLT1, is required for the induction of experimental autoimmune encephalomyelitis. Biochem Biophys Res Commun 2010; 394(3): 673-678.

211. Kihara Y, Yanagida K, Masago K, Kita Y, Hishikawa D, Shindou H, Ishii S, Shimizu T. Platelet-activating factor production in the spinal cord of experimental allergic encephalomyelitis mice via the group IVA cytosolic phospholipase A2lyso-PAFAT axis. J Immunol 2008; 181(7): 5008-5014.

212. Marusic S, Leach MW, Pelker JW, Azoitei ML, Uozumi N, Cui J, Shen MWH, DeClercq CM, Miyashiro JS, Carito BA, Thakker P, Simmons DL, Leonard JP, Shimizu T, Clark JD. Cytosolic phospholipase A2 $\alpha$-deficient mice are resistant to experimental autoimmune encephalomyelitis. $J$ Exp Med 2005; 202(6): 841-851. 
213. Kalyvas A, David S. Cytosolic phospholipase A2 plays a key role in the pathogenesis of multiple sclerosis-like disease. Neuron 2004; 41(3): 323-335.

214. Hegen M, Sun L, Uozumi N, Kume K, Goad ME, Nickerson-Nutter CL, Shimizu T, Clark JD. Cytosolic Phospholipase A2 $\alpha$-deficient Mice Are Resistant to Collagen-induced Arthritis. J Exp Med 2003; 197(10): 1297-1302.

215. Saito Y, Watanabe K, Fujioka D, Nakamura T, Obata JE, Kawabata K, Watanabe Y, Mishina H, Tamaru S, Kita Y, Shimizu T, Kugiyama K. Disruption of group IVA cytosolic phospholipase $\mathrm{A}(2)$ attenuates myocardial ischemia-reperfusion injury partly through inhibition of TNF-alpha-mediated pathway. Am J Physiol Heart Circ Physiol 2012; 302(10): 16.

216. Butz GM, Davisson RL. Long-term telemetric measurement of cardiovascular parameters in awake mice: a physiological genomics tool. Physiol Genomics 2001; 5(2): 89-97.

217. Silberman GA, Fan TH, Liu H, Jiao Z, Xiao HD, Lovelock JD, Boulden BM, Widder J, Fredd S, Bernstein KE, Wolska BM, Dikalov S, Harrison DG, Dudley $\mathrm{SC}$, Jr. Uncoupled cardiac nitric oxide synthase mediates diastolic dysfunction. Circulation 2010; 121(4): 519-528.

218. Zhao W, Ahokas RA, Weber KT, Sun Y. ANG II-induced cardiac molecular and cellular events: role of aldosterone. Am J Physiol Heart Circ Physiol 2006; 291(1): H336-343.

219. Yoshida K, Kobayashi N, Ohno T, Fukushima H, Matsuoka H. Cardioprotective effect of angiotensin II type 1 receptor antagonist associated with bradykininendothelial nitric oxide synthase and oxidative stress in Dahl salt-sensitive hypertensive rats. J Hypertens 2007; 25(8): 1633-1642.

220. Miller FJ, Jr., Gutterman DD, Rios CD, Heistad DD, Davidson BL. Superoxide production in vascular smooth muscle contributes to oxidative stress and impaired relaxation in atherosclerosis. Circ Res 1998; 82(12): 1298-1305.

221. Yaghini FA, Li F, Malik KU. Expression and mechanism of spleen tyrosine kinase activation by angiotensin II and its implication in protein synthesis in rat vascular smooth muscle cells. J Biol Chem 2007; 282(23): 16878-16890.

222. Livak KJ, Schmittgen TD. Analysis of relative gene expression data using realtime quantitative PCR and the 2(-Delta Delta C(T)) Method. Methods 2001; 25(4): 402-408. 
223. Zafari AM, Ushio-Fukai M, Minieri CA, Akers M, Lassegue B, Griendling KK. Arachidonic acid metabolites mediate angiotensin II-induced NADH/NADPH oxidase activity and hypertrophy in vascular smooth muscle cells. Antioxid Redox Signal 1999; 1(2): 167-179.

224. Yaghini FA, Song CY, Lavrentyev EN, Ghafoor HUB, Fang XR, Estes AM, Campbell WB, Malik KU. Angiotensin II-Induced Vascular Smooth Muscle Cell Migration and Growth Are Mediated by Cytochrome P450 1B1-Dependent Superoxide Generation. Hypertension 2010; 55(6): 1461-1467.

225. Young CN, Cao X, Guruju MR, Pierce JP, Morgan DA, Wang G, Iadecola C, Mark AL, Davisson RL. ER stress in the brain subfornical organ mediates angiotensin-dependent hypertension. J Clin Invest 2012; 122(11): 3960-3964.

226. Schroder M, Kaufman RJ. The mammalian unfolded protein response. Annu Rev Biochem 2005; 74: 739-789.

227. Burke JE, Dennis EA. Phospholipase A2 structure/function, mechanism, and signaling. J Lipid Res 2009; 50 Suppl: S237-242.

228. Sapirstein A, Bonventre JV. Specific physiological roles of cytosolic phospholipase A(2) as defined by gene knockouts. Biochim Biophys Acta 2000; 1488(1-2): 139-148.

229. Downey P, Sapirstein A, O'Leary E, Sun TX, Brown D, Bonventre JV. Renal concentrating defect in mice lacking group IV cytosolic phospholipase A(2). Am J Physiol Renal Physiol 2001; 280(4): F607-618.

230. Griffin SA, Brown WC, MacPherson F, McGrath JC, Wilson VG, Korsgaard N, Mulvany MJ, Lever AF. Angiotensin II causes vascular hypertrophy in part by a non-pressor mechanism. Hypertension 1991; 17(5): 626-635.

231. Su EJ, Lombardi DM, Siegal J, Schwartz SM. Angiotensin II induces vascular smooth muscle cell replication independent of blood pressure. Hypertension 1998; 31(6): 1331-1337.

232. Mervaala E, Muller DN, Schmidt F, Park JK, Gross V, Bader M, Breu V, Ganten D, Haller H, Luft FC. Blood pressure-independent effects in rats with human renin and angiotensinogen genes. Hypertension 2000; 35(2): 587-594.

233. Letavernier E, Perez J, Bellocq A, Mesnard L, de Castro Keller A, Haymann JP, Baud L. Targeting the calpain/calpastatin system as a new strategy to prevent cardiovascular remodeling in angiotensin II-induced hypertension. Circ Res 2008; 102(6): 720-728. 
234. Alexander LD, Alagarsamy S, Douglas JG. Cyclic stretch-induced cPLA2 mediates ERK 1/2 signaling in rabbit proximal tubule cells. Kidney Int 2004; 65(2): 551-563.

235. Gebremedhin D, Lange AR, Lowry TF, Taheri MR, Birks EK, Hudetz AG, Narayanan J, Falck JR, Okamoto H, Roman RJ, Nithipatikom K, Campbell WB, Harder DR. Production of 20-HETE and its role in autoregulation of cerebral blood flow. Circ Res 2000; 87(1): 60-65.

236. Sarr M, Chataigneau M, Martins S, Schott C, El Bedoui J, Oak MH, Muller B, Chataigneau T, Schini-Kerth VB. Red wine polyphenols prevent angiotensin IIinduced hypertension and endothelial dysfunction in rats: role of NADPH oxidase. Cardiovasc Res 2006; 71(4): 794-802.

237. Zanchi A, Schaad NC, Osterheld MC, Grouzmann E, Nussberger J, Brunner HR, Waeber B. Effects of chronic NO synthase inhibition in rats on renin-angiotensin system and sympathetic nervous system. Am J Physiol 1995; 268(6 Pt 2): H22672273.

238. Sander M, Victor RG. Neural mechanisms in nitric-oxide-deficient hypertension. Curr Opin Nephrol Hypertens 1999; 8(1): 61-73.

239. Guzik TJ, Hoch NE, Brown KA, McCann LA, Rahman A, Dikalov S, Goronzy J, Weyand C, Harrison DG. Role of the T cell in the genesis of angiotensin II induced hypertension and vascular dysfunction. $J$ Exp Med 2007; 204(10): 24492460.

240. Barhoumi T, Kasal DA, Li MW, Shbat L, Laurant P, Neves MF, Paradis P, Schiffrin EL. T regulatory lymphocytes prevent angiotensin II-induced hypertension and vascular injury. Hypertension 2011; 57(3): 469-476.

241. Zhao X, Bey EA, Wientjes FB, Cathcart MK. Cytosolic phospholipase A2 (cPLA2) regulation of human monocyte NADPH oxidase activity. cPLA2 affects translocation but not phosphorylation of p67(phox) and p47(phox). J Biol Chem 2002; 277(28): 25385-25392.

242. Pessach I, Leto TL, Malech HL, Levy R. Essential requirement of cytosolic phospholipase A(2) for stimulation of NADPH oxidase-associated diaphorase activity in granulocyte-like cells. J Biol Chem 2001; 276(36): 33495-33503.

243. Guan Y, Zhang Y, Wu J, Qi Z, Yang G, Dou D, Gao Y, Chen L, Zhang X, Davis LS, Wei M, Fan X, Carmosino M, Hao C, Imig JD, Breyer RM, Breyer MD. Antihypertensive effects of selective prostaglandin E2 receptor subtype 1 targeting. J Clin Invest 2007; 117(9): 2496-2505. 
244. Chen L, Miao Y, Zhang Y, Dou D, Liu L, Tian X, Yang G, Pu D, Zhang X, Kang J, Gao Y, Wang S, Breyer MD, Wang N, Zhu Y, Huang Y, Breyer RM, Guan Y. Inactivation of the E-prostanoid 3 receptor attenuates the angiotensin II pressor response via decreasing arterial contractility. Arterioscler Thromb Vasc Biol 2012; 32(12): 3024-3032.

245. Mistry M, Nasjletti A. Role of pressor prostanoids in rats with angiotensin II-saltinduced hypertension. Hypertension 1988; 11(6 Pt 2): 758-762.

246. Anning PB, Coles B, Bermudez-Fajardo A, Martin PE, Levison BS, Hazen SL, Funk CD, Kuhn H, O'Donnell VB. Elevated endothelial nitric oxide bioactivity and resistance to angiotensin-dependent hypertension in 12/15-lipoxygenase knockout mice. Am J Pathol 2005; 166(3): 653-662.

247. Muthalif MM, Benter IF, Khandekar Z, Gaber L, Estes A, Malik S, Parmentier JH, Manne V, Malik KU. Contribution of Ras GTPase/MAP kinase and cytochrome P450 metabolites to deoxycorticosterone-salt-induced hypertension. Hypertension 2000; 35(1 Pt 2): 457-463.

248. Wu CC, Gupta T, Garcia V, Ding Y, Schwartzman ML. 20-HETE and blood pressure regulation: clinical implications. Cardiol Rev 2014; 22(1): 1-12.

249. Wang F, Lu X, Peng K, Du Y, Zhou SF, Zhang A, Yang T. Prostaglandin EProstanoid4 Receptor Mediates Angiotensin II-Induced (Pro)Renin Receptor Expression in the Rat Renal Medulla. Hypertension 2014; 64(2): 369-377.

250. Kriska T, Cepura C, Magier D, Siangjong L, Gauthier KM, Campbell WB. Mice lacking macrophage 12/15-lipoxygenase are resistant to experimental hypertension. Am J Physiol Heart Circ Physiol 2012; 302(11): H2428-2438.

251. Davisson RL. Physiological genomic analysis of the brain renin-angiotensin system. Am J Physiol Regul Integr Comp Physiol 2003; 285(3): R498-511.

252. Okuno T, Lindheimer MD, Oparil S. Central effects of prostaglandin E2 on blood pressure and plasma renin activity in rats. Role of the sympathoadrenal system and vasopressin. Hypertension 1982; 4(6): 809-816.

253. Cao X, Peterson JR, Wang G, Anrather J, Young CN, Guruju MR, Burmeister MA, Iadecola C, Davisson RL. Angiotensin II-dependent hypertension requires cyclooxygenase 1-derived prostaglandin E2 and EP1 receptor signaling in the subfornical organ of the brain. Hypertension 2012; 59(4): 869-876.

254. Asirvatham-Jeyaraj N, King AJ, Northcott CA, Madan S, Fink GD. Cyclooxygenase-1 inhibition attenuates angiotensin II-salt hypertension and neurogenic pressor activity in the rat. Am J Physiol Heart Circ Physiol 2013; 305(10): H1462-1470. 
255. Ren G, Takano T, Papillon J, Cybulsky AV. Cytosolic phospholipase A(2)-alpha enhances induction of endoplasmic reticulum stress. Biochim Biophys Acta 2010; 4: $468-481$.

256. Spitler KM, Matsumoto T, Webb RC. Suppression of endoplasmic reticulum stress improves endothelium-dependent contractile responses in aorta of the spontaneously hypertensive rat. Am J Physiol Heart Circ Physiol 2013; 305(3): H344-353.

257. Freeman EJ, Ruehr ML, Dorman RV. ANG II-induced translocation of cytosolic PLA2 to the nucleus in vascular smooth muscle cells. Am J Physiol 1998; 274(1 Pt 1): C282-288.

258. Rollins TE, Smith WL. Subcellular localization of prostaglandin-forming cyclooxygenase in Swiss mouse 3T3 fibroblasts by electron microscopic immunocytochemistry. J Biol Chem 1980; 255(10): 4872-4875.

259. Cole BK, Kuhn NS, Green-Mitchell SM, Leone KA, Raab RM, Nadler JL, Chakrabarti SK. 12/15-Lipoxygenase signaling in the endoplasmic reticulum stress response. Am J Physiol Endocrinol Metab 2012; 302(6): E654-665.

260. Seliskar M, Rozman D. Mammalian cytochromes P450--importance of tissue specificity. Biochim Biophys Acta 2007; 1770(3): 458-466.

261. Capdevila JH, Falck JR, Imig JD. Roles of the cytochrome P450 arachidonic acid monooxygenases in the control of systemic blood pressure and experimental hypertension. Kidney Int 2007; 72(6): 683-689.

262. Imig JD. Epoxides and soluble epoxide hydrolase in cardiovascular physiology. Physiol Rev 2012; 92(1): 101-130.

263. Roman RJ. P-450 metabolites of arachidonic acid in the control of cardiovascular function. Physiol Rev 2002; 82(1): 131-185.

264. Hao CM, Breyer MD. Roles of lipid mediators in kidney injury. Semin Nephrol 2007; 27(3): 338-351.

265. Raymond KH, Lifschitz MD. Effect of prostaglandins on renal salt and water excretion. Am J Med 1986; 80(1A): 22-33.

266. Oyekan A, Balazy M, McGiff JC. Renal oxygenases: differential contribution to vasoconstriction induced by ET-1 and ANG II. Am J Physiol 1997; 273(1 Pt 2): R293-300. 
267. Rajagopalan S, Laursen JB, Borthayre A, Kurz S, Keiser J, Haleen S, Giaid A, Harrison DG. Role for endothelin-1 in angiotensin II-mediated hypertension. Hypertension 1997; 30(1 Pt 1): 29-34.

268. Yiu SS, Zhao X, Inscho EW, Imig JD. 12-Hydroxyeicosatetraenoic acid participates in angiotensin II afferent arteriolar vasoconstriction by activating Ltype calcium channels. J Lipid Res 2003; 44(12): 2391-2399.

269. Alonso-Galicia M, Maier KG, Greene AS, Cowley AW, Jr., Roman RJ. Role of 20-hydroxyeicosatetraenoic acid in the renal and vasoconstrictor actions of angiotensin II. Am J Physiol Regul Integr Comp Physiol 2002; 283(1): R60-68.

270. Kitiyakara C, Welch WJ, Verbalis JG, Wilcox CS. Role of thromboxane receptors in the dipsogenic response to central angiotensin II. Am J Physiol Regul Integr Comp Physiol 2002; 282(3): R865-869.

271. Imig JD. Eicosanoid regulation of the renal vasculature. Am J Physiol Renal Physiol 2000; 279(6): F965-981.

272. Leslie CC. Properties and regulation of cytosolic phospholipase A2. J Biol Chem 1997; 272(27): 16709-16712.

273. Burgermeister E, Endl J, Scheuer WV. Activation of cytosolic phospholipase A2 in human T-lymphocytes involves inhibitor-kappaB and mitogen-activated protein kinases. Eur J Pharmacol 2003; 466(1-2): 169-180.

274. Alvarez Y, Valera I, Municio C, Hugo E, Padron F, Blanco L, Rodriguez M, Fernandez N, Crespo MS. Eicosanoids in the innate immune response: TLR and non-TLR routes. Mediators Inflamm 2010; 201929(10): 15.

275. Sadik CD, Luster AD. Lipid-cytokine-chemokine cascades orchestrate leukocyte recruitment in inflammation. J Leukoc Biol 2012; 91(2): 207-215.

276. Harizi H, Gualde N. The impact of eicosanoids on the crosstalk between innate and adaptive immunity: the key roles of dendritic cells. Tissue Antigens 2005; 65(6): 507-514.

277. Serhan CN. Pro-resolving lipid mediators are leads for resolution physiology. Nature 2014; 510(7503): 92-101.

278. Bonventre JV. Calcium in renal cells. Modulation of calcium-dependent activation of phospholipase A2. Environ Health Perspect 1990; 84: 155-162.

279. Schramek H, Wang Y, Konieczkowski M, Simonson MS, Dunn MJ. Endothelin-1 stimulates cytosolic phospholipase A2 activity and gene expression in rat glomerular mesangial cells. Kidney Int 1994; 46(6): 1644-1652. 
280. Nakamura H, Nemenoff RA, Gronich JH, Bonventre JV. Subcellular characteristics of phospholipase A2 activity in the rat kidney. Enhanced cytosolic, mitochondrial, and microsomal phospholipase A2 enzymatic activity after renal ischemia and reperfusion. $J$ Clin Invest 1991; 87(5): 1810-1818.

281. Furuya Y, Tagami S, Hasegawa A, Ishii J, Hirokawa J, Yoshimura H, Honda T, Sakaue S, Aoki K, Murakami M, Kudo I, Kawakami Y. Increased glomerular cytosolic phospholipase A2 activity of OLETF rats with early diabetes. Exp Clin Endocrinol Diabetes 1999; 107(5): 299-305.

282. Cybulsky AV, Takano T, Papillon J, McTavish AJ. Complement-induced phospholipase A2 activation in experimental membranous nephropathy. Kidney Int 2000; 57(3): 1052-1062.

283. Aukema HM, Adolphe J, Mishra S, Jiang J, Cuozzo FP, Ogborn MR. Alterations in renal cytosolic phospholipase A2 and cyclooxygenases in polycystic kidney disease. Faseb J 2003; 17(2): 298-300.

284. Nangaku M, Fujita T. Activation of the renin-angiotensin system and chronic hypoxia of the kidney. Hypertens Res 2008; 31(2): 175-184.

285. Gurley SB, Coffman TM. The renin-angiotensin system and diabetic nephropathy. Semin Nephrol 2007; 27(2): 144-152.

286. Urushihara M, Kinoshita Y, Kondo S, Kagami S. Involvement of the intrarenal renin-angiotensin system in experimental models of glomerulonephritis. J Biomed Biotechnol 2012; 601786(10): 2 .

287. Chapman AB, Johnson A, Gabow PA, Schrier RW. The renin-angiotensinaldosterone system and autosomal dominant polycystic kidney disease. $N$ Engl $J$ Med 1990; 323(16): 1091-1096.

288. Polichnowski AJ, Cowley AW, Jr. Pressure-induced renal injury in angiotensin II versus norepinephrine-induced hypertensive rats. Hypertension 2009; 54(6): 1269-1277.

289. Wu J, Thabet SR, Kirabo A, Trott DW, Saleh MA, Xiao L, Madhur MS, Chen W, Harrison DG. Inflammation and mechanical stretch promote aortic stiffening in hypertension through activation of p38 mitogen-activated protein kinase. Circ Res 2014; 114(4): 616-625.

290. Kalyankrishna S, Malik KU. Norepinephrine-induced stimulation of p38 mitogenactivated protein kinase is mediated by arachidonic acid metabolites generated by activation of cytosolic phospholipase A(2) in vascular smooth muscle cells. $J$ Pharmacol Exp Ther 2003; 304(2): 761-772. 
291. Riggleman A, Harvey J, Baylis C. Endothelin mediates some of the renal actions of acutely administered angiotensin II. Hypertension 2001; 38(1): 105-109.

292. Schiffrin EL. T lymphocytes: a role in hypertension? Curr Opin Nephrol Hypertens 2010; 19(2): 181-186.

293. Luft FC, Dechend R, Muller DN. Immune mechanisms in angiotensin II-induced target-organ damage. Ann Med 2012; 44(1): 653396.

294. Shmelzer Z, Karter M, Eisenstein M, Leto TL, Hadad N, Ben-Menahem D, Gitler D, Banani S, Wolach B, Rotem M, Levy R. Cytosolic phospholipase A2alpha is targeted to the p47phox-PX domain of the assembled NADPH oxidase via a novel binding site in its C2 domain. J Biol Chem 2008; 283(46): 31898-31908.

295. Hoch NE, Guzik TJ, Chen W, Deans T, Maalouf SA, Gratze P, Weyand C, Harrison DG. Regulation of T-cell function by endogenously produced angiotensin II. Am J Physiol Regul Integr Comp Physiol 2009; 296(2): 10.

296. Rasini E, Cosentino M, Marino F, Legnaro M, Ferrari M, Guasti L, Venco A, Lecchini S. Angiotensin II type 1 receptor expression on human leukocyte subsets: a flow cytometric and RT-PCR study. Regul Pept 2006; 134(2-3): 69-74.

297. Kim N, Luster AD. Regulation of immune cells by eicosanoid receptors. ScientificWorldJournal 2007; 7: 1307-1328. 


\section{VITA}

Nayaab S. Khan was born on 1984 in Mumbai, India. She attended and graduated from Jai Hind College, University of Mumbai in May 2005, with a B.Sc. in Life Sciences. Following graduation, while she was preparing for her application for Master's program to universities in England, she worked as a loan process officer at Citi bank global services, Mumbai. In August 2006, she commenced her Master's program in Biomedical Sciences at Nottingham Trent University, UK. Along with her studies, she also worked part time as a senior business associate at the Royal Bank of Scotland. In August 2009, she entered the Integrated Program in Biomedical sciences at The University of Tennessee Health Science Center. She joined Dr. Malik's laboratory, where she studied the role of $\mathrm{cPLA}_{2} \alpha$ in Ang II induced hypertension and associated pathophysiology. Nayaab successfully defended her Ph.D. dissertation in December 2014. 